\title{
Redes Bayesianas: um método para avaliação de interdependência e contágio em séries temporais multivariadas
}

\author{
João Vinícius de França Carvalho
}

\author{
DissERTAÇÃO APRESENTADA \\ $\mathrm{AO}$ \\ Instituto DE MATEmÁtica E EstatísticA \\ $\mathrm{DA}$ \\ Universidade DE SÃo PAUlo \\ PARA \\ OBTENÇÃO DO TÍTULO \\ $\mathrm{DE}$ \\ Mestre em CiÊnCIAS
}

Programa: Estatística

Orientador: Profa. Dra. Chang Chiann

Durante o desenvolvimento deste trabalho o autor recebeu auxílio financeiro do CNPq 


\title{
Redes Bayesianas: um método para avaliação de interdependência e contágio em séries temporais multivariadas
}

\author{
Esta dissertação contém as correções e alterações \\ sugeridas pela Comissão Julgadora durante a defesa \\ realizada por João Vinícius de França Carvalho em 25/04/2011. \\ O original encontra-se disponível no Instituto de \\ Matemática e Estatística da Universidade de São Paulo.
}

Comissão Julgadora:

- Profa. Dra. Chang Chiann (orientadora) - IME-USP

- Prof. Dr. Pedro Alberto Morettin - IME-USP

- Prof. Dr. Luís Eduardo Afonso - FEA-USP 


\section{Agradecimentos}

Agradeço aos meus pais Neusa e João, acima de tudo, pela maravilhosa formação que me proporcionaram. Não apenas com educação formal, mas como meus grandes exemplos na vida e por serem pessoas com o coração muito bom. Exemplos de batalhadores, sempre lutaram para prover a mim e a minha irmã todo o amor e apoio necessários para desenvolvermos confiança para encarar o mundo. A eles, todo o meu amor, idolatria e gratidão!

Não posso deixar de mencionar a minha irmã Ana Cláudia, por todo o apoio e cumplicidade desde a infância. Obrigado por estar sempre ao meu lado! Amo muito!

À minha grande mestra e orientadora professora Chang Chiann pela grande amizade e por ter tido tanta paciência comigo desde o tempo do CEA, ainda na graduação, até a conclusão desta dissertação. Aprendi muito com você nas atividades didáticas, monitorias em que estivemos juntos, em disciplinas. Sempre serei muito grato!

Logicamente não poderia faltar uma mensagem de carinho à Lourrine, por tantos grandes momentos que passamos juntos e alegrias proporcionadas.

À Mariana pelo incondicional apoio e pela sua essencial e cuidadosa colaboração na revisão deste texto.

Ao professor Luís Eduardo Afonso, pela amizade e confiança no meu desenvolvimento didático e acadêmico, além da paciência fora do comum. Reconheço que não sou um aluno fácil nem nunca serei. Ao professor Luiz Augusto Ferreira Carneiro, pela confiança no meu desenvolvimento profissional e por compreender meus momentos de ausência da consultoria atuarial da FIPECAFI, em prol do alcance de um grande objetivo. Agradeço também ao professor Nikolai Vatchev Kolev, grande incentivador da minha jornada pelo mundo acadêmico.

Agradecimento especial aos amigos dos tempos da graduação do IME e mais recentemente da FEA, além do pessoal do mestrado. Saibam que guardo boas lembranças de todos.

Finalmente, ao CNPq pelo auxílio financeiro.

"Quanto mais aumentam os conhecimentos do homem, tanto mais aumentam suas dúvidas, seu isolamento e sua solidão."

(Provérbio árabe) 


\section{Resumo}

O objetivo deste trabalho consiste em identificar a existência de contágio financeiro utilizando a metodologia de redes bayesianas. Além da rede bayesiana, a análise da interdependência de mercados internacionais em períodos de crises financeiras, ocorridas entre os anos 1996 e 2009, foi modelada com outras duas técnicas - modelos GARCH multivariados e de Cópulas, envolvendo países nos quais foi possível avaliar seus efeitos e que foram objetos de estudos similares na literatura. Com os períodos de crise bem definidos e metodologia calcada na teoria de grafos e na inferência bayesiana, executou-se uma análise sequencial, em que as realidades que precediam períodos de crise foram consideradas situações a priori para os eventos (verossimilhanças). Desta combinação resulta a nova realidade (a posteriori), que serve como priori para o período subsequente e assim por diante. Os resultados apontaram para grande interligação entre os mercados e diversas evidências de contágio em períodos de crise financeira, com causadores bem definidos e com grande respaldo na literatura. Ademais, os pares de países que apresentaram evidências de contágio financeiro pelas redes bayesianas em mais períodos de crises foram os mesmos que apresentaram os mais altos valores dos parâmetros estimados pelas cópulas e também aqueles cujos parâmetros foram mais fortemente significantes no modelo GARCH multivariado. Assim, os resultados obtidos pelas redes bayesianas tornam-se mais relevantes, o que sugere boa aderência deste modelo ao conjunto de dados utilizados neste estudo. Por fim, verificou-se que, após as diversas crises, os mercados estavam muito mais interligados do que no período inicialmente adotado.

Palavras-chave: interdependência, contágio financeiro, Redes Bayesianas, GARCH multivariado, cópulas. 


\section{Abstract}

This work aims to identify the existence of financial contagion using a metodology of Bayesian networks. Besides Bayesian networks, the analysis of the international markets' interdependence in times of financial crises, occurred between 1996 and 2009, was modeled using two other techniques - multivariate GARCH models and Copulas models, involving countries in which its effects were possible to assess and which were subject to similar studies in the literature. With well-defined crisis periods and a metodology based on graph theory and Bayesian inference, a sequential analysis was executed, in which the realities preceding periods of crisis were considered to be prior situations to the events (likelihood). From this combination results the new posterior reality, which serves as a prior to the subsequent period and so on. The results pointed to a large interconnection between markets and several evidences of contagion in times of financial crises, with well-defined responsibles and highly supported by the literature. Moreover, the pairs of countries that show evidence of financial contagion by Bayesian networks in over periods of crises were the same as that presented the highest values of the parameters estimated by copulas and the most strongly significant parameters in the multivariate GARCH model. Thus, the results obtained by Bayesian networks become more relevant, suggesting good adherence of the model to the data set used in this study. Finally, it was found that after the various crises, the markets were much more connected.

Keywords: interdependence, financial contagion, Bayesian Networks, multivariate GARCH, copulas. 


\section{Sumário}

Lista de Figuras $\quad$ vii

$\begin{array}{lc}\text { Lista de Tabelas } & \text { ix }\end{array}$

1 Introdução $\quad 1$

1.1 Considerações preliminares sobre as crises financeiras . . . . . . . . . . . . 1

1.1.1 1997: A crise dos tigres asiáticos . . . . . . . . . . . . 2

1.1.2 1998: A crise da Rússia . . . . . . . . . . . . . . . . . . 2

1.1.3 1999: A crise do Brasil . . . . . . . . . . . . . . . . . 3

1.1.4 2001/2002: A crise da Argentina . . . . . . . . . . . . . . 4

1.1.5 2008/2009: A crise dos EUA . . . . . . . . . . . . . 5

1.2 Objetivos e organização do trabalho . . . . . . . . . . . . . . 6

2 Breve revisão da literatura $\quad 8$

3 Análise descritiva, filtragem univariada e modelagem da interdependência $\begin{array}{ll}\text { por meio de GARCH multivariado } & 14\end{array}$

3.1 Introdução . . . . . . . . . . . . . . . . . . . . . . . . . . . . . 14

3.2 Retornos e Fatos estilizados . . . . . . . . . . . . . . . . . . . . . 14

3.3 Análise descritiva das séries . . . . . . . . . . . . . . . . . 16

3.3.1 O conjunto de dados e as crises financeiras . . . . . . . . . . . . 16

3.3 .2 Análise das séries . . . . . . . . . . . . . . . . . . . 17

3.4 Modelos GARCH . . . . . . . . . . . . . . . . . . . . . . 22

3.4.1 Processo ARCH univariado . . . . . . . . . . . . . . . . 22

3.4.2 Processo GARCH univariado . . . . . . . . . . . . . . . 22 
3.4 .3 Processo GARCH Multivariado . . . . . . . . . . . . . . . . . . 24

3.5 Resultados Parciais . . . . . . . . . . . . . . . . 26

3.6 Considerações Parciais . . . . . . . . . . . . . . . . . . . . 34

4 Modelagem da interdependência por meio de Cópulas 35

4.1 Introdução . . . . . . . . . . . . . . . . . . . . . 35

4.2 Medidas de Dependência e Cópulas . . . . . . . . . . . . . . 36

4.3 Principais famílias de Cópulas . . . . . . . . . . . . . . . . 38

4.3 .1 Família Arquimediana . . . . . . . . . . . . . . . . 38

4.3.2 Cópulas Normal e t-Student . . . . . . . . . . . . . . . . 39

4.3 .3 Inferência Paramétrica . . . . . . . . . . . . . . . . 41

4.4 Resultados . . . . . . . . . . . . . . . . . . . 42

4.5 Considerações Parciais . . . . . . . . . . . . . . . . . . 45

5 Modelagem da interdependência por meio de Redes Bayesianas $\quad 47$

5.1 Introdução . . . . . . . . . . . . . . . . . . . . . . . 47

5.1 .1 Inteligência Artificial . . . . . . . . . . . . . . 47

5.2 Probabilidade e independência . . . . . . . . . . . . . . . . . 48

5.3 Teoria básica de Grafos . . . . . . . . . . . . . . . . . . . . . . . . 49

5.4 Redes Bayesianas . . . . . . . . . . . . . . . . . . . 49

5.4 .1 Arcos causais . . . . . . . . . . . . . . . . 50

5.4 .2 d-Separação . . . . . . . . . . . . . . . . . . . 51

5.4 .3 Equivalência de Markov . . . . . . . . . . . . . . . 52

5.4.4 Verificando dependências em uma Rede Bayesiana . . . . . . . . . . 53

5.4.5 Mais sobre Redes Bayesianas causais . . . . . . . . . . . 56

5.5 Inferência em Redes Bayesianas . . . . . . . . . . . . . . 58

5.5.1 Aprendizagem dos parâmetros: a abordagem bayesiana . . . . . . . 58

5.5.2 O procedimento Master Prior . . . . . . . . . . . . 60

5.5.3 A seleção da melhor estrutura para a Rede Bayesiana . . . . . . . . . 62

5.5.4 Observações sequenciais . . . . . . . . . . . . . 64

5.6 Resultados . . . . . . . . . . . . . . . . . . 65 
6 Conclusões $\quad 75$

6.1 Considerações Finais . . . . . . . . . . . . . . . . . . . 75

6.2 Sugestões para Pesquisas Futuras . . . . . . . . . . . . . . . . . 76

$\begin{array}{ll}\text { A Conjugação } & 77\end{array}$

$\begin{array}{lll}\text { B A distribuição Wishart e sua inversa } & 78\end{array}$

$\begin{array}{ll}\text { C A distribuição Normal-Gamma Inversa } & 80\end{array}$

$\begin{array}{ll}\text { D A distribuição t-Student } & 81\end{array}$

$\begin{array}{lll}\text { E Estimativas dos parâmetros das redes bayesianas } & 82\end{array}$

Referências Bibliográficas $\quad 94$ 


\section{Lista de Figuras}

3.1 Evolução dos índices no período de análise. . . . . . . . . . . . . . 18

3.2 Evolução dos log-retornos do Brasil, Argentina e México no período de análise. 19

3.3 Evolução dos log-retornos do EUA, Malásia e Rússia no período de análise. . 19

3.4 Gráficos do tipo quantil-quantil dos resíduos dos modelos marginais $\operatorname{ARMA}(1,1)$ $\operatorname{GARCH}(1,1)$ ajustados. . . . . . . . . . . . . . . . 28

3.5 Gráficos de dispersão bivariada entre os resíduos dos modelos marginais $\operatorname{ARMA}(1,1)$ GARCH $(1,1)$ ajustados. . . . . . . . . . . . . . . . . . 29

3.6 Gráficos de dispersão bivariada entre os resíduos dos modelos marginais $\operatorname{ARMA}(1,1)$ $\operatorname{GARCH}(1,1)$ ajustados (cont.). . . . . . . . . . . . . . 29

3.7 Evolução das correlações bivariadas entre os resíduos dos modelos marginais $\operatorname{ARMA}(1,1)-G A R C H(1,1)$ ajustados. . . . . . . . . . . . . . . . . 30

3.8 Evolução das correlações bivariadas entre os resíduos dos modelos marginais $\operatorname{ARMA}(1,1)-\operatorname{GARCH}(1,1)$ ajustados (cont.) . . . . . . . . . . . . . . 31

4.1 Amostras simuladas das cópulas Frank, Gumbel e Clayton, com as respectivas densidades representadas pelas curvas de nível. . . . . . . . . . . . . . . . . . 39

4.2 Amostras simuladas das cópulas Normal e t-Student, com as respectivas densidades representadas pelas curvas de nível. . . . . . . . . . . . . . . . . . . . 41

5.1 Dependência de uma variável não observada. . . . . . . . . . . . . . . . 51

5.2 Um exemplo ilustrativo de equivalência de Markov. . . . . . . . . . . . . . 53

5.3 Um exemplo ilustrativo de distribuição de probabilidade que satisfaz a condição de Markov e d-separação. . . . . . . . . . . . . . . . . . . . . 54

5.4 Um exemplo ilustrativo de inexistência de um cobertor de Markov. . . . . . . 55

5.5 Um exemplo ilustrativo de como uma causa oculta pode afetar a fidedignidade da Rede Bayesiana. . . . . . . . . . . . . . . . . . . 57 
5.6 Rede Bayesiana no período anterior à crise asiática, até 1997. . . . . . . . . 66

5.7 Rede Bayesiana durante a crise asiática, em 1997. . . . . . . . . . . . . . 67

5.8 Rede Bayesiana no período anterior à crise russa, até 1998. . . . . . . . . . 68

5.9 Rede Bayesiana durante a crise russa, 1998. . . . . . . . . . . . . . 68

5.10 Rede Bayesiana no período anterior à crise brasileira, até 1999 . . . . . . . . 69

5.11 Rede Bayesiana durante a crise brasileira, em 1999. . . . . . . . . . . . . . 69

5.12 Rede Bayesiana no período anterior à crise argentina, até 2001 . . . . . . . . 70

5.13 Rede Bayesiana durante a crise argentina, em 2001. . . . . . . . . . . . . . 71

5.14 Rede Bayesiana no período anterior à crise dos EUA, até 2008. . . . . . . . . 72

5.15 Rede Bayesiana durante a crise dos EUA, em 2008. . . . . . . . . . . . 72

5.16 Rede Bayesiana para o período final da amostra, até o fim de $2009 . \quad$. . . . 73 


\section{Lista de Tabelas}

3.1 Definição ad-hoc dos períodos em que houve crise. . . . . . . . . . . . . . 17

3.2 Estatísticas Descritivas dos log-retornos para os países avaliados em cada período. . . . . . . . . . . . . . . . . . . 21

3.3 Estimativas para os modelos $\operatorname{ARMA}(1,1)-\operatorname{GARCH}(1,1)$ com erros t-Student para cada série. . . . . . . . . . . . . . . . . . . 27

3.4 Comparação entre diferentes estruturas de correlação condicional no modelos GARCH multivariado com erros t-Student. . . . . . . . . . . . . . . . . . . . 32

3.5 Estimativas do modelo GARCH multivariado com estrutura de correlação condicional DVEC $(1,1)$.

4.1 As principais cópulas arquimedianas. . . . . . . . . . . . . . . . . 38

4.2 Critérios de seleção da família de cópulas para cada par de séries. . . . . . . 43

4.3 Estimativas e erros-padrão dos parâmetros das cópulas ajustadas para cada par de séries. . . . . . . . . . . . . . . . . . . . . . . . . . 44

4.4 Índices de cauda e correlações estimados a partir da cópula empírica t-Student. 45

5.1 Partição da base de dados para o desenvolvimento sequencial da Rede Bayesiana. 66

5.2 Períodos de crise em que foram encontrados os contágios financeiros entre cada par de países. . . . . . . . . . . . . . . . . . . . 74

E.1 Parâmetros estimados da rede bayesiana pré-crise asiática. . . . . . . . . . . 83

E.2 Parâmetros estimados da rede bayesiana durante a crise asiática. . . . . . . . . 84

E.3 Parâmetros estimados da rede bayesiana pré-crise russa. . . . . . . . . . . . . 85

E.4 Parâmetros estimados da rede bayesiana durante a crise russa. . . . . . . . . 86

E.5 Parâmetros estimados da rede bayesiana pré-crise brasileira. . . . . . . . . . 87

E.6 Parâmetros estimados da rede bayesiana durante a crise brasileira. . . . . . . 88 
E.7 Parâmetros estimados da rede bayesiana pré-crise argentina. . . . . . . . . . 89

E.8 Parâmetros estimados da rede bayesiana durante a crise argentina. . . . . . . 90

E.9 Parâmetros estimados da rede bayesiana pré-crise dos EUA. . . . . . . . . . 91

E.10 Parâmetros estimados da rede bayesiana durante a crise dos EUA. . . . . . . 92

E.11 Parâmetros estimados da rede bayesiana no período final, pós-crise dos EUA. 93 


\section{Capítulo 1}

\section{Introdução}

\subsection{Considerações preliminares sobre as crises financeiras}

Em uma economia com muitas interligações, sinais de crise financeira em um determinado país pode se propagar a ponto de se tornar mundial. O desenvolvimento de tecnologias da informação e de meios de transporte criou condições para fortalecimento do setor financeiro, de modo que, com apenas um aperto de botão em um microcomputador, é possível realocar grandes cifras monetárias em questão de segundos, sendo factível para os investidores, portanto, obter lucros rapidamente. No entanto, como um jogo de soma zero, esta mesma rápida operação pode trazer consigo consequências importantes para a contraparte.

O capital especulativo não possui compromisso com a produção, tampouco com o país e, ao menor sinal de instabilidade na economia, as aplicações financeiras são realocadas e países com baixas reservas perdem altos montantes, aumentando a probabilidade de ocorrerem problemas internos decorrentes da falta de liquidez. Em momentos de instabilidade, há a tendência de que os países mais fragilizados recorram a fortes e sucessivos aumentos da taxa de juros paga a investidores estrangeiros, com o intuito de evitar a saída de capital, além de tentar incentivar outros investidores a depositar suas riquezas. No entanto, pode haver um efeito perverso nesta política de aumento de juros: a diminuição de investimentos, uma vez que as contas do governo ficam ainda mais vulneráveis, e as dívidas serão pagas a uma taxa ainda maior.

No caso de esta política não se mostrar eficaz, os compromissos assumidos por este país podem se tornar inexequíveis, abalando a confiança dos investidores e promovendo quebra de empresas, aumento nas taxas de desemprego, desvalorização da moeda e de seu poder de compra e, no limite, a propagação desta situação - que será denominada crise - para outros países. Em maior ou menor grau, foram estes os fenômenos observados no México em 1994, com diversos países asiáticos em 1997, com a Rússia em 1998, com o Brasil em 1999, com a Argentina entre 2001 e 2002 e com os EUA em 2008.

Por conta desta última, após anos de expansão das economias por todo o mundo, foi retomada a discussão sobre a dinâmica de interligação da economia e o possível contágio de crises econômicas, devido à chamada crise do subprime nos EUA, que fez com que diversos setores da economia daquele país - e também em outros países - entrassem em recessão. Além disso, o tema ganhou notoriedade pelas altas cifras emprestadas pelo governo a companhias de determinados setores de atividade econômica nos EUA, revelando as preocupações governamentais com a solvência de algumas empresas consideradas relevantes para não propagar 
insolvência.

Nas subseções a seguir, serão feitas breves recapitulações das grandes crises financeiras mundiais, que serão objeto de estudo desta dissertação, a fim de contextualizar o leitor e facilitar a posterior interpretação dos resultados obtidos a partir das modelagens. Ocorreram, ainda, crises de menor magnitude no período considerado para esta dissertação, que compreende outubro de 1996 e dezembro de 2009, tais como a queda da Nasdaq em 2000, os atentados terroristas de 11 de setembro de 2001, as incertezas dos investidores quanto à alteração da política econômica na transição presidencial no Brasil em 2002 e a crise de Dubai no fim de 2009. No entanto, por terem sido de menor magnitude, ou de tempo bastante reduzido ou não terem sido verificados grandes efeitos sistêmicos pela literatura, por opção metodológica foram desprezadas.

\subsubsection{7: A crise dos tigres asiáticos}

Alguns países do leste da Ásia apresentaram uma grande capacidade de desenvolvimento e modernização de suas indústrias entre as décadas de 1960 e 1990, entre eles Coréia do Sul, Taiwan e Cingapura e, em um segundo momento, Malásia, Indonésia, Tailândia e, em menor grau, Filipinas. No entanto, a partir de julho de 1997 apareceram os primeiros sinais de que os últimos quatro países citados sofriam dificuldades para equilibrar as contas externas e saldar dívidas de curto prazo, bem como seus bancos incorriam em alto risco de inadimplência por parte dos clientes. Esta situação levou os investidores a realocarem suas aplicações de ações de empresas ali estabelecidas por investimentos em moedas e títulos de economias mais sólidas.

Como consequência, houve a queda do valor das ações nas bolsas e imediata desvalorização das moedas locais e aumento da inflação. Se por um lado a desvalorização da moeda doméstica favorece as exportações, uma vez que as mercadorias passam a ter preços mais competitivos no mercado internacional, por outro encarece as importações, aumentando a dívida em moeda estrangeira, levando à falência de empresas e provocando desemprego e recessão econômica. Como não é interessante a manutenção de crise econômica de uma região que até então mostrava-se próspera, foi organizado um pacote de ajuda por parte do Fundo Monetário Internacional (FMI), com a concessão de empréstimos visando o equilíbrio das contas públicas dos países envolvidos.

O evento considerado o desencadeador da crise foi o anúncio de que o governo tailandês tornaria o seu câmbio flutuante. Tal notícia foi dada no dia 02 de julho de 1997 e até setembro do mesmo ano, Filipinas, Malásia e Indonésia tomaram a mesma decisão e viram suas moedas desvalorizarem em pelo menos $50 \%$ frente ao dólar americano. Embora os efeitos dessa crise tivessem provocado recessão até a metade de 1998, os mais fortes efeitos nos mercados financeiros deram-se até a metade do primeiro trimestre de 1998.

Maiores detalhes sobre esta crise podem ser obtidas em Canuto [2000] e no trabalho de Furman e Stiglitz [1998].

\subsubsection{8: A crise da Rússia}

Em meados de 2008, a Rússia necessitava de mais de US\$ 120 bilhões para quitar dívidas de curto prazo e sua situação econômica estava complicada: com uma indústria sucateada, incapaz de pagar salários a seus trabalhadores, arrecadação insuficiente de impostos, herança 
de um regime socialista que havia terminado, o país era fortemente dependente da exportação de commodities como o petróleo (principalmente), gás natural e minérios. Como decorrência da crise asiática de 1997, houve uma curta recessão global que diminuiu a demanda por commodities, derrubando os preços do petróleo e prejudicando assim a balança comercial do país.

Além disso, com o socorro do FMI aos países asiáticos em crise em 1997, a oferta de crédito internacional tornou-se reduzida. Diante deste cenário,o governo norte-americano, por meio do FMI, organizou um pacote de ajuda à Rússia no dia 13 de julho de 1998, que se mostrou insuficiente e, em alguns dias, os investidores começaram a retirar seus recursos da bolsa do país, provocando forte volatilidade. Exatamente um mês após o anúncio da aprovação do pacote, a bolsa sofreu um colapso, ficando 35 minutos paralisada para negociações e, no fechamento, apresentou queda de $65 \%$. No dia 17 de agosto do mesmo ano, o governo russo decidiu desvalorizar o rublo, sua moeda, e declarar moratória de sua dívida externa por pelo menos 90 dias.

A moratória expirou no dia 15 de novembro de 1998 e, apesar disso, a volatilidade da bolsa russa foi reduzida cerca de um mês antes, dando sinais de que a recuperação poderia ser rápida, o que, de fato, foi: a economia russa recuperou-se rapidamente devido ao aumento do preço do petróleo no mercado internacional, o que fez com que o país, entre 1999 e 2000, acumulasse grande superávit comercial.

Mais informações a respeito desta crise podem ser obtidos no trabalho de Dungey et al. [2002] e no artigo de Baig e Goldfajn [2000], que traz, além da cronologia, detalhes sobre a relação desta crise com a futura especulação contra a moeda brasileira.

\subsubsection{9: A crise do Brasil}

No Brasil, que em 1994 havia posto em prática um plano econômico (o Plano Real) para controlar a inflação, sucederam-se anos de juros altos e baixo investimento público, além de um câmbio artificialmente sobrevalorizado. Esta política acarretou aumento nos déficits comerciais e perda de competitividade da indústria nacional, uma vez que as mercadorias nacionais, essencialmente primárias, tornaram-se relativamente caras no mercado internacional e os produtos estrangeiros, considerados de melhor qualidade, podiam ser adquiridos com preços mais competitivos por conta de uma moeda forte.

A vigência de tal política necessitava da manutenção de juros altos de forma a garantir a captação de recursos do exterior. No entanto, com as crises dos tigres asiáticos e da Rússia, a oferta de crédito internacional foi reduzida, bem como a demanda e o valor de mercado das commodities, prejudicando a atratividade de investimentos externos. A arrecadação de recursos por meio de privatizações não era mais eficaz e os altos juros inibiam o desenvolvimento do mercado interno e tampouco atraía investidores estrangeiros.

Diante deste cenário, o governo brasileiro foi obrigado a abandonar o câmbio semi-fixo, desvalorizando o real frente ao dólar, durante o mês de janeiro de 1999. A mudança teve diversos efeitos negativos como crise política no governo, aumento do endividamento das empresas que se endividaram em dólares e redução no consumo de produtos importados. No entanto, apresentou uma série de efeitos positivos, como redução do déficit na balança de pagamentos e aumento de receitas para os produtores exportadores, tanto agropecuários quanto extrativistas e industriais. Desta maneira, além de aumentar o saldo da balança comercial, esta medida também fez com que a indústria nacional fosse mais competitiva, 
não só visando a exportação mas para abastecimento do mercado interno, uma vez que um produto similar nacional poderia facilmente substituir um mais caro importado.

A retomada da economia brasileira mostrou-se muito mais rápida do que se era esperado, apresentando crescimento relativamente vigoroso no anos de 2000 e 2001. Aliás, com o aquecimento da indústria nacional, aliado ao baixo investimento em infra-estrutura por parte do Estado, o Brasil chegou a enfrentar problemas de oferecimento de energia elétrica.

Como já mencionado, a rápida desvalorização do real ocorreu durante o mês de janeiro e teve seus efeitos em bolsas sentidos apenas durante o próprio mês, uma vez que o evento que foi considerado como ponto de inflexão foi a posse de Armínio Fraga no comando do Banco Central, considerando um nome de respeito e capaz de implementar mudanças, as quais ocorreram em fevereiro de 1999.

Maiores detalhes sobre o panorama político e econômico desta crise no Brasil podem ser obtidas em Averbug e Giambiagi [2000] e no já citado trabalho de Baig e Goldfajn [2000], que associou cronologicamente os eventos da crise brasileira à moratória russa.

\subsubsection{1/2002: A crise da Argentina}

De modo similar ao seu vizinho e principal parceiro econômico Brasil, a Argentina adentrou a década de 1990 convivendo com a hiperinflação. No começo da década, foi lançado um plano para reduzir a inflação, denominado Plano de Conversão, no qual um peso valeria um dólar americano. Apesar da retomada de crescimento da economia nacional, a dívida externa só aumentava, porém mantendo-se em níveis controlados por conta do baixo nível dos juros nos EUA, que impulsionava os investimentos em países emergentes.

Entretanto, como mencionado anteriormente, as crises dos tigres asiáticos e da Rússia fizeram com que a oferta de crédito fosse reduzida em todo o mundo. Além disso, houve migração de recursos para títulos de países considerados mais seguros para investir, como os EUA e países da Europa. Em 1999, como o Brasil, principal parceiro econômico da Argentina, desvalorizou sua moeda frente ao dólar americano, houve redução de exportações argentinas ao país, visto que o produto argentino tornou-se muito caro e o governo optou por manter o seu Plano de Conversão. Este fenômeno foi um gatilho para desencadear uma grave crise que viria nos próximos anos.

Em dezembro de 2001, com a dívida atrelada ao dólar, o governo argentino declara restrição do saque de dinheiro de contas correntes e estado de sítio, além da moratória de sua dívida. Com graves problemas sociais, políticos e econômicos, assumem a presidência do país cinco presidentes distintos em 12 dias. A situação passa a ficar menos grave quando o presidente Eduardo Duhalde anuncia, em janeiro de 2002, a desvalorização do peso argentino frente ao dólar. O anúncio da desvalorização provocou, como em todas as crises financeiras globais mencionadas, uma fuga maciça de capitais do país.

A recuperação da economia argentina, que se encontrou em situação mais complicada do que todos os outros países que experimentaram passar por uma crise, foi mais longa. No entanto, a bolsa de valores, que já havia sofrido quedas bastante fortes, acalmou-se com os anúncios do presidente Duhalde em flexibilizar o câmbio, ocorridos efetivamente no fim de fevereiro de 2002. Mesmo assim, a bolsa argentina permaneceu com alta volatilidade até o fim de 2002.

Mais informações a respeito desta crise podem ser obtidos no trabalho de Fund [2003]. 


\subsubsection{8/2009: A crise dos EUA}

Após alguns anos de expansão das economias mundiais e relativa tranquilidade para os investidores em todo o mundo, em meados de 2006 foram decretadas falências de algumas instituições credoras (que operavam créditos hipotecários de alto risco - subprime mortgages) nos EUA. Tais empréstimos, considerados de alto risco por não necessitarem de comprovação de renda ou histórico de pagamentos, eram lastreados em imóveis e transformados em derivativos pelas instituições credoras, sendo negociados por investidores ao redor do mundo. A transformação do risco tomado pelas instituições credoras em derivativos visava tornar líquidos papéis com baixa probabilidade de recuperação de recursos; dessa forma as instituições criaram carteiras homogêneas com uma grande quantidade destes créditos, emitindo títulos (bonds) lastreados naqueles créditos para negociar, por forma de derivativos, em mercado financeiro internacional. Desta maneira, poderiam atrair investimentos e normalizar prováveis problemas de liquidez. No entanto os derivativos eram negociados em pacotes atrativos, ainda que o investidor não soubesse exatamente de todos os detalhes das operações. Somente em 2007 os investidores foram informados do real risco das aplicações, bem como da existência de grandes prejuízos e também da possibilidade de desencadeamento de uma crise sistêmica, envolvendo diversos setores da economia, bem como outros países. Um interessante texto de Feldstein [2007] já sinalizava para a grave crise que estaria por vir.

Apesar de o crédito ser imobiliário, os subprimes envolviam operações financeiras de outras naturezas, como crédito à pessoa física por meio de cartão de crédito, aluguel de carros e financiamento estudantil, entre outras. Como as dívidas contraídas eram bastante elevadas, seus pagamentos só poderiam ser cumpridos caso houvesse uma nova concessão de crédito para pagamento dos anteriores, alongando o prazo de pagamentos, sempre lastreando as operações nos mesmos ativos dados outrora como garantia. Naturalmente, esta situação só se manteria sustentável enquanto os preços dos imóveis estivessem crescendo (gerando um fenômeno chamado bolha) ou, ao menos, estabilizados.

Como as taxas de juros eram pós-fixadas, os primeiros sinais de dificuldade ocorreram a partir do aumento dos juros do mercado interbancário, uma sinalização da desconfiança entre bancos acerca da capacidade em honrar compromissos de curto prazo. Aliados a esses sinais, ocorre a uma queda generalizada dos preços dos imóveis, comprometendo as receitas de diversas instituições e, assim, resultando em falta de liquidez. Porém, com a negociação de títulos lastreados nesses ativos, as instituições credoras repassaram o problema a instituições de outros países, tornando o problema, que inicialmente era regional, em uma grave crise global.

Diante deste cenário, duas empresas de grande porte do setor de empréstimos pessoais e hipotecários foram estatizadas entre agosto e setembro de 2008. No entanto, o evento considerado o gatilho desta crise para os mercados em bolsa foi a declaração de concordata feita pelo tradicional banco de investimentos norte-americano Lehman Brothers em 15 de setembro de 2008, sendo que, um dia antes, outra das principais instituições financeiras estava envolvida em um processo de aquisição devido à sua fragilidade em manter suas operações. O sentimento por parte dos investidores de que poderia haver disseminação da crise para outros setores da economia, já bastante abalado com a falência do Lehman Brothers, foi definitivamente assimilado quando, em 17 de setembro de 2008, o Federal Reserve (FED), o banco central dos EUA, anunciou um pacote de empréstimo de US $\$ 85$ bilhões à maior seguradora do mundo, a AIG, que operava em cerca de 130 países e em diversos setores de atividade, mediante controle estatal de $80 \%$ da empresa. O final da crise, devido à sua recente ocorrência, não é facilmente observável, mas o National Bureau of Economic Research 
$(N B E R)$, um dos principais provedores de informações econômicas dos EUA, afirma ${ }^{1}$ que o país saiu oficialmente da recessão após esta crise no final do segundo trimestre de 2009, de tal forma que este será considerado o marco final da crise.

Esta crise financeira, ocorrida entre 2008 e 2009 e considerada a pior desde a quebra da bolsa de Nova Iorque em 1929, teve reflexos em diversos países, além de ter suscitado muitas críticas da população acerca da injeção governamental de recursos públicos para salvar instituições financeiras de falências, que seriam decorrência de risco moral e ingerência de seus diretores. Alguns dos principais bancos do mundo, como o inglês Northern Rock, o suíço $U B S$ e o francês Société Générale, registraram perdas enormes, a ponto de haver, inclusive, intervenção estatal em alguns deles, fato que no Reino Unido não ocorria desde 1860. Até na Islândia ocorreu fenômeno similar. No Brasil, a crise atingiu sólidas instituições de outros ramos de atividade que operavam derivativos: foram contabilizadas enormes perdas financeiras, e empresas como a Sadia, Votorantim e Aracruz, entraram em processos de fusões e aquisições.

Por fim, mas não menos importante, diversos países da Comunidade Européia anunciaram em meados de outubro de 2008 pacotes similares de injeção de recursos, visando reduzir o risco local de liquidez. Neste mesmo ano, países como Portugal, Itália, Grécia e Espanha foram considerados frágeis por possuírem economias suscetíveis a crises dadas suas altas taxas de endividamento e déficit público, o que poderia prejudicar o desempenho da Zona do Euro, que registrava no período a maior retração econômica de sua história.

Mais detalhes desta crise podem ser obtidos no trabalho de Borça-Júnior e Torres-Filho [2008] e em GPO [2011], fonte governamental dos EUA sobre a crise do subprime, cuja linguagem é bastante simples e visa informar a população acerca da cronologia, causas e efeitos desta crise.

\subsection{Objetivos e organização do trabalho}

Este trabalho tem como objetivo principal a utilização de uma técnica de inteligência artificial como alternativa de modelagem de dados financeiros, a qual é denominada de rede bayesiana, com a comparação de diferentes técnicas estatísticas para a avaliação da interdependência de mercados internacionais em períodos de crises financeiras, ocorridas entre os anos 1996 e 2009, envolvendo países nos quais foi possível avaliar seus efeitos e que foram objetos de estudos similares na literatura. Além da rede bayesiana, a análise da interdependência será modelada, ainda, com outras duas técnicas - modelos GARCH multivariados e de Cópulas - amplamente utilizadas como abordagem para este problema, e, de certa forma, clássicos.

Um outro objetivo é estudar os efeitos da crise do subprime no contexto internacional, evento ainda pouco explorado na literatura.

O trabalho está dividido em mais cinco capítulos, além desta introdução. No capítulo seguinte é feita uma revisão da literatura sobre o tema. No terceiro capítulo serão apresentadas as definições gerais das séries temporais multivariadas, com enfoque nos modelos GARCH, para que seja possível avaliar a associação cruzada das volatilidades de cada série. Já no Capítulo 4, a interdependência é modelada utilizando a abordagem da teoria de cópu-

\footnotetext{
${ }^{1}$ Esta informação pode ser obtida no sítio do NBER, disponível em: www.nber.org/cycles/cyclesmain.html.
} 
las, com a estimação dos parâmetros e comparação dos ajuste dos modelos por tradicionais famílias de cópulas. No Capítulo 5 será abordada a teoria de redes bayesianas para avaliar a estrutura de interdependência e detecção de possíveis contágios, por meio de análises gráficas e estimação de parâmetros. Finalizando, no Capítulo 6 serão discutidas as conclusões obtidas neste trabalho sobre as aplicações abordadas e sugestões de pesquisas futuras. 


\section{Capítulo 2}

\section{Breve revisão da literatura}

Com o advento das sucessivas crises financeiras internacionais descritas no capítulo anterior, embora o conceito de interdependência entre os mercados possua um razoável consenso, a definição de contágio financeiro ${ }^{2}$ está longe de ser uma questão definitiva. Diversos autores atentaram-se ao tema após as crises dos mercados financeiros emergentes, entre os anos de 1997 e 2001, e este assunto foi uma das maiores fontes para desenvolvimento de técnicas matemáticas avançadas visando explicar e até mesmo prever o surgimento de crises em mercados financeiros. Nesta revisão será dada prioridade para os trabalhos que representaram evolução na detecção de contágio por meio de modelos estatísticos, em vez de apresentar aqueles que somente descrevem os mecanismos de transmissão.

Dornbusch et al. [2000] discutem sobre a arquitetura do mercado financeiro, principalmente sobre uma reforma a fim de reduzir os riscos de contaminação, que estariam ligados a fatores mais específicos como co-movimentos de taxas de câmbio, preços de ações e títulos públicos, entre outros. Em um segundo trabalho, Dornbusch et al. [2001] ampliam as suspeitas de que o espalhamento de crises não se dá somente em períodos de crises e introduzem a idéia de que os choques podem ocorrer também em períodos de relativa tranquilidade e, para verificar empiricamente, utilizam os mesmos fatores citados no primeiro trabalho. Este trabalho foi deveras relevante pelo fato de os autores sugerirem uma proposição bastante importante: seja qual for a definição adotada para contágio, este pode ser causado por fundamentos macroeconômicos estruturais de uma economia ou por decisões de investidores $e$ outros agentes financeiros.

Existem diversos artigos que tratam dos fundamentos macroeconômicos como propagadores de crises. Hernández e Valdés [2001] afirmam que os principais canais de contaminação de crises seriam os fundamentos dos países em questão. Os autores listaram como mecanismos de transmissão as ligações comerciais entre países, similaridades e fragilidades macroeconômicas, além de outras ligações financeiras, tais como corporações de um país atuando em outro, práticas institucionais de hedge em países cujos retornos são correlacionados, problemas de liquidez de investidores, informações assimétricas e comportamento de manadas por parte de investidores estrangeiros. As políticas de hedge, executadas principalmente com títulos públicos e com ações de empresas sólidas de diferentes países, mostram-se particularmente interessantes para ilustrar uma situação em que grandes investidores possuem mecanismos capazes de influenciar as suas taxas de retorno, sobretudo quando o mercado possui a possibilidade de arbitragem.

\footnotetext{
${ }^{2}$ Para ver outras definições de contágio, acessar o sítio do Banco Mundial, disponível em: www1.worldbank.org/economicpolicy/managing.
} 
Forbes e Rigobon [2002], em artigo clássico, vão para uma linha mais ortodoxa, considerando o conceito de contágio como um aumento significativo nas correlações entre países, por meio do retorno de seus mercados acionários, em momentos de crise. E vão além: este aumento verificado só é considerado como contágio se for sabido que se está em período de crise, senão tal incremento advém somente da maior interdependência entre os mercados financeiros. Esta definição seria posteriormente mais recorrente na literatura e é denominada shift-contagion.

Durante a abordagem empírica do problema, e tendo em vista a detecção de contágio durante as crises do México em 1994 (conhecida como efeito Tequila) e asiática em 1997, a base de dados utilizada por Forbes e Rigobon [2002] contém países asiáticos, da América Latina, membros da OCDE e outros mercados emergentes, totalizando 29 países. Utilizando um modelo multivariado do tipo VAR (Vetor Autorregressivo) e utilizando correção para a correlação por meio de heterocedasticidade, os autores verificam pouca existência de contágio em cada uma das crises. Por fim, os autores argumentam que o aumento da correlação em momentos de crise pode ser uma decorrência do aumento concomitante da volatilidade e não por choques peculiares de algum dos mercados.

Em complemento ao trabalho de Forbes e Rigobon [2002], Corsetti et al. [2005] apresentam uma vasta lista de referências para outros trabalhos, além de uma visão crítica do aumento da correlação como indicativo de ocorrência de contágio, argumentando que aumento da volatilidade dos retornos durante um período de crise pode ser causado por uma variância maior, advinda não só de alguns fatores comuns, mas também por algum ruído específico de um determinado país. Em contraste aos predecessores, os autores derivam uma medida de interdependência a partir de um modelo fatorial padrão dos retornos, que não impõe quaisquer restrições sobre a variância dos fatores comuns relativos à variância do choque específico de um país. Além disso, eles demonstram que restrições aplicadas sobre ruídos específicos de cada país, implícitas nos modelos utilizados pela literatura até então, podem gravemente enviesar os testes em direção à hipótese de "não contágio".

Para aplicação de sua metodologia do trabalho em uma situação real, e a fim de mostrar que suas afirmações possuem relevância empírica, Corsetti et al. [2005] utilizam a mesma base de dados usada por Forbes e Rigobon [2002] que, em uma das situações, detectaram contágio para apenas um país, a Itália. Utilizando a abordagem proposta, os autores chegam à evidência de que seriam pelo menos 5 os casos de contágio (Cingapura, Filipinas, França e Reino Unido, além da própria Itália). Os autores enfatizam ainda que não há uma maneira única de se derivar uma medida de interdependência a partir de um modelo de ativos, uma vez que seus resultados sugerem que os ruídos específicos de cada país não podem ser ignorados quando são executados testes de quebras estruturais nas transmissões de choques.

Ainda nesta época, Lopes e Migon [2002] utilizaram Análise Fatorial incorporando modelos de volatilidade estocástica. Além da referida contribuição, os autores foram os pioneiros também na utilização de uma abordagem bayesiana para o problema de comovimentos em índices de preços de ações e, adotando a mesma definição de Forbes e Rigobon [2002], mostraram que a estrutura de covariância variando no tempo pode ser modelada por um ou dois fatores comuns. Além disso, algum tipo de contágio, medido por mudanças bruscas nas correlações das séries temporais, esteve presente na maioria das séries em análise durante períodos de instabilidade econômica verificados entre 1994 e 2001.

Sucedendo o pioneirismo de Lopes e Migon [2002], surge o trabalho de Ciccarelli e Rebucci [2003] que propõem a construção de modelo bayesiano com coeficientes variando no tempo estimado com métodos MCMC (Monte Carlo Markov Chain) e amostrador de Gibbs para 
mensurar o contágio empiricamente. Primeiramente, os autores simulam processos univariados e avaliam que sua performance mostra-se bastante consistente. Em seguida, utilizam a mesma estrutura em um conjunto de dados reais, envolvendo os efeitos da crise argentina de 2001-2002 na balança comercial do Chile. Essa aplicação mostra-se interessante por algumas razões: a primeira por conta de o Chile ser um país pequeno e, portanto, com informações completas e limitadas (eliminando o possível problema de endogeneidade). A segunda foi devido ao lento desdobramento da crise argentina, o que tornou mais simples a análise de adequação do modelo, principalmente porque durou praticamente todo o período considerado e o modelo pode ser aplicado em tempo real. Finalmente, porque se desconhecia as principais razões da desvalorização do peso chileno na época.

Os resultados obtidos por Ciccarelli e Rebucci [2003] foram favoráveis tanto na presença de heterocedasticidade quanto na presença de variáveis omitidas, além de não necessitar da demarcação dos períodos de crises. O modelo distinguiu contágio não somente de interdependência, mas também de quebras estruturais e pôde ser utilizado para detectar contágio positivo ou negativo.

Uma vez que as discussões correntes tratavam da estrutura da volatilidade condicional e, consequentemente, usavam o conceito de shift-contagion, era natural a utilização dos modelos de séries temporiais que tratassem do problema da heterocedasticidade condicional. Tendo como cerne os GARCH multivariados e suas diferentes estruturas de correlação e distribuição de resíduos, surgiram diversos trabalhos abordando desta forma o problema de interdependência e contágio. Os principais são o trabalho de Lombardi et al. [2004] (que encontra evidências sobre o padrão de contágio entre Brasil e Argentina entre 1992 e 2004), Marçal e Pereira [2008] (cujo trabalho detecta evidências de contágio entre Brasil, Argentina, México e Rússia, além de verificar a presença de comportamento assimétrico nas volatilidades), Filetti et al. [2008] (os autores fazem a detecção de contágio por alisamento exponencial, GARCH multivariado e Análise Fatorial para Brasil, Argentina, México, Rússia e Malásia entre 1995 e 2004, tendo encontrado muitas evidências de contágio por todas as análises executadas).

Já mais recentemente, o conceito de contágio associado a choques na volatilidade e mesmo no conceito linear de correlação foi ampliado, passando a entrar no campo das medidas de dependência não lineares. Um dos trabalhos pioneiros, Chollete et al. [2005] propôs-se a modelar a estrutura de dependência do mercado internacional de ações, utilizando modelos paramétricos de cópulas. Os autores estudaram o comportamento do grupo das 5 principais economias do mundo (EUA, Alemanha, Japão, Reino Unido e França, chamado de G5), países da América Latina (Argentina, Brasil, Chile e México), além dos asiáticos Hong Kong, Cingapura e Taiwan, no período entre 1990 e 2002, aplicando diversas misturas de cópulas, de forma bivariada. Os resultados sugeriram a interessante possibilidade de que as economias dos países desenvolvidos e em desenvolvimento diferem quanto à sua exposição ao risco de queda, com as economias dos países em desenvolvimento com risco de queda potencialmente menor, uma vez que para o G5 a dependência assimétrica dominou o modelo e, para os demais, houve evidências de mistura sobre a assimetria da dependência.

O artigo de Rodriguez [2007], amplia a metodologia de se mensurar as crises, não só fazendo a avaliação da interdependência por meio dos coeficientes globais, como também com a defesa, feita pelo autor, do argumento de que as quebras estruturais na dependência da cauda formam uma dimensão importante de contágio; para isso, ele se utiliza dos índices de cauda, inclusive para averiguar potenciais assimetrias. Na seção empírica, o autor verifica contágio intrarregional entre dois grupos: países asiáticos (Tailândia, Malásia, Indonésia, 
Coréia do Sul e Filipinas, entre 1996 e 1998) e latino-americanos (Brasil, Argentina e Chile, entre 1993 e 1995). Para os períodos de crise, os resultados apontaram para existência de contágio, com especial agravamento na dependência nas caudas.

De modo similar a este último trabalho, Peng e Ng [2009] estudam o comportamento conjunto de 4 conhecidos índices americanos (S\&P 100, S\&P 500, NASDAQ 100 and DJIA) e outros 5 europeus (DAX, DJ Euro STOXX 50, SMI, CAC 40 e FTSE 100), entre 2001 e 2009, com os autores calculando os índices de volatilidade (VIX - índice de volatilidade - e VXO - índice de volatilidade implícita, ambos da bolsa de Chicago) por diferentes métodos. Os resultados mostraram que há aumento da dependência durante os períodos de turbulência financeira, o que implica a existência de contágio financeiro. Além disso, os movimentos dos valores extremos entre os índices de volatilidade apresentam significativa ascenção a partir de meados de 2006, ascenção esta não verificada entre os demais índices de ações utilizados no trabalho.

Utilizando as cópulas condicionais, trivariadas com coeficiente variando no tempo, o trabalho de Abbara [2009] traz um grande avanço ao estudo da análise de contágio, realizando a modelagem de retornos de índices dos mercados norte-americanos, latino-americanos e europeus, no período compreendido entre 1995 e 2008, contendo, portanto, o início da crise dos EUA. O trabalho, além de fornecer uma ampla gama de artigos sobre aplicação de cópulas, chega a diversas conclusões. A primeira delas é que, utilizando metodologias combinadas, o mercado dos EUA determina grande parte das características da dependência entre os mercados financeiros latino-americanos, como a assimetria na dependência nas caudas e evolução na dependência em fortes quedas. Estes resultados não foram verificados para os mercados europeus, o que permite diferenciar o efeito dos EUA na dinâmica dos mercados das duas regiões. Seguindo o conceito de shift-contagion, a segunda conclusão obtida pelo autor sugere que, ao adotar modelos trivariados de cópulas e condicionando os demais países dois a dois nos EUA, fez desaparecer a evidência de contágio verificada na análise incondicional entre os mercados latino-americanos. Novamente, o resultado não foi verificado para os mercados europeus, mas esta análise alertou para o problema de omissão de variáveis na análise de contágio.

Apesar de todo o esforço para determinar movimentos simultâneos na evolução das séries, sempre se abordou na literatura as medidas de associação, sejam elas lineares ou não lineares. Naturalmente, o desejável seria determinar eventuais causalidades para os movimentos observados em períodos tranquilos e naqueles em que as crises possam ser verificadas. Apesar de a interdependência entre mercados acionários nacionais ser amplamente estudada, a aplicação de metodologias causais neste tema de contágio ainda é bastante escassa. O primeiro trabalho que procurou dar este tratamento de causalidade foi Granger [1969], cujo conceito de causalidade sugere que toda informação relevante para a predição de duas variáveis $\mathrm{X}$ e Y está contida apenas nas próprias séries de tempo sobre essas duas variáveis. Dessa forma, uma série temporal estacionária X causa, no sentido de Granger, uma outra série estacionária Y se as melhores predições estatisticamente significantes de Y puderem ser obtidas com a inclusão de valores defasados de $\mathrm{X}$ aos valores defasados de $\mathrm{Y}$. Existem versões mais modernas deste conceito, mas como essa é a idéia central, as demais não serão abordadas.

No entanto, com o desenvolvimento de técnicas estatísticas avançadas em concomitância com o aumento do poder computacional, foi possível explorar os conceitos mais fortes de (in)dependência probabilística mesmo dispondo de muitas variáveis simultaneamente, uma estrutura que convencionou-se chamar de grafos acíclicos direcionais ( $D A G)$. Os fundamen- 
tos teóricos não serão aqui mencionados. Isso será abordado com detalhes no Capítulo 5 desta dissertação.

O trabalho de Bessler e Yang [2003] é o primeiro a explorar esta técnica dos $D A G$ 's para abordar o problema da dinâmica de interdependência dos mercados de ações, utilizando conjuntamente um modelo de correção de erros (para estrutura de longo prazo) e um modelo $V A R$ (denotando a análise de curto prazo). Neste contexto, e no período compreendido entre 1997 e 1999, os autores constroem $D A G$, que fornece uma estrutura de causalidade entre nove mercados acionários no mundo (Austrália, Japão, Hong Kong, Alemanha, Suíça, França, Reino Unido, EUA e Canadá). Os resultados obtidos mostram que o mercado japonês está entre os mais exógenos, enquanto os canadenses e franceses entre os menos exógenos no estudo. O mercado dos EUA é altamente influenciado pelas suas próprias inovações históricas, mas também é influenciado por inovações no mercado do Reino Unido, Suíça, Hong Kong, França e Alemanha. O mercado dos EUA foi o único que mostrou ter um impacto consistente sobre os movimentos de preços em outros grandes mercados de ações no longo prazo.

Combinando as últimas duas metodologias citadas - cópulas e estrutura causal por meio de um DAG - Viale et al. [2008] inovam no tratamento do conceito de contágio. Seguindo o conceito proposto por Chang e Majnoni [2002], que definem o contágio financeiro como uma mudança na estrutura de dependência entre um determinado conjunto de retornos do mercado financeiro, os autores sugerem que a propagação dos choques depende tanto dos fundamentos econômicos específicos de um determinado país quanto dos mecanismos de transmissão (por meio de expectativas) que ligam os fundamentos às correlações de retornos dos ativos. Como estratégia de análise, Viale et al. [2008] implementam um estimador semiparamétrico, Bayesiano, robusto e não-padrão para a função de uma mistura de cópula. Esta abordagem robusta pode ser considerada uma extensão do classificador quadrático de Bayes, que utiliza uma mistura de modelos para estimar a densidade de classe subordinada, com a vantagem de ser capaz de gerenciar mais classes de distribuições a priori.

Em seguida, Viale et al. [2008] identificam a estrutura (qualitativa) e a dinâmica da dependência entre os mercados por meio de nós, ligações de influência (arcos), e os fluxos em um esforço para modelar explicitamente a rede bayesiana de crença dos investidores para um determinado conjunto de retornos dos mercados financeiros envolvidos (Argentina, Bolívia, Brasil, Chile, Paraguai, Uruguai, Venezuela, México, Rússia e mercados livres da Ásia, exceto o Japão, totalizando 27 países), durante o período de 1994 a 2002. Utilizando diversas variáveis de desempenho de quase todos os países (fatores como divida soberana, retorno esperado de títulos públicos, mercado acionário e taxa de câmbio), os autores rejeitam a hipótese nula de interdependência apenas em favor da presença de contágio financeiro para o Mercosul, durante o período em análise, encontrando evidências de clusters geográficos.

Apesar dos achados relevantes, Viale et al. [2008] estimam as redes bayesianas apenas em três situações: 1) para a amostra inteira e em momentos de 2) decaimento e 3) subida dos mercados. Esta abordagem não se mostra adequada, uma vez que não fica nítido qual é o critério de determinação dessas fases.

Utilizando uma nova medida de dependência local, Stove et al. [2010] avaliaram os mercados acionários da Argentina, Brasil, Chile e México durante três crises financeiras: mexicana, asiática e do subprime. A idéia central da metodologia utilizada pelos autores consiste em aproximar uma distribuição de retorno arbitrária bivariada por uma família de distribuições gaussianas bivariadas. Em cada ponto de distribuição de retorno há uma distribuição Normal, o que fornece uma boa aproximação àquele ponto. A correlação da distribuição Gaussiana 
aproximada é tida como a correlação local naquela vizinhança. Ao examinar a correlação Gaussiana local em um período estável e depois no período de crise, testou-se a ocorrência de contágio por um procedimento de testes bootstrap. Como resultado, os autores encontram alguma evidência de contágio.

Para este trabalho, o conceito de contágio que será adotado é similar ao proposto por Chang e Majnoni [2002], porém com a vantagem de se ter amplo sentido estatístico: eventuais alterações da estrutura de dependência probabilística em um cenário de crise, relativamente aos de tranquilidade verificados anteriormente, serão denominadas contágio financeiro. 


\section{Capítulo 3}

\section{Análise descritiva, filtragem univariada e modelagem da interdependência por meio de GARCH multivariado}

\subsection{Introdução}

No presente capítulo são apresentadas algumas definições e modelos de séries temporais financeiras que serão utilizadas no decorrer do trabalho. Primeiramente são definidas as métricas utilizadas para se avaliar as séries, em seguida é feita a análise descritiva de cada uma das séries que serão utilizadas nesta dissertação para, posteriormente, apresentar os modelos para a heterocedasticidade condicional (GARCH) nas versões uni e multivariadas. Finalmente, será feita a modelagem das séries financeiras, objeto desta dissertação.

Todas as notações e terminologias deste capítulo seguem de perto aquelas apresentadas em McNeil et al. [2005], Morettin e Toloi [2006] e Morettin [2008].

\subsection{Retornos e Fatos estilizados}

Denota-se por $P_{t}$ o preço de um ativo qualquer no t-ésimo instante de tempo. No entanto, é preferível trabalhar com as taxas de variação, por se tratar de um processo livre de escala e por possuírem propriedades estatísticas mais interessantes como estacionariedade e ergodicidade. Desta maneira, define-se retornos líquidos simples por

$$
R_{t}=\frac{P_{t}-P_{t-1}}{P_{t-1}}=\frac{\Delta P_{t}}{P_{t-1}}
$$

Denotando $p_{t}=\log P_{t}$ (com o logaritmo na base $e$ ), define-se o retorno composto continuamente ou simplesmente log-retorno como:

$$
\begin{gathered}
r_{t}=\log \frac{P_{t}}{P_{t-1}}=\log \left(1+R_{t}\right)=p_{t}-p_{t-1}, \\
r_{t}=\Delta \log P_{t} .
\end{gathered}
$$


Vale ressaltar que, para retornos simples $\left(R_{t}\right)$ pequenos, $\log \left(1+R_{t}\right) \approx R_{t}$, de tal forma que os retornos simples $\left(R_{t}\right)$ e os log-retornos $\left(r_{t}\right)$ serão, geralmente, valores próximos. Além disso, retornos financeiros, objeto desta dissertação, podem apresentar algumas peculiaridades como ausência de tendência e sazonalidade (muito comuns em séries temporais). Desta maneira, é possível resumir os principais fatos estilizados relativos a retornos financeiros, a saber:

1. retornos são, em geral, não correlacionados;

2. os quadrados dos retornos são autocorrelacionados, apresentando correlação de defasagem e uma estrutura de queda lenta quanto maior for o passado;

3. séries de retornos apresentam agrupamentos de volatilidades ao longo do tempo;

4. a distribuição incondicional dos retornos apresenta caudas mais pesadas do que uma distribuição normal. Quando a distribuição for aproximadamente simétrica, ela pode ser leptocúrtica, e;

5. algumas séries de retornos são não-lineares, no sentido supracitado.

Em situações em que se tem um número muito grande de observações, é comum fazer a suposição de normalidade para a distribuição de frequência. No entanto, verifica-se que tal suposição não é válida na grande maioria dos casos em séries temporais financeiras, devido ao fato de as distribuições amostrais dos retornos terem grande densidade nas caudas ou por possuírem assimetria.

Para mensurar estas possíveis fugas da suposição original, definem-se medidas para a curtose e para a assimetria. A assimetria é uma medida de dispersão que indica a diferença entre dois lados opostos da distribuição (relativamente à média) e sua fórmula é dada por:

$$
A(X)=E\left[\frac{(X-\mu)^{3}}{\sigma^{3}}\right],
$$

em que $\mu$ e $\sigma^{2}$ representam a média e a variância de uma variável aleatória $\mathrm{X}$.

De posse de uma amostra de tamanho $n$ desta variável aleatória $r_{t}$ e estimando $\mu$ e $\sigma^{2}$ por $\bar{r}$ e $s^{2}=\frac{1}{n} \sum_{t=1}^{n}\left(r_{t}-\bar{r}\right)^{2}$, respectivamente, então a versão amostral da assimetria será dada por:

$$
\widehat{A}(r)=\frac{1}{(n-1) s^{3}} \sum_{t=1}^{n}\left(r_{i}-\bar{r}\right)^{3},
$$

em que $s$ é o desvio-padrão e $\bar{r}$ é a média do processo observado $r_{t}, t=1, \ldots, n$.

Já a curtose pode ser entendida como a medida de dispersão que fornece a densidade das caudas da distribuição de frequência e sua expressão é dada por:

$$
K(r)=E\left[\frac{(X-\mu)^{4}}{\sigma^{4}}\right]-3
$$

e, com os mesmos estimadores para os parâmetros, obtém-se a curtose amostral, como descrito a seguir: 


$$
\widehat{K}(r)=\frac{1}{(n-1) s^{4}} \sum_{t=1}^{n}\left(r_{i}-\bar{r}\right)^{4}-3 .
$$

Como efeito de comparação, a medida da assimetria da distribuição normal padrão é igual a zero (ausência de assimetria). Se esta medida for negativa, a distribuição é assimétrica à esquerda e, se positiva, assimétrica à direita. A respeito da curtose, a distribuição normal padrão tem valor igual a 3, o que justifica a subtração por 3. Se esta medida amostral for maior que 3 (ou, com a subtração, positiva), há indícios de violação da suposição de distribuição normal e uma distribuição com caudas mais densas deve ser procurada, como uma distribuição t-student, por exemplo.

\subsection{Análise descritiva das séries}

Esta seção tem por objetivo principal apresentar e estudar de modo preliminar as séries temporais que serão utilizadas no decorrer do trabalho. Primeiro, o conjunto de dados será apresentado desde a construção da base de dados para, em seguida, serem elaborados e comentados os cálculos dos índices já constantes neste capítulo.

\subsubsection{O conjunto de dados e as crises financeiras}

A base de dados é composta por índices de bolsas de valores ${ }^{3}$ de 6 países que, segundo a literatura, estão associados a crises financeiras. Esses países são Brasil (BRA), utilizando o índice Ibovespa; Argentina (ARG), com o índice Merval; México (MEX), pelo índice IPC; Estados Unidos (EUA), utilizando o índice Dow Jones; Malásia (MAL), a partir do índice KLSE; e, finalmente, a Rússia (RUS) com o seu índice RTSI. A amostra contém informações diárias, no período compreendido entre os dias 08/10/1996 e 30/12/2009, o que resultaria em 3452 dias úteis de observações.

De modo a dispor de informações completas a respeito de uma distribuição conjunta entre os países, fez-se necessária uma combinação entre as datas dos países, devido à existência de feriados em alguns países sem correspondência nos demais. Desta maneira, optou-se por descartar as datas que não tivessem informação de todos os países simultaneamente. Ao final do processo, sobraram 2608 observações que satisfaziam esta condição. Em seguida, foi a vez de determinar os períodos de crise. Com base em pesquisas de notícias de jornais diários, foi possível determinar a data exata do começo das crises. No entanto, o fim da crise foi uma determinação ad-hoc do autor, com base visual na estabilização das volatilidades dos principais envolvidos nas crises. Como resumo destas datas, a Tabela 3.1, a seguir, traz as partições definidas como marcos de início e fim de crises.

\footnotetext{
${ }^{3}$ Todas as informações foram obtidas no sítio http://finance.yahoo.com/, acessado em julho de 2010.
} 
Tabela 3.1: Definição ad-hoc dos períodos em que houve crise.

\begin{tabular}{ccccc}
\hline Períodos & Descrição & Início & Fim & Quantidade de observações \\
\hline 1 & Tranquilidade & $08 / 10 / 1996$ & $02 / 07 / 1997$ & 145 \\
2 & Crise Asiática & $03 / 07 / 1997$ & $26 / 01 / 1998$ & 117 \\
3 & Tranquilidade & $27 / 01 / 1998$ & $26 / 04 / 1998$ & 49 \\
4 & Crise da Rússia & $27 / 04 / 1998$ & $16 / 12 / 1998$ & 133 \\
5 & Tranquilidade & $17 / 12 / 1998$ & $04 / 01 / 1999$ & 6 \\
6 & Crise do Brasil & $05 / 01 / 1999$ & $03 / 03 / 1999$ & 30 \\
7 & Tranquilidade & $04 / 03 / 1999$ & $20 / 11 / 2001$ & 534 \\
8 & Crise da Argentina & $21 / 11 / 2001$ & $30 / 12 / 2002$ & 208 \\
9 & Tranquilidade & $31 / 12 / 2002$ & $16 / 09 / 2008$ & 1134 \\
10 & Crise dos EUA & $17 / 09 / 2008$ & $13 / 03 / 2009$ & 89 \\
11 & Tranquilidade & $14 / 03 / 2009$ & $30 / 12 / 2009$ & 163 \\
\hline & Total & $08 / 10 / 1996$ & $30 / 12 / 2009$ & 2608 \\
\hline
\end{tabular}

Conclui-se, pela Tabela 3.1, que ocorreram 5 crises financeiras no período de análise e estas crises correspondem a aproximadamente $11 \%$ do conjunto de observações. Nas figuras subsequentes, os períodos mencionados na Tabela 3.1 terão como regra a seguinte definição: as datas de início e fim de crise estarão representadas por uma linha pontilhada vertical, de tal forma que a cor vermelha denota as datas de início e a cor azul, as datas de fim de crise.

\subsubsection{Análise das séries}

Inicialmente, a fim de ignorar a escala dos dados, todos os dados foram divididos pelo seu respectivo valor inicial (e multiplicados, posteriormente, por 100), de tal maneira que seja factível analisar apenas um gráfico contendo todas as séries. A Figura 3.1 a seguir mostra a evolução dos índices de todos os países em questão ao longo do período de análise. 


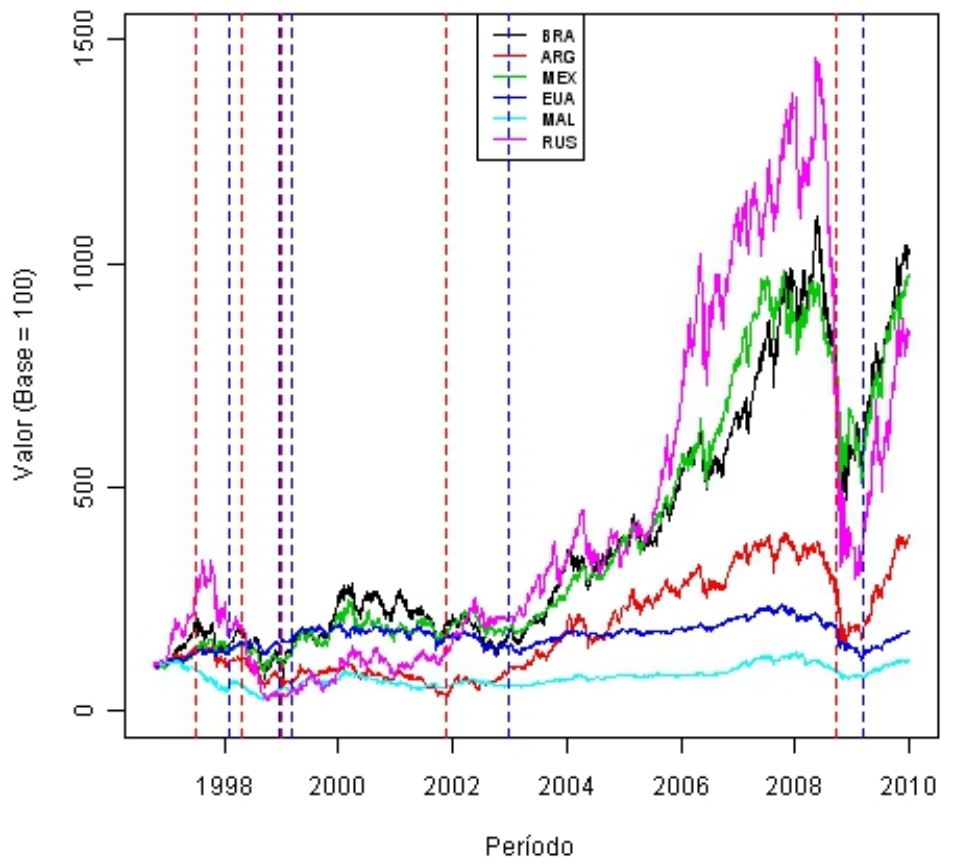

Figura 3.1: Evolução dos índices no período de análise.

De acordo com a Figura 3.1 é possível perceber que algumas séries apresentam grande crescimento no período de análise. Como maiores destaques, tem-se o Brasil e o México, que estiveram sempre entre os países que apresentaram maior crescimento, além da Rússia, que durante três anos (meados de 2005 até a véspera da crise dos EUA) era o país que mais havia crescido. Por outro lado, é notória a estabilidade dos índices dos EUA e Malásia, tendo sofrido (relativamente) fortes oscilações somente em períodos de crises. Finalmente, o caso da Argentina parece ser o caso intermediário entre os dois grupos supradescritos: no início do período analisado, comportou-se como a Malásia; já após a crise do Brasil, descolouse e passou a experimentar tendência similar à verificada no grupo dos países emergentes, composto por Brasil, México e Rússia.

Eliminando a tendência de cada uma das séries ao tomar seus log-retornos, pode-se verificar um pouco melhor o que ocorreu com a volatilidade das séries em cada um dos períodos de crises. 

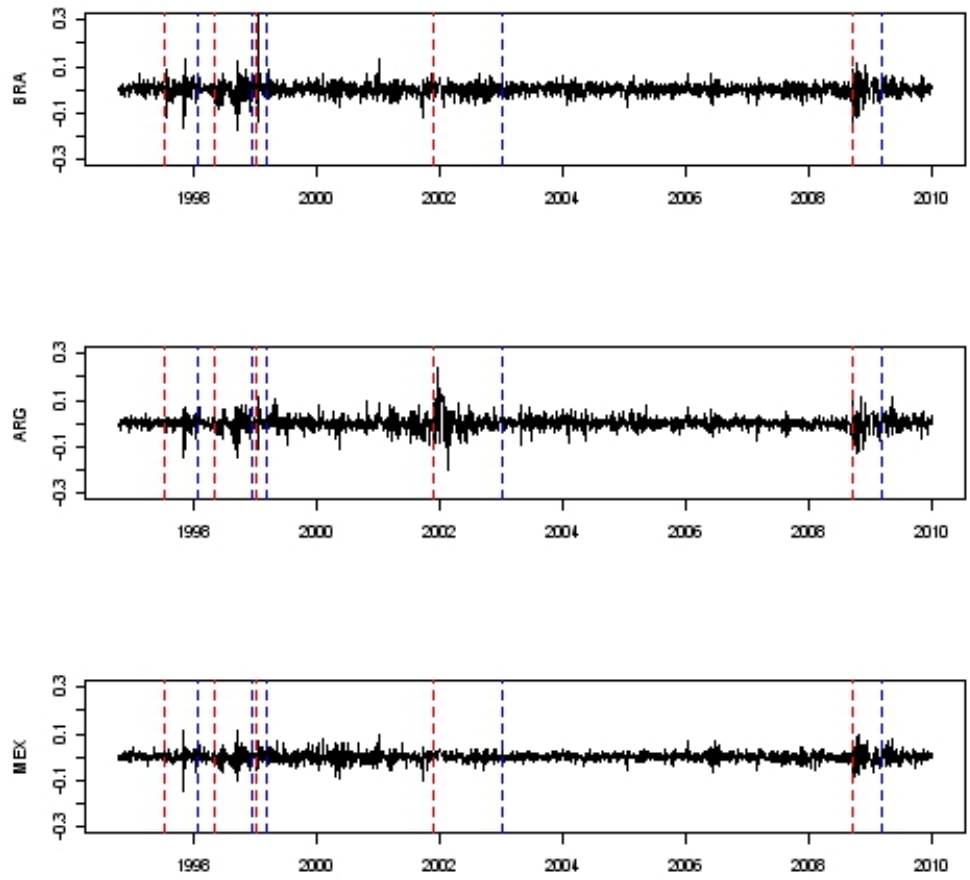

Figura 3.2: Evolução dos log-retornos do Brasil, Argentina e México no perído de análise.
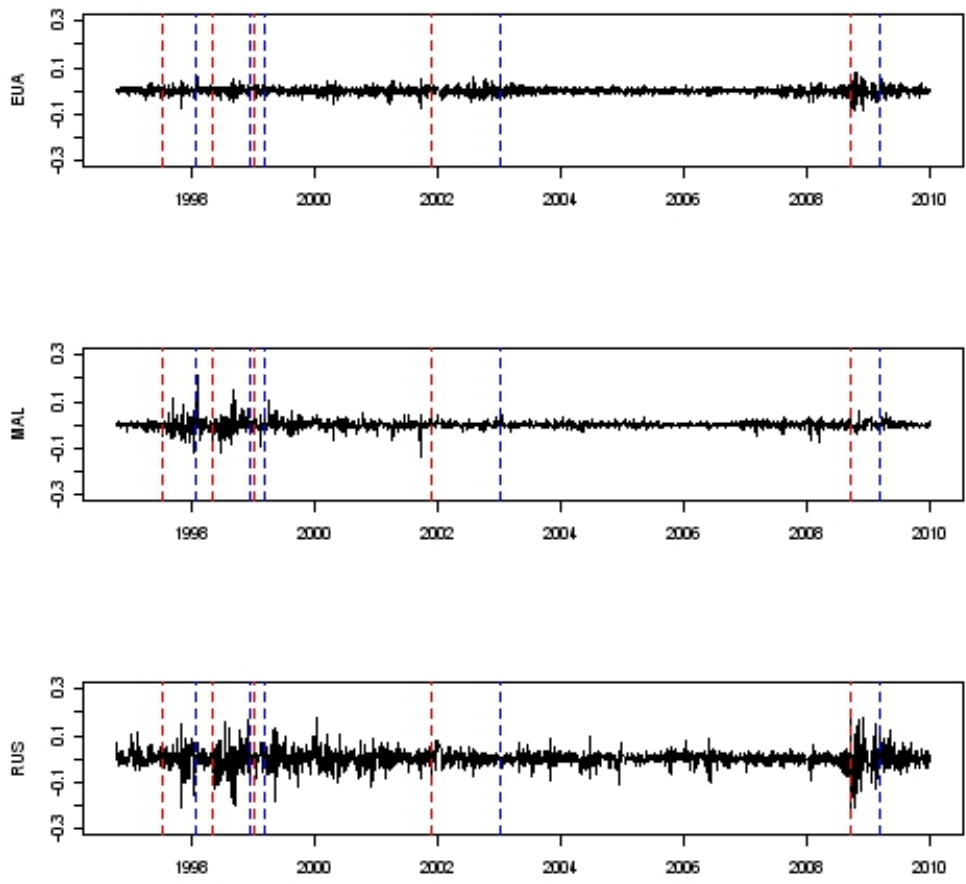

Figura 3.3: Evolução dos log-retornos do EUA, Malásia e Rússia no período de análise. 
A partir das Figuras 3.2 e 3.3, é possível verificar que as volatilidades mais altas estão compreendidas em momentos em que houve alguma crise. Durante a primeira crise (Asiática), nota-se que o mercado mais afetado parece ter sido a Malásia e, embora seja possível verificar algum movimento de volatilidade mais alta nas demais séries, apenas a Rússia apresentou persistência no aumento da volatilidade. No que diz respeito à segunda crise (Russa), a Rússia apresentou grande volatilidade em todo o período desta crise, bem como a Malásia. Movimentos similares, embora menos intensos, foram observados no Brasil, na Argentina e no México. Aparentemente, os EUA foram o país menos afetado, uma vez que a sua volatilidade, ainda que maior, teve um aumento apenas leve.

A terceira crise (Brasileira) foi bastante rápida, com apenas 9 observações, mas apresentou um aumento na volatilidade do Brasil, em maior grau, e também na Argentina e no México. Nos demais países, ao que parece, não houve maior influência. Já a quarta crise, na Argentina, apenas no próprio país foi observado um grande aumento na volatilidade. Finalmente, a última grande crise financeira do período de análise (crise do subprime nos EUA), parece ter sido a que mais envolveu países: Brasil, Argentina, México e Rússia, além dos EUA, tiveram drásticos aumentos em suas volatilidades, nunca antes observados em tais magnitudes. Vale ressaltar que, nesta última crise, apenas a Malásia mostrou-se ilesa aos seus desdobramentos, evidenciando algum comportamento distinto em relação aos demais.

A seguir, serão apresentadas as medidas descritivas calculadas para cada uma das séries, bem como suas correlações em cada um dos períodos: sejam eles de crises (já mencionados na Tabela 3.1) ou em períodos de tranquilidade (nos períodos em que não há crise). 
Tabela 3.2: Estatísticas Descritivas dos log-retornos para os países avaliados em cada período.

\begin{tabular}{|c|c|c|c|c|c|c|c|}
\hline Medida & Período & Brasil & Argentina & México & EUA & Malásia & Rússia \\
\hline \multirow{12}{*}{ Média } & P1 - Tranquilidade & 0,0048 & 0,0023 & 0,0021 & 0,0018 & $-0,0004$ & 0,0067 \\
\hline & P2 - Crise Asiática & $-0,0028$ & $-0,0025$ & $-0,0001$ & $-0,0001$ & $-0,0055$ & $-0,0040$ \\
\hline & P3 - Tranquilidade & 0,0016 & 0,0003 & 0,0003 & 0,0021 & $-0,0026$ & $-0,0040$ \\
\hline & P4 - Crise Russa & $-0,0116$ & $-0,0111$ & $-0,0064$ & $-0,0039$ & $-0,0036$ & $-0,0323$ \\
\hline & P5 - Tranquilidade & 0,0015 & 0,0033 & 0,0030 & 0,0038 & 0,0091 & 0,0079 \\
\hline & P6 - Crise Brasileira & 0,0065 & $-0,0199$ & $-0,0077$ & $-0,0019$ & 0,0082 & $-0,0072$ \\
\hline & P7 - Tranquilidade & 0,0011 & $-0,0009$ & 0,0008 & 0,0002 & 0,0000 & 0,0024 \\
\hline & P8 - Crise Argentina & 0,0012 & 0,0152 & 0,0039 & $-0,0004$ & 0,0038 & 0,0083 \\
\hline & P9 - Tranquilidade & 0,0010 & 0,0012 & 0,0010 & 0,0001 & 0,0003 & 0,0011 \\
\hline & P10 - Crise dos EUA & $-0,0032$ & $-0,0059$ & $-0,0034$ & $-0,0053$ & $-0,0023$ & $-0,0083$ \\
\hline & P11 - Tranquilidade & 0,0035 & 0,0049 & 0,0031 & 0,0023 & 0,0025 & 0,0048 \\
\hline & Média Geral & 0,0009 & 0,0005 & 0,0009 & 0,0002 & 0,0000 & 0,0008 \\
\hline \multirow{12}{*}{ Desvio-Padrão } & P1 - Tranquilidade & 0,0163 & 0,0130 & 0,0115 & 0,0108 & 0,0097 & 0,0260 \\
\hline & P2 - Crise Asiática & 0,0409 & 0,0280 & 0,0253 & 0,0143 & 0,0343 & 0,0470 \\
\hline & P3 - Tranquilidade & 0,0254 & 0,0206 & 0,0187 & 0,0110 & 0,0335 & 0,0428 \\
\hline & P4 - Crise Russa & 0,0521 & 0,0428 & 0,0335 & 0,0175 & 0,0424 & 0,0630 \\
\hline & P5 - Tranquilidade & 0,0409 & 0,0294 & 0,0224 & 0,0124 & 0,0221 & 0,0483 \\
\hline & P6 - Crise Brasileira & 0,1518 & 0,0633 & 0,0422 & 0,0182 & 0,0152 & 0,0341 \\
\hline & P7 - Tranquilidade & 0,0232 & 0,0254 & 0,0221 & 0,0140 & 0,0180 & 0,0361 \\
\hline & P8 - Crise Argentina & 0,0289 & 0,0780 & 0,0133 & 0,0155 & 0,0106 & 0,0281 \\
\hline & P9 - Tranquilidade & 0,0198 & 0,0207 & 0,0141 & 0,0116 & 0,0094 & 0,0221 \\
\hline & P10 - Crise dos EUA & 0,0457 & 0,0460 & 0,0355 & 0,0347 & 0,0146 & 0,0690 \\
\hline & P11 - Tranquilidade & 0,0190 & 0,0228 & 0,0174 & 0,0132 & 0,0092 & 0,0299 \\
\hline & Desvio-Padrão Geral & 0,0260 & 0,0257 & 0,0187 & 0,0139 & 0,0164 & 0,0329 \\
\hline \multirow{12}{*}{ Assimetria } & P1 - Tranquilidade & 0,4255 & $-0,1797$ & 0,3874 & $-0,1914$ & $-0,8445$ & 1,0852 \\
\hline & P2 - Crise Asiática & $-0,5260$ & $-1,6403$ & $-0,9959$ & $-0,8104$ & 0,3553 & $-0,7040$ \\
\hline & P3 - Tranquilidade & $-0,8265$ & 0,1800 & $-0,2925$ & 0,9382 & 2,1373 & 0,2102 \\
\hline & P4 - Crise Russa & $-0,1087$ & $-0,6209$ & 0,6522 & 0,3061 & 1,4527 & $-0,3727$ \\
\hline & P5 - Tranquilidade & 0,0640 & 0,3263 & 0,1730 & 0,4227 & 0,8671 & 1,1168 \\
\hline & P6 - Crise Brasileira & 1,4710 & 0,6279 & 0,5413 & 0,3885 & 0,2263 & $-0,7730$ \\
\hline & P7 - Tranquilidade & 0,2186 & 0,0491 & 0,0001 & $-0,4365$ & $-0,4716$ & $-0,0497$ \\
\hline & P8 - Crise Argentina & 0,2071 & 0,1831 & 0,4661 & $-0,3860$ & 1,4898 & 0,3667 \\
\hline & P9 - Tranquilidade & $-0,4019$ & $-0,1420$ & $-0,2856$ & $-0,1019$ & $-0,6761$ & $-0,8899$ \\
\hline & P10 - Crise dos EUA & $-0,0553$ & $-0,4493$ & 0,3019 & 0,1095 & 0,8310 & 0,0229 \\
\hline & P11 - Tranquilidade & 0,1742 & 0,3557 & 0,3462 & $-0,0206$ & 1,1514 & 0,3998 \\
\hline & Assimetria Geral & 0,7270 & $-0,1058$ & $-0,1402$ & $-0,3112$ & 0,8396 & $-0,4423$ \\
\hline \multirow{12}{*}{ Curtose } & P1 - Tranquilidade & 1,1328 & 0,8229 & 1,0338 & 1,5869 & 1,4333 & 2,2639 \\
\hline & P2 - Crise Asiática & 2,4695 & 6,5528 & 10,0343 & 5,6594 & 1,5824 & 3,3576 \\
\hline & P3 - Tranquilidade & 1,6136 & 2,3473 & 1,4981 & 5,8338 & 15,9160 & 1,9241 \\
\hline & P4 - Crise Russa & 1,3058 & 0,8491 & 3,0775 & 0,6817 & 2,5809 & 0,6622 \\
\hline & P5 - Tranquilidade & $-0,9125$ & 0,5993 & 0,7235 & 0,7951 & 0,6083 & 1,4969 \\
\hline & P6 - Crise Brasileira & 1,1202 & $-0,4543$ & $-1,2329$ & $-1,5696$ & $-1,5531$ & $-0,5948$ \\
\hline & P7 - Tranquilidade & 2,9373 & 2,6703 & 2,1238 & 2,7715 & 8,7243 & 2,5071 \\
\hline & P8 - Crise Argentina & 0,4363 & 1,1418 & $-0,6716$ & $-0,4499$ & 3,7784 & 0,1125 \\
\hline & P9 - Tranquilidade & 2,3297 & 3,0010 & 3,2340 & 3,8500 & 6,2008 & 17,2304 \\
\hline & P10 - Crise dos EUA & 0,3435 & 0,3048 & 0,0172 & $-0,1348$ & 2,8665 & 0,6270 \\
\hline & P11 - Tranquilidade & 0,8299 & 2,5856 & 2,5895 & 0,9192 & 4,2695 & 0,8300 \\
\hline & Curtose Geral & 20,6204 & 7,7923 & 5,1843 & 4,8056 & 21,0138 & 7,0908 \\
\hline
\end{tabular}

A Tabela 3.2 traz as estatísticas descritivas relevantes para a compreensão do comportamento dos log-retornos de cada uma das séries em estudo. Começando pela média, nota-se que há certa estabilidade em cada um dos períodos e que, no geral, ela se aproxima de zero. Nos períodos de crise, no entanto, a maioria das séries apresentam log-retornos negativos, fato intrínseco à ocorrência das crises. Outra decorrência da crise pode ser vista na segunda estatística apresentada na Tabela 3.2: o desvio-padrão, em períodos de crise, apresenta um aumento bastante expressivo. Como é possível perceber, durante a crise asiática a volatilidade da Malásia aumentou cerca de 252\%, a volatilidade da Rússia, durante a crise russa, aumentou cerca de $47 \%$; ainda mais forte foi o crescimento da volatilidade brasileira na crise do Brasil (aproximadamente 270\%); a Argentina teve um crescimento superior a 207\% em sua volatilidade durante a crise ocorrida no país. Finalmente, nos EUA, que apresentam volatilidade histórica em torno de $3 \%$, verificou-se uma volatilidade de quase $7 \%$ no período da crise do subprime. 
A respeito da assimetria amostral, pôde-se verificar que, embora haja alguma alteração em períodos de crise, ela mantém-se estável e leve. Talvez a assimetria mais evidente seja a do Brasil no momento da crise brasileira, que fornece uma idéia interessante: embora seja constatada crise durante algum instante, é possível obter mais retornos anormais positivos do que negativos, durante o período de maior volatilidade. Isso mostra sinais de recuperação rápida, o que justifica o curto período da ocorrência da crise. Finalmente, a curtose: verificase na Tabela 3.2 que, a menos de poucas exceções em certos períodos, a distribuição de frequências amostral possui cauda muito mais densa que a distribuição Normal para todos os países, em todos os períodos, evidenciando que uma distribuição t-Student parece mais adequada para ajustar os log-retornos do que uma Normal.

\subsection{Modelos GARCH}

Alguns modelos mais importantes para séries temporais financeiras serão apresentados nesta Seção. Em conformidade com a definição de contágio adotada para esta dissertação, serão estudados modelos especialmente apropriados para a avaliação da variância condicional variando no tempo. Trata-se de uma estrutura não-linear, denominada de família ARCH (autorregressive conditional heteroskedasticity) e suas generalizações. Não serão abordadas propriedades matemáticas de tais modelos, embora estas possam ser consultadas em detalhes nos textos de McNeil et al. [2005], Morettin e Toloi [2006] e Morettin [2008].

\subsubsection{Processo ARCH univariado}

Um modelo ARCH (autoregressive conditional heteroscedasticity) é definido da seguinte maneira. Seja $\left(Z_{t}\right)_{t \in \mathbb{Z}}$ um processo ruído branco padrão. O processo $\left(X_{t}\right)_{t \in \mathbb{Z}}$ segue um $\mathrm{ARCH}(\mathrm{p})$ se é estritamente estacionário e satisfaz, para todo $t \in \mathbb{Z}$ e valores estritamente positivos $\left(\sigma_{t}\right)_{t \in \mathbb{Z}}$, as equações:

$$
X_{t}=\sigma_{t} Z_{t}, \quad \sigma_{t}^{2}=\alpha_{0}+\sum_{i=1}^{p} \alpha_{i} X_{t-i}^{2}
$$

em que $\alpha_{0}>0$ e $\alpha_{i} \geq 0, i=1, \ldots, p$. Pela definição do processo, nota-se que valores grandes para $X_{t}$ são precedidos de valores grandes e o mesmo deve acontecer para valores pequenos.

Além disso, decorre da definição que a variância incondicional $X_{t}$ é constante, enquanto a variância condicional (na informação passada) do processo $X_{t}$ varia no tempo e está descrita na equação de $\sigma_{t}^{2}$ na Equação 3.1.

Usualmente, adota-se que $Z_{t} \sim N(0,1)$ ou $Z_{t} \sim t_{v}$ ( $t$-Student com $v$ graus de liberdade). No entanto, pode-se adotar outras distribuições, como a Distribuição Generalizada de Erro $(G E D)$.

\subsubsection{Processo GARCH univariado}

Os processos GARCH (generalized autoregressive conditional heteroscedasticity) são processos ARCH generalizados, no sentido que as volatilidades $\sigma_{t}^{2}$ dependem tanto das volatilidades passadas quanto dos valores ao quadrado do processo. 
Seja $\left(Z_{t}\right)_{t \in \mathbb{Z}}$ um processo ruído branco padrão. O processo $\left(X_{t}\right)_{t \in \mathbb{Z}}$ segue um GARCH(p,q) se é estritamente estacionário e satisfaz, para todo $t \in \mathbb{Z}$ e valores estritamente positivos

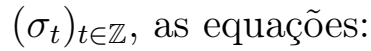

$$
X_{t}=\sigma_{t} Z_{t}, \quad \sigma_{t}^{2}=\alpha_{0}+\sum_{i=1}^{p} \alpha_{i} X_{t-i}^{2}+\sum_{j=1}^{q} \beta_{j} \sigma_{t-j}^{2},
$$

em que $\alpha_{0}>0, \alpha_{i} \geq 0, i=1, \ldots, p, \beta_{j} \geq 0, j=1, \ldots, q$.

$\mathrm{Na}$ prática, modelos GARCH de ordem baixa são amplamente utilizados. É possível demonstrar que um modelo $\operatorname{GARCH}(1,1)$ é equivalente a um $A R C H(\infty)$, o que indica que períodos de grande volatilidade tendem a ser persistentes, no sentido de que, sendo $\left|X_{t}\right|$ grande, basta que ou $\left|X_{t-1}\right|$ ou $\sigma_{t-1}$ seja grande. Desta maneira, modelos GARCH tendem a ser mais parcimoniosos na quantidade de parâmetros do que modelos ARCH.

Existem diversas variações desta classe de modelos. Os mais conhecidos são os EGARCH (Exponential GARCH) e TARCH (Threshold ARCH), que mensuram, respectivamente, a assimetria do impacto dos retornos, de forma que retornos negativos tendem a produzir volatilidades maiores, e avaliam impactos de variáveis dummies (como influência de boas/más notícias). Esses modelos são abordados em detalhes em Morettin [2008], mas não serão estudados aqui.

No entanto, uma extensão simples do modelo GARCH pode ser útil para quando existir estrutura autorregressiva na média e não só na variância e sua estimação é feita de modo conjunto. Este modelo é chamado de $A R M A-G A R C H$.

Seja $\left(Z_{t}\right)_{t \in \mathbb{Z}}$ um processo ruído branco padrão. O processo $\left(X_{t}\right)_{t \in \mathbb{Z}}$ é dito um processo $\operatorname{ARMA}\left(p_{1}, q_{1}\right)$ com erros $\operatorname{GARCH}\left(p_{2}, q_{2}\right)$ se é estacionário em covariância e satisfaz conjuntamente as equações:

$$
\begin{gathered}
X_{t}=\mu_{t}+\sigma_{t} Z_{t} \\
\mu_{t}=\mu+\sum_{i=1}^{p_{1}} \phi_{i}\left(X_{t-i}-\mu\right)+\sum_{j=1}^{q_{1}} \theta_{j}\left(X_{t-j}-\mu_{t-j}\right), \\
\sigma_{t}^{2}=\alpha_{0}+\sum_{i=1}^{p_{2}} \alpha_{i}\left(X_{t-i}-\mu_{t-i}\right)^{2}+\sum_{j=1}^{q_{2}} \beta_{j} \sigma_{t-j}^{2},
\end{gathered}
$$

em que $\alpha_{0}>0, \alpha_{i} \geq 0, i=1, \ldots, p_{2}, \beta_{j} \geq 0, j=1, \ldots, q_{2}$ e $\sum_{i=1}^{p_{2}} \alpha_{i}+\sum_{j=1}^{q_{2}} \beta_{j}<1$.

Além disso, para ser consistente com processos ARMA padrão (ver Morettin [2008] para detalhes acerca do processo ARMA univariado), foram impostas as condições de estacionariedade e invertibilidade: os polinômios $\underset{\sim}{\phi}(z)=1-\phi_{1} z-\ldots-\phi_{p 1} z^{p 1}$ e $\underset{\sim}{\theta}(z)=1+\theta_{1} z+\ldots+\theta_{q 1} z^{q 1}$ não devem ter raízes comuns nem raízes dentro do círculo unitário.

Para a avaliação da interdependência, o processo ARMA-GARCH será importante para a posterior filtragem de cada uma das séries, uma vez que o interesse reside na interdependência das variáveis, desconsiderando os efeitos dos passados univariados, que poderiam ocultar relações multivariadas relevantes. 


\subsubsection{Processo GARCH Multivariado}

O modelo multivariado para uma série temporal vetorial analisa simultaneamente múltiplos componentes. Além da análise em cada componente individual $X_{i t}$ por meio da autocorrelação contida em cada série, as relações dinâmicas entre as séries componentes também são analisadas. Um modelo multivariado para os elementos de risco é um processo estocástico $\left(X_{t}\right)_{t \in \mathbb{Z}}$, ou seja, uma família de vetores aleatórios, indexados por inteiros e definidos em algum espaço de probabilidade $(\Omega, F, \mathbb{P})$.

Assumindo a existência dos momentos, define-se a função média $\underset{\sim}{\mu}(t)$ e a função matriz de covariâncias $\Gamma(t, s)$ de $(\underset{\sim}{X})_{t \in \mathbb{Z}}$ por:

$$
\underset{\sim}{\mu}(t)=E\left({\underset{\sim}{X}}_{t}\right), \quad t \in \mathbb{Z}, \quad \Gamma(t, s)=E[\underset{\sim}{X} t-\mu(t)][\underset{\sim}{X}-\underset{\sim}{\mu}(s)]^{\prime}, \quad t, s \in \mathbb{Z} .
$$

Como caso particular, $\Gamma(t, t)=\operatorname{Cov}\left(\underset{\sim}{X_{t}}\right)$. Observando as correlações entre duas séries quaisquer $i$ e $j$, desde que $i \neq j$, os elementos $\gamma_{i, j}(t, s)$ de $\Gamma(t, s)$ satisfazendo:

$$
\gamma_{i, j}(t, s)=\operatorname{Cov}\left(X_{t, i}, X_{s, j}\right)=\operatorname{Cov}\left(X_{s, j}, X_{t, i}\right)=\gamma_{j, i}(s, t)
$$

fica nítido que $\Gamma(t, s)=\Gamma(t, s)^{\prime}$ para todo t, s. No entanto, a matriz $\Gamma$ não precisa ser simétrica, então $\Gamma(t, s) \neq \Gamma(s, t)$. Este fato evidencia que valores defasados de uma variável podem estar mais fortemente associados a valores futuros de alguma outra série, e vice-versa.

O coeficiente de correlação contemporâneo entre $X_{i t}$ e $X_{j t}$ é dado por

$$
\rho_{i j}(0)=\frac{\gamma_{i j}(0)}{\sqrt{\gamma_{i i}(0) \gamma_{j j}(0)}} .
$$

A matriz de correlações contemporâneas é simétrica com todos os elementos da diagonal principal iguais a um e fora dela, as correlações entre as diversas séries, dado o mesmo instante de tempo. Os elementos da matriz de correlações de defasagem (lag) $\tau$ são definidos por:

$$
\rho_{i j}(\tau)=\frac{\gamma_{i j}(\tau)}{\sqrt{\gamma_{i i}(0) \gamma_{j j}(0)}},
$$

que expressa a quantidade de correlação entre $X_{i, t+\tau}$ e $X_{j, t}$. Portanto, quando $\tau>0$, tem-se a relação linear de uma série sobre a defasagem da outra. Isso é particularmente útil ao construir o modelo GARCH multivariado mais adiante e fazer o seu diagnóstico.

O fato que $\rho_{i j}(\tau) \neq \rho_{j i}(\tau)$, para todo $\mathrm{i}, \mathrm{j}$ dá-se, intuitivamente, pelo fato de que estes dois coeficientes de correlação medem relações lineares diferentes entre $X_{i t}$ e $X_{j t}$.

Uma vez evidenciada a estrutura multivariada e as dependências lineares, define-se a estrutura geral de um modelo GARCH multivariado. Seja $\left(Z_{t}\right)_{t \in \mathbb{Z}}$ um processo ruído branco padrão (de vetor de médias igual a zero e matriz de variâncias-covariâncias identidade). O processo $\left(\underset{\sim}{X_{t}}\right)_{t \in \mathbb{Z}}$ segue um GARCH multivariado se é estritamente estacionário e satisfaz as equações: 


$$
\underset{\sim}{X}=\Sigma_{t}^{1 / 2} \underline{\sim}_{t}, \quad t \in \mathbb{Z},
$$

em que $\Sigma_{t}^{1 / 2} \in \mathbb{R}^{d \times d}$ é a decomposição de Choleski de uma matriz positiva definida $\Sigma_{t}$ que é mensurável com respeito à história do processo até o instante de tempo $t-1$, e $d$ é a quantidade de séries envolvidas no problema.

$\mathrm{Na}$ prática, as inovações são supostas normais multivariadas $\left(\underset{\sim}{Z} \sim N_{d}\left(0, I_{d}\right)\right)$ ou, mais realisticamente, utilizando uma distribuição esférica mais apropriada, com média 0 e matriz de covariâncias $I_{d}$, como a t-Student $\left({\underset{\sim}{Z} t}_{t} \sim t_{d}\left(v, 0,(v-2) I_{d} / v\right)\right)$.

Da forma que está definida, a matriz de variâncias-covariâncias condicional $\Sigma_{t}$ corresponde à volatilidade $\sigma_{t}^{2} \mathrm{em}$ um processo GARCH univariado. Pode-se decompor $\Sigma_{t}=$ $\Delta_{t} P_{t} \Delta_{t}$, de tal forma que:

$$
\Delta_{t}=\Delta\left(\Sigma_{t}\right)=\operatorname{diag}\left(\sigma_{t, 1}, \ldots, \sigma_{t, d}\right), \quad P_{t}=\left(\Delta\left(\Sigma_{t}\right)\right)^{-1} \Sigma_{t}\left(\Delta\left(\Sigma_{t}\right)\right)^{-1},
$$

em que $\Delta_{t}$ será chamada de matriz de volatilidade, $P_{t}$, a matriz de correlação condicional e $d$ é a quantidade de séries. Vale ressaltar que a grande dificuldade de se construir modelos GARCH multivariados reside na especificação da dependência de $\Sigma_{t}$ (ou de $\Delta_{t}$ e $P_{t}$ ).

\section{Modelos para a Correlação Condicional}

Serão apresentadas, nesta Subseção ${ }^{4}$, algumas das especificações para a estrutura da matriz de correlação condicional a serem utilizadas no trabalho, enquanto as volatilidades seguem modelos GARCH univariados. No entanto, tais especificações não serão aprofundadas em nível de detalhe de cada estrutura, que podem ser vistos em McNeil et al. [2005] ou Zivot e Wang [2005].

Correlação Condicional Constante (CCC)

O processo $\left(\underset{\sim}{X_{t}}\right)_{t \in \mathbb{Z}}$ segue um CCC-GARCH se o processo definido na Equação 3.8 puder ter a matriz de variâncias-covariâncias na forma $\Delta_{t} P_{c} \Delta_{t}$, de tal forma que:

1. $P_{c}$ é uma matriz de correlação positiva-definida, constante, e;

2. $\Delta_{t}$ é uma matriz de volatilidade diagonal com elementos $\sigma_{t, k}^{2}$ satisfazendo:

$$
\sigma_{t, k}^{2}=\alpha_{k 0}+\sum_{i=1}^{p_{k}} \alpha_{k i} X_{t-i, k}^{2}+\sum_{j=1}^{q_{k}} \beta_{k j} \sigma_{t-j, k}^{2}, \quad k=1, \ldots, d
$$

em que $\alpha_{k 0}>0, \alpha_{k i} \geq 0, i=1, \ldots, p_{k}, \beta_{k j} \geq 0, j=1, \ldots, q_{k}$.

VEC Diagonal (DVEC)

O processo $\left(\underset{\sim}{X_{t}}\right)_{t \in \mathbb{Z}}$ segue um DVEC se puder ter estrutura geral definida pela Equação 3.8, com as volatilidades variando no tempo na forma $\Sigma_{t}$ satisfazendo as equações:

\footnotetext{
${ }^{4}$ A disposição da apresentação dá-se pela complexidade estrutural e não pela ordem cronológica.
} 


$$
\Sigma_{t}=A_{0}+\sum_{i=1}^{p} A_{i} \circ\left(X_{t-i} X_{t-i}^{\prime}\right)+\sum_{j=1}^{q} B_{j} \Sigma_{t-j}
$$

em que o denota o produto de Hadamard (que significa multiplicação elemento a elemento de duas matrizes de igual tamanho) $A_{0}, A_{i}, B_{j}$ são todas matrizes simétricas em $\mathbb{R}^{d \times d}$, tal que $A_{0}$ tem elementos positivos na diagonal e as outras matrizes possuem elementos nãonegativos na diagonal. A partir desta representação, é possível mostrar que, em um modelo $\operatorname{DVEC}(1,1)$, cada elemento de $\Sigma_{t}$ segue um $\operatorname{GARCH}(1,1)$.

O modelo de Baba, Engle, Kroner e Kraft (BEKK)

O processo $\left(X_{t}\right)_{t \in \mathbb{Z}}$ segue um BEKK-GARCH se puder ter estrutura geral definida pela Equação 3.8, e se a matriz de variâncias-covariâncias $\Sigma_{t}$ satisfizer, para todo $t \in \mathbb{Z}$ :

$$
\Sigma_{t}=A_{0}+\sum_{i=1}^{p} A_{i}^{\prime} X_{t-i} X_{t-i}^{\prime} A_{i}+\sum_{j=1}^{q} B_{j}^{\prime} \Sigma_{t-j} B_{j},
$$

em que todos os coeficientes das matrizes A e B estão em $\mathbb{R}^{d \times d}$ e $A_{0}$ é uma matriz simétrica e positiva-definida e $d$ é a quantidade de séries.

\subsection{Resultados Parciais}

Como já citado na subseção 3.4.2, será ajustado um modelo $\operatorname{ARMA}(1,1)$-GARCH$(1,1)$ para cada uma das séries a fim de garantir que as relações multivariadas não sejam mascaradas pela autodependência temporal de cada uma das séries. A ordem dos modelos tanto para a média e variância condicional foi fixa por simplicidade, uma vez que o objetivo não é a parcimônia na escolha da quantidade de parâmetros, mas sim que os resíduos sejam estacionários nos dois momentos. Desta maneira, a Tabela 3.3, a seguir, apresenta a estimativa dos parâmetros do modelo univariado ajustado ${ }^{5}$ em cada série.

\footnotetext{
${ }^{5}$ Todos os resultados, uni e multivariados, desta seção foram obtidos no módulo FinMetrics versão 2.0.4 do software $S$-PLUS versão 8.0.
} 
Tabela 3.3: Estimativas para os modelos ARMA(1,1)-GARCH(1,1) com erros $t$-Student para cada série.

\begin{tabular}{|c|c|c|c|c|c|c|}
\hline Parâmetro & Brasil & Argentina & México & EUA & Malásia & Rússia \\
\hline \multirow[t]{2}{*}{$\phi_{1}$} & $-0,3649$ & 0,2307 & $-0,1565$ & 0,5010 & 0,3892 & 0,3038 \\
\hline & $(0,3131)$ & $(0,4446)$ & $(0,2013)$ & $(0,3786)$ & $(0,1533)$ & $(0,2009)$ \\
\hline \multirow[t]{2}{*}{$\theta_{1}$} & 0,4159 & $-0,1914$ & 0,2467 & $-0,5340$ & $-0,2924$ & $-0,2184$ \\
\hline & $(0,3054)$ & $(0,4495)$ & $(0,1982)$ & $(0,3694)$ & $(0,1602)$ & $(0,2071)$ \\
\hline \multirow[t]{2}{*}{$\alpha_{1}$} & 0,0943 & 0,1287 & 0,0887 & 0,0797 & 0,1215 & 0,1219 \\
\hline & $(0,0135)$ & $(0,0193)$ & $(0,0134)$ & $(0,0112)$ & $(0,0177)$ & $(0,0156)$ \\
\hline \multirow[t]{2}{*}{$\beta_{1}$} & 0,8725 & 0,8508 & 0,8956 & 0,9144 & 0,8923 & 0,8743 \\
\hline & $(0,0169)$ & $(0,0188)$ & $(0,0141)$ & $(0,0112)$ & $(0,0112)$ & $(0,0134)$ \\
\hline \multirow[t]{2}{*}{$v$} & 6,7534 & 4,1102 & 5,0448 & 6,9439 & 3,5508 & 4,7563 \\
\hline & $(0,7324)$ & $(0,3965)$ & $(0,4998)$ & $(0,8392)$ & $(0,2657)$ & $(0,4475)$ \\
\hline \multicolumn{7}{|c|}{ p-valores do teste Ljung-Box para estacionariedade dos resíduos padronizados } \\
\hline & 0,2934 & 0,6932 & 0,3465 & 0,8442 & 0,3385 & 0,1315 \\
\hline \multicolumn{7}{|c|}{ p-valores do teste Ljung-Box para estacionariedade dos resíduos padronizados ao quadrado } \\
\hline & 0,1264 & 0,4497 & 0,3146 & 0,8103 & 0,9996 & 0,6906 \\
\hline \multicolumn{2}{|c|}{ p-valores do tes } & e Multiplic & dores de & Lagrange & para efeit & ARCH nos resíduos \\
\hline & 0,1842 & 0,4535 & 0,3814 & 0,8611 & 0,9999 & 0,7336 \\
\hline
\end{tabular}

Adotando um nível de significância de 5\%, pode-se observar, a partir da Tabela 3.3, que tanto os resíduos padronizados quanto os seus quadrados são estacionários, o que evidencia uma boa escolha dos modelos adotados. Percebe-se, também, que não há a necessidade de se aumentar a ordem do modelo GARCH, uma vez que o menor p-valor obtido dentre as séries para o teste LM (Multiplicadores de Lagrange) foi de 0,1842 para o Brasil, série mais volátil dentre as analisadas. A série mais estável é a dos EUA, como é possível avaliar pelo maior valor de graus de liberdade estimado $(6,94)$ da distribuição t-Student. Adicionalmente, nota-se que todos os efeitos GARCH mostraram-se significantes, implicando que há forte persistência do aumento de volatilidade.

Os resíduos de cada um dos modelos univariados, cujas estimativas estão apresentadas na Tabela 3.3, serão objetos de aplicações das técnicas multivariadas apresentadas neste e nos capítulos subsequentes. Para tanto, faz-se necessária a análise dos resíduos destes modelos marginais, além da verificação de eventuais movimentos conjuntos das séries a fim de obter evidências a respeito da dependência entre elas. As análises preliminares uni e bivariadas seguem nas Figuras 3.4, 3.5 e 3.6. 

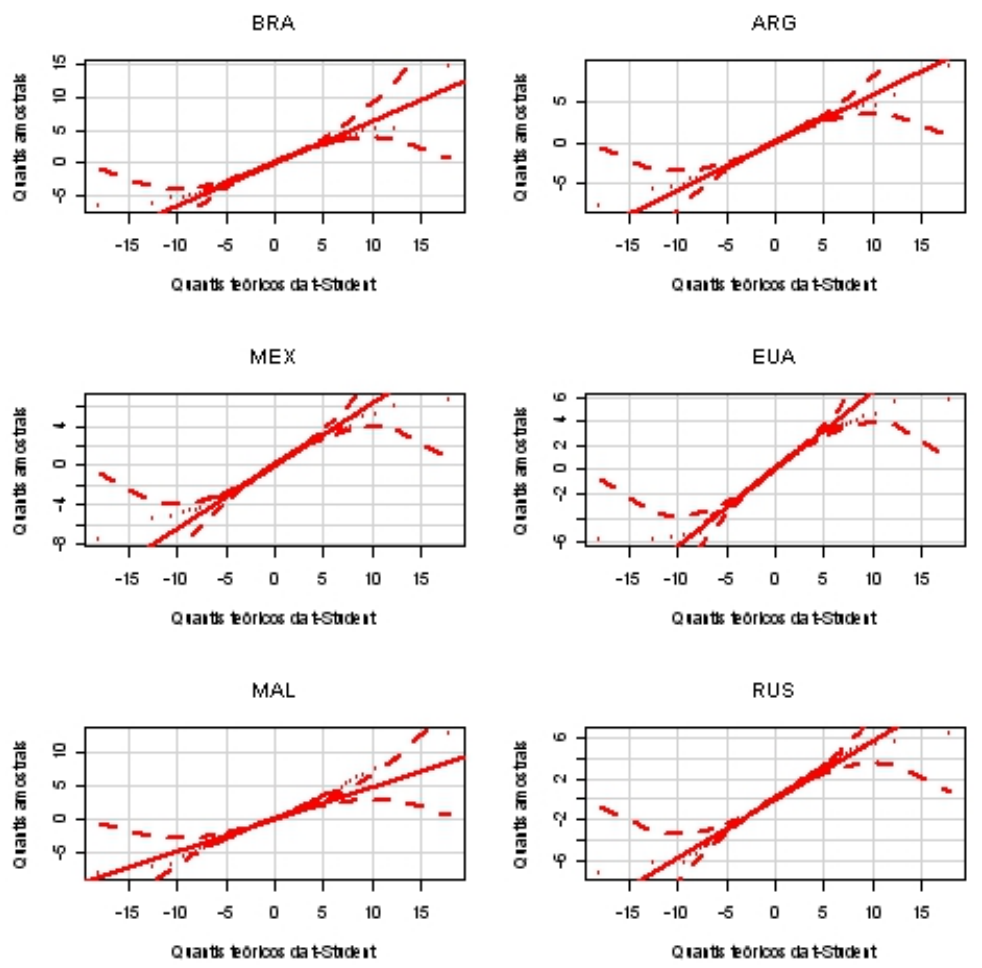

Figura 3.4: Gráficos do tipo quantil-quantil dos resíduos dos modelos marginais ARMA(1,1)$\operatorname{GARCH}(1,1)$ ajustados.

Aparentemente, por meio dos gráficos de comparações de quantis, a distribuição t-student é bastante adequada e aderente a cada uma das séries de resíduos padronizados. Analisando conjuntamente as evidências provenientes da Figura 3.4 e dos testes apresentados na Tabela 3.3, tem-se que o objetivo de realizar a filtragem prévia nos dados foi bem sucedida, uma vez que agora se dispõe dos resíduos independentes e identicamente distribuídos, que serão as novas séries a serem estudadas. Este fato será bastante importante para poder ter garantias de que os modelos construídos neste trabalho não serão invalidados pela violação de premissas.

Em seguida, começa-se a observar os resíduos dos modelos $\operatorname{ARMA}(1,1)-\operatorname{GARCH}(1,1)$ marginais de modo bivariado. As Figuras 3.5 e 3.6 trazem os diagramas de dispersão, que serão relevantes para a construção das cópulas no próximo capítulo. 

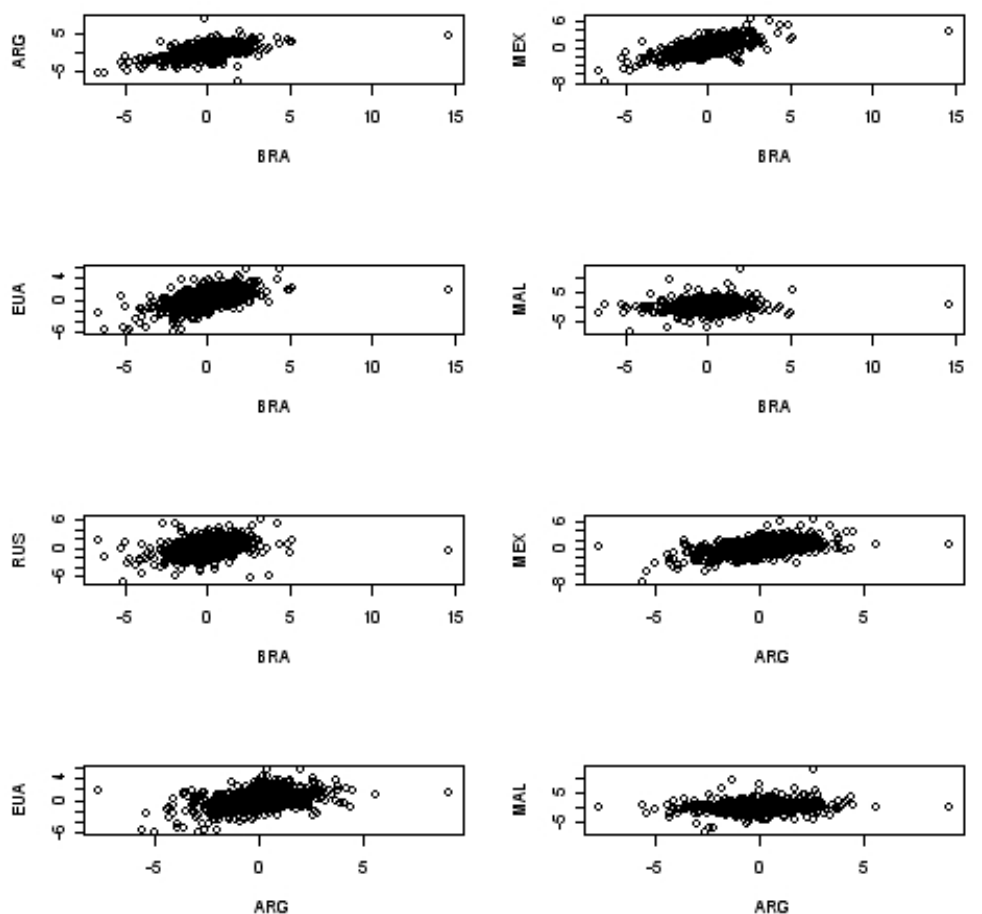

Figura 3.5: Gráficos de dispersão bivariada entre os resíduos dos modelos marginais ARMA(1,1)$\operatorname{GARCH}(1,1)$ ajustados.
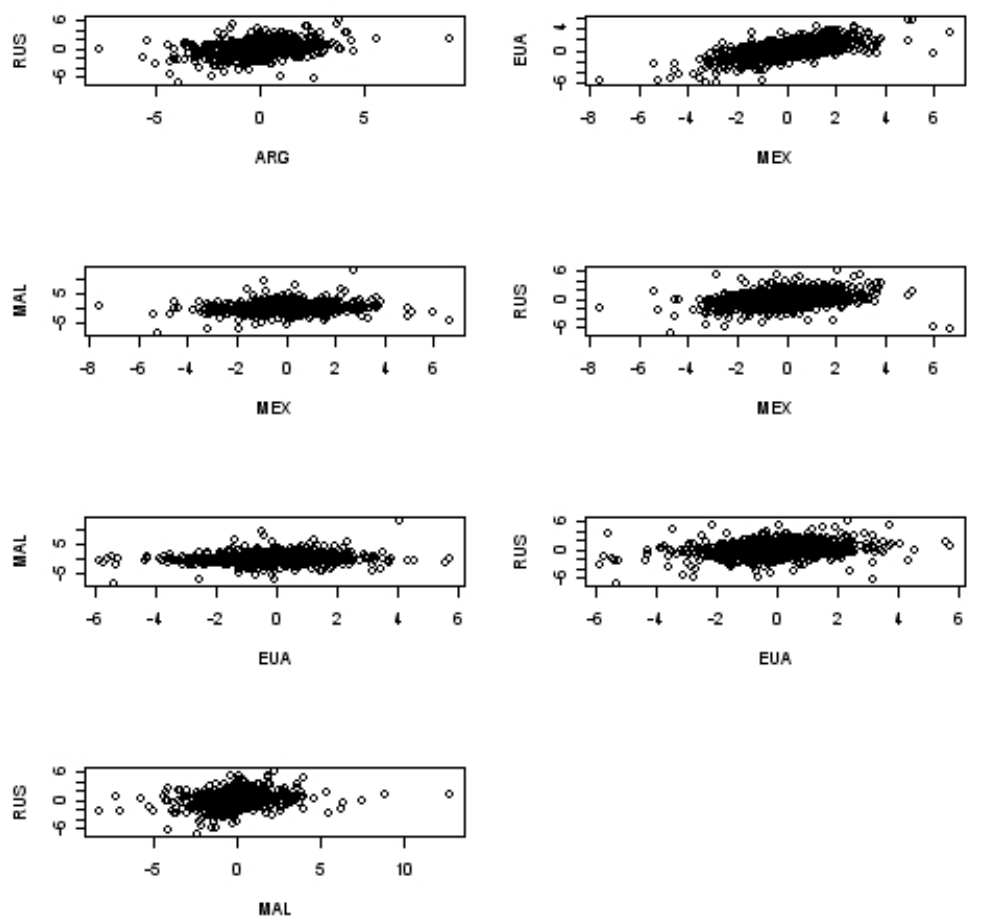

Figura 3.6: Gráficos de dispersão bivariada entre os resíduos dos modelos marginais ARMA(1,1)GARCH(1,1) ajustados (cont.). 
A partir das Figuras 3.5 e 3.6 nota-se que parece haver alguma dependência entre todas as séries de estudo, sendo mais fortes entre os mercados latino-americanos (Brasil, Argentina e México) e EUA, todos entre si. Já a Malásia aparentemente não possui dependência com nenhum outro mercado, apenas fica a dúvida se há alguma tendência na sua nuvem de pontos com a Rússia. Finalmente, a Rússia apresenta uma leve tendência na relação com os mercados latino-americanos, sendo esta mais suave quando se avalia com os EUA.

As Figuras 3.7 e 3.8, a seguir, fornecem as correlações variando no tempo para cada par de séries.
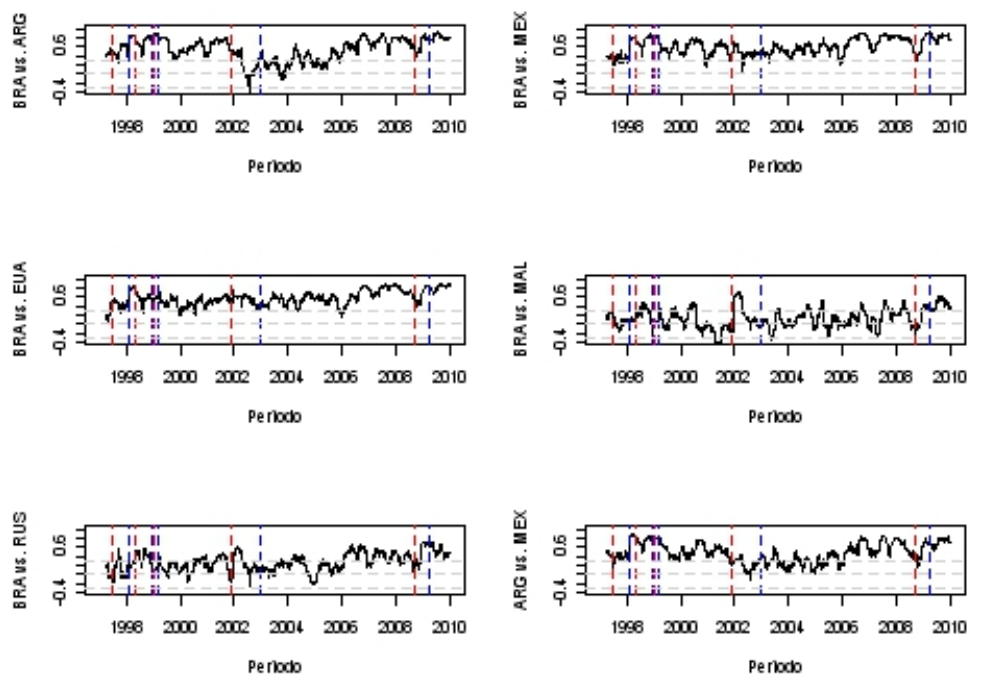

Penodo

Penodo
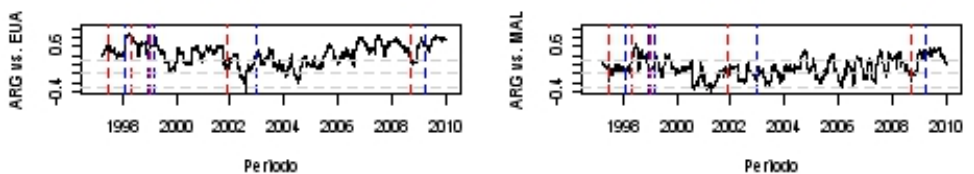

Figura 3.7: Evolução das correlações bivariadas entre os resíduos dos modelos marginais ARMA(1,1)-GARCH(1,1) ajustados. 

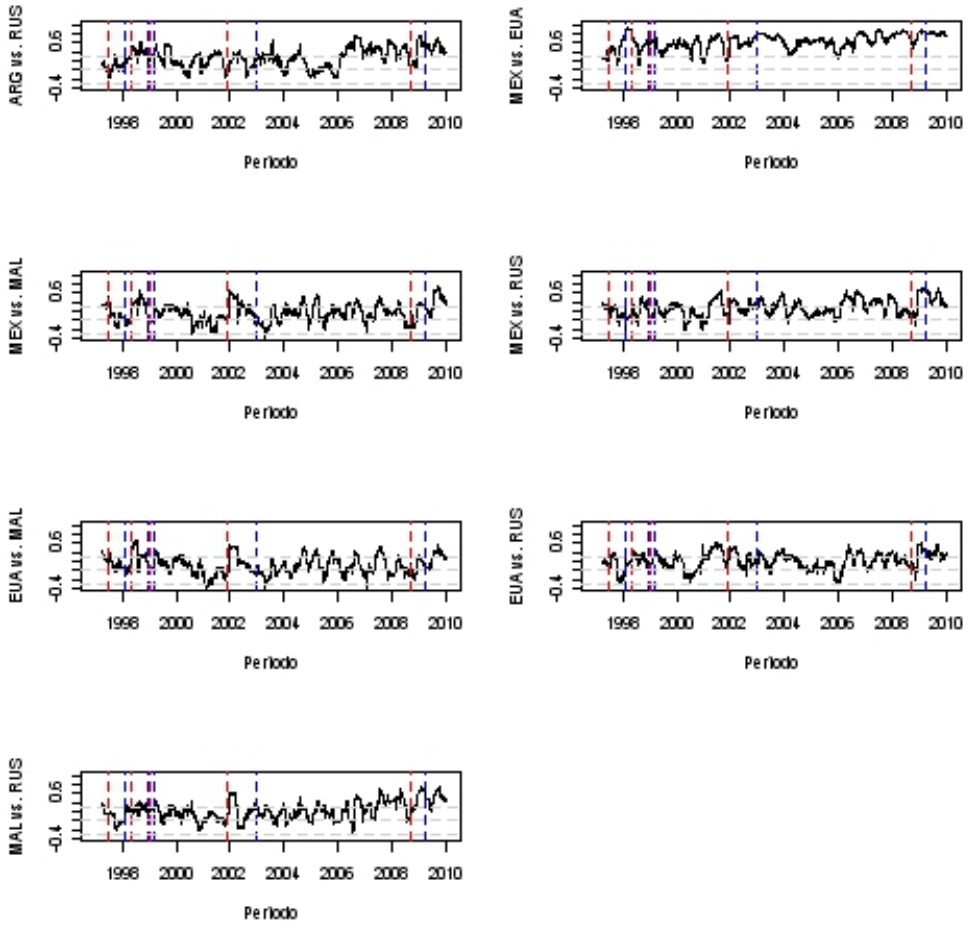

Figura 3.8: Evolução das correlações bivariadas entre os resíduos dos modelos marginais ARMA(1,1)-GARCH(1,1) ajustados (cont.).

A partir das Figuras 3.7 e 3.8 pode-se perceber que, em linhas gerais, há aumento da correlação serial em períodos de crise, de modo que este efeito é mais nítido na crise do subprime dos EUA, quando todas as correlações aumentam. Além disso, verifica-se que as correlações bivariadas entre Brasil, Argentina, México e EUA encontram-se sistematicamente acima de 0,3. Entre Brasil e Argentina houve um claro descolamento das duas curvas após a crise da Argentina, tendo aumentado com o passar do tempo e atingindo, em meados de 2007, os patamares mais altos desde o início das observações. As mais altas correlações verificadas por todo o período são entre México e EUA.

Sobre os demais países, a Malásia mostra-se descolada de todos, apresentando, durante a crise asiática, aumento de correlação com a Argentina e um movimento contrário em relação à Rússia, chegando, inclusive, a possuir correlação negativa em diversos períodos com os dois países, de modo que o mesmo pode ser observado em sua correlação com o Brasil e com os EUA. Finalmente, a Rússia apresenta correlação crescente em períodos de crise com a maioria dos países, mas apresenta, mesmo em períodos tranquilos, correlação moderada com os países latino-americanos (Brasil, Argentina e México).

Uma vez analisada a filtragem marginal de cada uma das séries, prossegue-se a análise com os resultados dos modelos de séries temporais multivariadas, utilizando diferentes estruturas de correlação condicional, que foram apresentadas na seção 2.3. 
Tabela 3.4: Comparação entre diferentes estruturas de correlação condicional no modelos GARCH multivariado com erros t-Student.

\begin{tabular}{ccccc}
\hline Estrutura & $\ln L(\theta) / N$ & Parâmetros & AIC & BIC \\
\hline CCC $(1,1)$ & 16,8193 & 24 & $-87685,38$ & $-87538,72$ \\
CCC $(2,2)$ & 16,8204 & 36 & $-87661,41$ & $-87444,35$ \\
CCC $(3,3)$ & 16,6259 & 48 & $-86622,67$ & $-86335,22$ \\
CCC $(4,4)$ & 16,6017 & 60 & $-86472,29$ & $-86114,44$ \\
DVEC $(1,1)$ & 16,8997 & 69 & $\mathbf{- 8 8 0 0 9 , 2 5}$ & $\mathbf{- 8 7 5 9 8 , 6 0}$ \\
DVEC $(2,2)$ & 16,6499 & 111 & $-86622,12$ & $-85965,09$ \\
DVEC $(3,3)$ & 16,6501 & 153 & $-86538,94$ & $-85635,52$ \\
DVEC $(4,4)$ & 16,6503 & 195 & $-86456,05$ & $-85306,25$ \\
BEKK $(1,1)$ & 16,8472 & 99 & $-87675,48$ & $-87088,85$ \\
BEKK $(2,2)$ & 16,6499 & 171 & $-86501,74$ & $-85492,73$ \\
BEKK $(4,1)$ & $\mathbf{1 6 , 9 4 3 2}$ & 207 & $-87960,01$ & $-86739,81$ \\
\hline
\end{tabular}

A informação relevante que se pode extrair da Tabela 3.4 é o fato de que há convergência entre as escolhas dos critérios de informação de Akaike e Bayesiano, que são parcimoniosos quanto à seleção de modelos em relação ao número de parâmetros estimados. Ambos apontam para a estrutura de correlação condicional $\operatorname{DVEC}(1,1)$. Vale notar que, não fosse o apontamento para o mesmo modelo, a log-verossimilhança sugeriria o modelo $\operatorname{BEKK}(4,1)$, que conteria nada menos que 207 parâmetros para serem analisados.

O intuito de avaliar o modelo escolhido é simplesmente identificar uma estrutura multivariada para o problema e não avaliar padrões de contágio. Para verificar se a estrutura multivariada é ou não significante, é preciso analisar as estimativas dos parâmetros do modelo GARCH multivariado com a estrutura de correlação $\operatorname{DVEC}(1,1)$ e isso será feito na Tabela 3.5, a seguir. 
Tabela 3.5: Estimativas do modelo GARCH multivariado com estrutura de correlação condicional $\operatorname{DVEC}(1,1)$.

\begin{tabular}{|c|c|c|c|c|c|}
\hline$\theta$ & $\hat{\theta}$ & $\hat{\theta} / \hat{\sigma}$ & $\theta$ & $\hat{\theta}$ & $\hat{\theta} / \hat{\sigma}$ \\
\hline $\mathrm{C}(1)$ & 0,002020 & 6,004 & $\operatorname{ARCH}(1 ; 4,2)$ & 0,042 & 9,037 \\
\hline $\mathrm{C}(2)$ & 0,001349 & 4,134 & $\operatorname{ARCH}(1 ; 5,2)$ & 0,028 & 3,084 \\
\hline $\mathrm{C}(3)$ & 0,001748 & 6,844 & $\operatorname{ARCH}(1 ; 6,2)$ & 0,025 & 4,191 \\
\hline $\mathrm{C}(4)$ & 0,000631 & 3,537 & $\operatorname{ARCH}(1 ; 3,3)$ & 0,041 & 10,095 \\
\hline $\mathrm{C}(5)$ & 0,000615 & 3,646 & $\operatorname{ARCH}(1 ; 4,3)$ & 0,046 & 10,212 \\
\hline $\mathrm{C}(6)$ & 0,002494 & 6,329 & $\operatorname{ARCH}(1 ; 5,3)$ & 0,006 & 1,641 \\
\hline $\mathrm{A}(1,1)$ & 0,000012 & 6,498 & $\operatorname{ARCH}(1 ; 6,3)$ & 0,018 & 3,949 \\
\hline $\mathrm{A}(2,1)$ & 0,000007 & 6,279 & $\operatorname{ARCH}(1 ; 4,4)$ & 0,066 & 9,309 \\
\hline $\mathrm{A}(3,1)$ & 0,000005 & 6,248 & $\operatorname{ARCH}(1 ; 5,4)$ & 0,025 & 1,679 \\
\hline $\mathrm{A}(4,1)$ & 0,000003 & 5,098 & $\operatorname{ARCH}(1 ; 6,4)$ & 0,014 & 2,434 \\
\hline $\mathrm{A}(5,1)$ & 0,000001 & 1,953 & $\operatorname{ARCH}(1 ; 5,5)$ & 0,080 & 10,634 \\
\hline $\mathrm{A}(6,1)$ & 0,000004 & 3,091 & $\operatorname{ARCH}(1 ; 6,5)$ & 0,021 & 3,090 \\
\hline $\mathrm{A}(2,2)$ & 0,000011 & 6,653 & $\operatorname{ARCH}(1 ; 6,6)$ & 0,090 & 9,910 \\
\hline $\mathrm{A}(3,2)$ & 0,000003 & 5,324 & $\operatorname{GARCH}(1 ; 1,1)$ & 0,916 & 132,203 \\
\hline $\mathrm{A}(4,2)$ & 0,000002 & 4,858 & $\operatorname{GARCH}(1 ; 2,1)$ & 0,923 & 145,628 \\
\hline $\mathrm{A}(5,2)$ & 0,000002 & 2,035 & $\operatorname{GARCH}(1 ; 3,1)$ & 0,932 & 157,790 \\
\hline $\mathrm{A}(6,2)$ & 0,000004 & 3,388 & $\operatorname{GARCH}(1 ; 4,1)$ & 0,936 & 151,120 \\
\hline $\mathrm{A}(3,3)$ & 0,000004 & 5,781 & $\operatorname{GARCH}(1 ; 5,1)$ & 0,927 & 32,770 \\
\hline $\mathrm{A}(4,3)$ & 0,000002 & 4,933 & $\operatorname{GARCH}(1 ; 6,1)$ & 0,941 & 64,080 \\
\hline $\mathrm{A}(5,3)$ & 0,0000005 & 1,684 & $\operatorname{GARCH}(1 ; 2,2)$ & 0,911 & 127,020 \\
\hline $\mathrm{A}(6,3)$ & 0,000002 & 2,967 & $\operatorname{GARCH}(1 ; 3,2)$ & 0,943 & 173,430 \\
\hline $\mathrm{A}(4,4)$ & 0,000002 & 4,862 & $\operatorname{GARCH}(1 ; 4,2)$ & 0,940 & 172,010 \\
\hline $\mathrm{A}(5,4)$ & 0,000003 & 1,129 & $\operatorname{GARCH}(1 ; 5,2)$ & 0,880 & 19,880 \\
\hline $\mathrm{A}(6,4)$ & 0,000001 & 2,274 & $\operatorname{GARCH}(1 ; 6,2)$ & 0,937 & 72,920 \\
\hline $\mathrm{A}(5,5)$ & 0,000002 & 5,332 & $\operatorname{GARCH}(1 ; 3,3)$ & 0,942 & 172,860 \\
\hline $\mathrm{A}(6,5)$ & 0,000001 & 2,646 & $\operatorname{GARCH}(1 ; 4,3)$ & 0,937 & 162,660 \\
\hline $\mathrm{A}(6,6)$ & 0,000014 & 5,524 & $\operatorname{GARCH}(1 ; 5,3)$ & 0,971 & 65,770 \\
\hline $\operatorname{ARCH}(1 ; 1,1)$ & 0,062660 & 10,700 & $\operatorname{GARCH}(1 ; 6,3)$ & 0,951 & 83,810 \\
\hline $\operatorname{ARCH}(1 ; 2,1)$ & 0,050910 & 10,265 & $\operatorname{GARCH}(1 ; 4,4)$ & 0,927 & 131,600 \\
\hline $\operatorname{ARCH}(1 ; 3,1)$ & 0,042840 & 10,150 & $\operatorname{GARCH}(1 ; 5,4)$ & 0,637 & 2,170 \\
\hline $\operatorname{ARCH}(1 ; 4,1)$ & 0,046900 & 9,220 & $\operatorname{GARCH}(1 ; 6,4)$ & 0,960 & 71,090 \\
\hline $\operatorname{ARCH}(1 ; 5,1)$ & 0,016900 & 2,343 & $\operatorname{GARCH}(1 ; 5,5)$ & 0,908 & 128,820 \\
\hline $\operatorname{ARCH}(1 ; 6,1)$ & 0,019590 & 3,402 & $\operatorname{GARCH}(1 ; 6,5)$ & 0,950 & 69,740 \\
\hline $\operatorname{ARCH}(1 ; 2,2)$ & 0,064990 & 11,070 & $\operatorname{GARCH}(1 ; 6,6)$ & 0,895 & 97,460 \\
\hline $\operatorname{ARCH}(1 ; 3,2)$ & 0,035700 & 8,944 & & & \\
\hline
\end{tabular}

A Tabela 3.5 apresenta as estimativas dos parâmetros para o modelo DVEC $(1,1)$ e a razão entre o valor estimado do parâmetro e seu desvio-padrão, conhecido como estatística t. Nesta tabela, $C(i)$ corresponde à média do i-ésimo log-retorno, enquanto $\mathrm{A}(\mathrm{i}, \mathrm{j})$ corresponde ao $(\mathrm{i}, \mathrm{j})$ ésimo elemento da matriz $A_{0}, \operatorname{ARCH}(\mathrm{i} ; \mathrm{j}, \mathrm{k})$ corresponde ao $(\mathrm{j}, \mathrm{k})$-ésimo elemento da matriz $A_{i}$ e GARCH$(\mathrm{j} ; \mathrm{i}, \mathrm{k})$ corresponde ao (i,k)-ésimo elemento da matriz $B_{j}$ da Equação 3.11, de modo que as séries, em ordem numérica, são: 1 é a série do Brasil, 2 da Argentina, 3 do México, 4 dos EUA, 5 da Malásia e, finalmente, 6 da Rússia. Vale ressaltar, ainda, que valores de $\hat{\theta} / \hat{\sigma}$ inferiores a 2 (destacados em vermelho na Tabela 3.5) implicam não-significância ao 
nível de $5 \%$.

Nota-se que quase todos os parâmetros são significantes: das 69 estimativas, apenas 5 delas mostram-se pouco importantes. Na matriz $A_{0}$, as relações entre Malásia e Brasil, Malásia e México, além de EUA e Malásia, além dos efeitos ARCH entre Malásia e México e entre EUA e Malásia não se mostraram significantes, fato que sugere a pouca interligação entre esses mercados.

\subsection{Considerações Parciais}

Neste capítulo foram apresentadas as abordagens tradicionais da literatura para modelagem conjunta de séries temporais financeiras. A fim de retirar autodependência de cada uma das séries de modo a não interferir nas estimativas das relações cruzadas, foram realizadas filtragens univariadas nas séries em estudo, cujos resíduos serão os objetos das modelagens dos próximos capítulos. Em seguida, após a determinação da melhor estrutura de correlação condicional para o GARCH multivariado, verificou-se que há evidências de forte interdependência entre os mercados, uma vez que apenas 5 dos 69 parâmetros estimados do modelo selecionado mostraram-se não-significantes.

No próximo capítulo será avaliada a estrutura de dependência de cada mercado, de modo a validar, de modo bivariado, a interdependência mais geral, não-linear, entre os países em estudo. 


\section{Capítulo 4}

\section{Modelagem da interdependência por meio de Cópulas}

As limitações da correlação linear como medida de dependência entre séries fazem-se presente em muitas situações, em particular em séries temporais financeiras. Neste capítulo é apresentada brevemente a teoria de cópulas, que surge como uma alternativa para detectar a estrutura de dependência entre variáveis aleatórias, em especial nas caudas das distribuições. As notações seguirão de perto Nelsen [2006], que é a referência clássica do assunto, e McNeil et al. [2005].

\subsection{Introdução}

Em algum sentido, toda função distribuição conjunta para um vetor aleatório de fatores de risco contém implicitamente tanto a descrição do comportamento marginal de um risco individual quanto a estrutura de dependência entre as variáveis. A abordagem de cópulas fornece uma possibilidade de isolar a descrição desta estrutura e, devido à sua naturalidade em tratar em nível quantílico a dependência, a técnica tornou-se uma das mais utilizadas em diversas áreas do conhecimento.

Pode-se definir ${ }^{6}$ cópula como a função que faz uma junção ou um acoplamento multivariado de várias variáveis aleatórias, a partir de suas funções distribuição marginais univariadas.

A importância das cópulas no estudo das distribuições multivariadas é resumida pelo Teorema de Sklar (1959), que mostra que todas as funções distribuição multivariadas podem ser decompostas em função de cópulas e que as cópulas podem ser utilizadas em conjunção com as funções distribuição univariadas para construir funções distribuição multivariadas.

Teorema de Sklar [1959]. Seja $F$ a função distribuição conjunta com marginais $\left(F_{1}, \ldots, F_{d}\right)$. Então existe uma cópula $C:[0,1]^{d} \rightarrow[0,1]$ tal que, para todo $x_{1}, \ldots, x_{d}$ em $\overline{\mathbb{R}}=[-\infty, \infty]$,

$$
F\left(x_{1}, \ldots, x_{d}\right)=C\left(F_{X_{1}}\left(x_{1}\right), \ldots, F_{X_{d}}\left(x_{d}\right)\right) .
$$

Se as marginais são continuas, então $C$ é única; caso contrário $C$ é univocamente determinada em $\operatorname{DomF}_{1} \times \operatorname{DomF}_{2} \times \ldots \times \operatorname{DomF}_{d}$, em que Dom $F_{i}=F_{i}(\overline{\mathbb{R}})$ denota o dominio de $F_{i}$. Se $C$ é uma cópula e $F_{1}, \ldots, F_{d}$ são funções distribuição univariadas, então a função $F$ definida na Equação 4.1 é uma função distribuição com marginais $F_{1}, \ldots, F_{d}$.

\footnotetext{
${ }^{6}$ Nelsen [2006] apresenta algumas outras definições para cópulas.
} 
Demonstração. Ver Nelsen [2006].

Analogamente à Equação 4.1, pode-se escrever a função cópula como:

$$
C\left(u_{1}, \ldots, u_{d}\right)=F\left(F_{X_{1}}^{-1}\left(u_{1}\right), \ldots, F_{X_{d}}^{-1}\left(u_{d}\right)\right) .
$$

Assim, como $f_{Z}(z)=\frac{\partial F_{Z}(z)}{\partial z}$, obtém-se a função densidade da cópula fazendo:

$$
c\left(F_{X_{1}}\left(x_{1}\right), \ldots, F_{X_{d}}\left(x_{d}\right)\right)=\frac{\partial^{d} C\left(F_{X_{1}}\left(x_{1}\right), \ldots, F_{X_{d}}\left(x_{d}\right)\right)}{\partial F_{X_{1}}\left(x_{1}\right) \ldots \partial F_{X_{d}}\left(x_{d}\right)} .
$$

Portanto, pode-se escrever a função densidade de probabilidade multivariada do vetor aleatório $X=\left(X_{1}, \ldots, X_{d}\right)$ como:

$$
f\left(x_{1}, \ldots, x_{d}\right)=c\left(F_{X_{1}}\left(x_{1}\right), \ldots, F_{X_{d}}\left(x_{d}\right)\right) \prod_{i=1}^{d} f_{X_{i}}\left(x_{i}\right) .
$$

Todas as definições supracitadas pressupõem a existência de funções uni e multivariadas para os dados. No entanto, nem sempre é possível fazer tal suposição e faz-se necessária a adoção de cópulas que permitam utilizar unicamente os dados, caso denominado nãoparamétrico. Utilizam-se as entradas de cada função distribuição empírica, como evidenciado a seguir:

$$
\widehat{F_{i, n}(x)}=\frac{1}{n+1} \sum_{t=1}^{n} 1\left(X_{t, i} \leq x\right)
$$

com $1(A)$ denotando a função indicadora do conjunto A.

Tendo uma fórmula explícita para as entradas da cópula, define-se a cópula não-paramétrica (ou empírica) $C_{n}$, analogamente à Equação 4.1, por:

$$
\widehat{F}\left(x_{1}, \ldots, x_{d}\right)=C_{n}\left(\widehat{F_{X_{1}}\left(x_{1}\right)}, \ldots, \widehat{F_{X_{d}}\left(x_{d}\right)}\right) .
$$

Pode-se demonstrar que $\left.\left.C_{n}\left(\widehat{F_{X_{1}}\left(x_{1}\right.}\right), \ldots, \widehat{F_{X_{d}}\left(x_{d}\right.}\right)\right)$ é um estimador da quantidade desconhecida $C\left(u_{1}, \ldots, u_{d}\right)$, cuja distribuição assintótica é a Cópula Normal.

Como esta técnica não é o centro das discussões nesta dissertação (apenas um modelo para avaliação da interdependência), será utilizada a dimensão 2 para as cópulas a partir deste instante. Mais detalhes sobre a teoria de cópulas multivaridas podem ser encontradas em Nelsen [2006]. Uma completa discussão sobre cópulas multivariadas, condicionais e com coeficientes variando no tempo é feita por Abbara [2009].

\subsection{Medidas de Dependência e Cópulas}

Como já foi comentado neste capítulo, para ajustar uma função cópula a um conjunto de dados, é preciso conhecer a estrutura amostral de dependência. Para tanto, definem-se os 
coeficientes de correlação baseados em postos de Spearman $\left(\rho_{s}\right)$ e Kendall $(\tau)$, a seguir:

$$
\begin{gathered}
\hat{\rho}_{s}=\frac{12}{n\left(n^{2}-1\right)} \sum_{t=1}^{n}\left(\operatorname{rank}\left(X_{t, i}\right)-\frac{1}{2}(n+1)\right)\left(\operatorname{rank}\left(X_{t, j}\right)-\frac{1}{2}(n+1)\right), \\
\hat{\tau}=\left(\begin{array}{c}
n \\
2
\end{array}\right)^{-1} \sum_{1 \leq t<s \leq n} \operatorname{sign}\left(\left(X_{t, i}-X_{s, i}\right)\left(X_{t, j}-X_{s, j}\right),\right.
\end{gathered}
$$

em que $X_{i}$ e $X_{j}$ são duas variáveis aleatórias de interesse, os operadores $\operatorname{rank}(\mathrm{A})$ e $\operatorname{sign}(\mathrm{A})$ denotam os postos e o sinal de A, respectivamente.

Pode-se interpretar o coeficiente $\rho_{s}$ de Spearman como sendo a correlação das funções distribuição e o $\tau$ de Kendall como a diferença das probabilidades de ocorrência de pares concordantes e discordantes nas observações.

Ambas as correlações supradefinidas preservam as propriedades do coeficiente de correlação linear de Pearson $(\rho)$. No entanto, ambos possuem uma vantagem em relação a este último: são invariantes a transformações monotônicas, o que é bastante desejável devido ao fato de usualmente se trabalhar com os log-retornos das séries financeiras.

Como demonstrado em Nelsen [2006], os coeficientes $\rho_{s}$ de Spearman e $\tau$ de Kendall possuem relação direta com as funções de cópula, a saber:

$$
\begin{gathered}
\rho_{s}=12 \iint_{[0,1]^{2}} C\left(u_{1}, u_{2}\right) d u_{1} d u_{2}-1, \\
\tau=4 \iint_{[0,1]^{2}} C_{2}\left(u_{1}, u_{2}\right) d C_{1}\left(u_{1}, u_{2}\right)-1,
\end{gathered}
$$

e também com as cópulas empíricas:

$$
\begin{gathered}
\hat{\rho}_{s}=\frac{12}{n^{2}-1} \sum_{j=1}^{n} \sum_{i=1}^{n} C_{n}\left(\frac{i}{n}, \frac{j}{n}\right)-\frac{i}{n}-\frac{j}{n} \\
\hat{\tau}=\frac{2 n}{n-1} \sum_{i=2}^{n} \sum_{j=2}^{n} \sum_{p=1}^{i-1} \sum_{q=1}^{j-1} c_{n}\left(\frac{i}{n}, \frac{j}{n}\right) c_{n}\left(\frac{p}{n}, \frac{q}{n}\right)-c_{n}\left(\frac{i}{n}, \frac{q}{n}\right) c_{n}\left(\frac{p}{n}, \frac{j}{n}\right) .
\end{gathered}
$$

Por fim, uma medida que é relevante para se ter a dimensão da dependência em nível quantílico é o chamado índice de cauda. É possível obter o índice da cauda superior $\left(\hat{\lambda_{u}}\right)$ e inferior $\left(\hat{\lambda_{l}}\right)$ a partir da cópula empírica resolvendo as equações a seguir:

$$
\begin{array}{r}
\hat{\lambda_{u}}=\frac{1-2 q+C_{n}(q, q)}{1-q}, q>\frac{1}{2}, \\
\hat{\lambda_{l}}=\frac{C_{n}(q, q)}{q}, q<\frac{1}{2},
\end{array}
$$


em que $q$ é o quantil em que se deseja avaliar a dependência.

\subsection{Principais famílias de Cópulas}

Nesta seção serão apresentadas as famílias de cópulas mais comuns na literatura e que serão utilizadas na modelagem das séries abordadas neste trabalho. Trata-se da família arquimediana e das cópulas Normal e t-Student, pertencentes à família elíptica. As demais famílias clássicas de cópulas podem ser encontradas em Nelsen [2006].

\subsubsection{Família Arquimediana}

As cópulas da família arquimediana são amplamente utilizadas por diversas razões: 1) a facilidade de construção, 2) uma grande variedade de cópulas pertencem a esta classe, e 3) possuem propriedades interessantes, sendo as principais delas a forma funcional explícita de suas versões mais famosas, além de preservar a simetria e propriedade associativa (na versão multivariada).

Suponha uma função $\phi:[0,1] \rightarrow[0, \infty]$ contínua e estritamente decrescente, com $\phi(1)=$ 0 e $\phi(0) \leq \infty$. Define-se a pseudo-inversa de $\phi$ com domínio $[0, \infty]$ por:

$$
\phi^{[-1]}(t)=\left\{\begin{array}{rll}
\phi^{-1}(t), & \text { para } & 0 \leq t \leq \phi(0) \\
0, & \text { para } & \phi(0)<t \leq \infty
\end{array}\right.
$$

Teorema das Cópulas Arquimedianas Bivariadas. Seja $\phi:[0,1] \rightarrow[0, \infty]$ uma função contínua e estritamente decrescente, com $\phi(1)=0$ e $\phi^{[-1]}(t)$ dado pela Equação 4.15. Então:

$$
C\left(u_{1}, u_{2}\right)=\phi^{[-1]}\left(\phi\left(u_{1}\right)+\phi\left(u_{2}\right)\right)
$$

é uma cópula se, e só se, $\phi$ é convexa.

Demonstração. Ver Nelsen [2006].

À função $\phi$ dá-se o nome de gerador de cópulas arquimedianas, quando as condições supradefinidas forem satisfeitas. Dependendo das formas funcionais adotadas para $\phi$, tem-se diferentes cópulas. A seguir, na Tabela 4.1, são apresentadas as cópulas escolhidas para a modelagem deste capítulo.

Tabela 4.1: As principais cópulas arquimedianas.

\begin{tabular}{cccc}
\hline Cópula & Gerador $\phi(t)$ & Forma funcional $C_{\theta}\left(u_{1}, u_{2}\right)$ & Intervalo do parâmetro \\
\hline Gumbel $C_{\theta}^{G u}$ & $(-\ln t)^{\theta}$ & $\exp \left[-\left(\left(-\ln u_{1}\right)^{\theta}+\left(-\ln u_{2}\right)^{\theta}\right)^{\frac{1}{\theta}}\right]$ & $\theta \geq 1$ \\
Clayton $C_{\theta}^{C l}$ & $\frac{1}{\theta}\left(t^{-\theta}-1\right)$ & $\left(u_{1}^{-\theta}+u_{2}^{-\theta}-1\right)^{-\frac{1}{\theta}}$ & $\theta \geq-1$ \\
Frank $C_{\theta}^{F r}$ & $-\ln \left(\frac{\exp ^{-\theta t}-1}{\exp ^{-\theta}-1}\right)$ & $-\frac{1}{\theta} \ln \left(1+\frac{\left(\exp \left(-\theta u_{1}\right)-1\right)\left(\exp \left(-\theta u_{2}\right)-1\right)}{\exp (-\theta)-1}\right)$ & $\theta \in \mathbb{R}$ \\
\hline
\end{tabular}

Como é possível observar na Tabela 4.1, as cópulas são definidas por apenas um parâmetro (definido por $\theta$ ) que carrega a informação da estrutura de dependência, como as medidas de 
dependência tratadas na Seção 4.2. Joe [1997] apresenta extensões dos modelos de cópulas arquimedianos com dois parâmetros de controle da dependência e também para os casos multivariados. No entanto, tais extensões não serão abordadas nesta dissertação pelo fato de que a modelagem por cópulas não é o principal enfoque desta dissertação.

Para efeito de ilustração, foi gerada uma amostra aleatória de tamanho 2000 de cada uma das cópulas descritas na Tabela $4.1(\operatorname{Frank}(\theta=1), \operatorname{Gumbel}(\theta=1,5)$ e Clayton $(\theta=1))$. Logo abaixo, suas respectivas curvas de nível. Os resultados estão apresentados na Figura 4.1, a seguir.
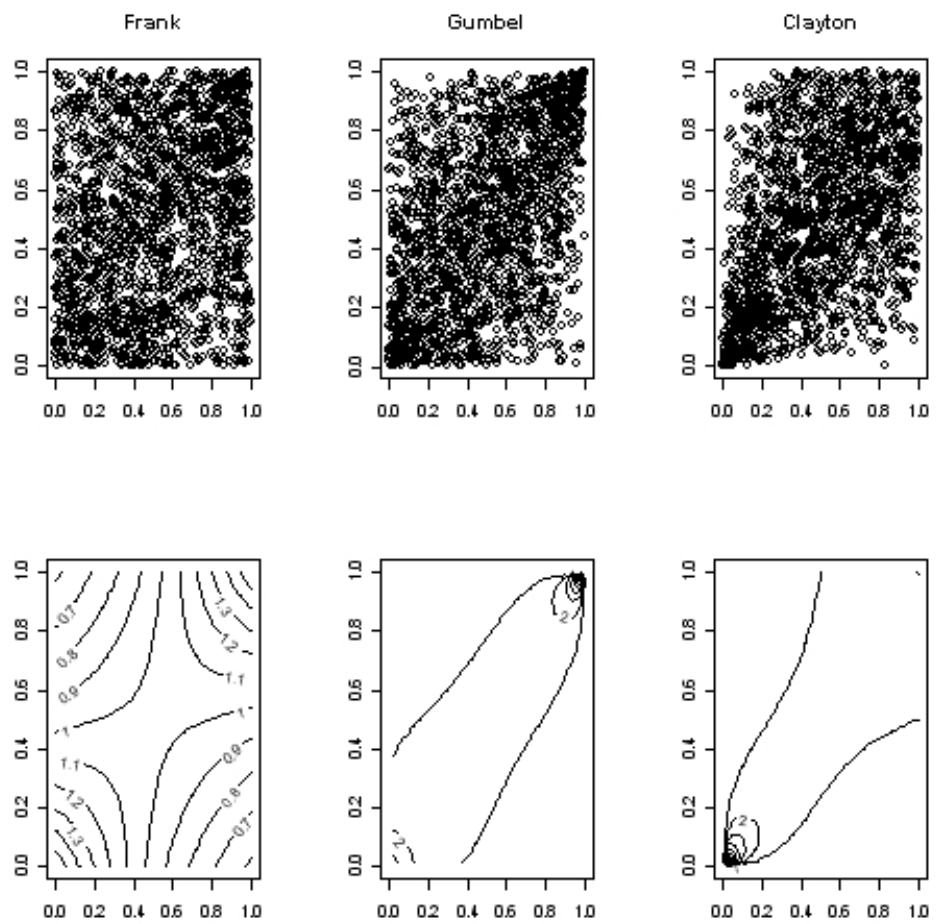

Figura 4.1: Amostras simuladas das cópulas Frank, Gumbel e Clayton, com as respectivas densidades representadas pelas curvas de nivel.

Como é possível perceber pela Figura 4.1, a cópula Frank é simétrica, uma vez que não se nota acúmulo em quaisquer caudas. Já a cópula Gumbel permite ajustar com qualidade a cauda superior, enquanto a cópula Clayton, modela bem a cauda inferior. Isto é uma implicação prática do cálculo dos índices de cauda teóricos para cada uma das cópulas, cujos resultados são $\lambda_{u}=\lambda_{l}=0$ para a cópula Frank, $\lambda_{u}=2-2^{-\frac{1}{\theta}}$ e $\lambda_{l}=0$ para a cópula Gumbel e, finalmente, $\lambda_{u}=0$ e $\lambda_{l}=2^{-\frac{1}{\theta}}$ para a cópula Clayton.

\subsubsection{Cópulas Normal e t-Student}

As duas cópulas bivariadas a serem tratadas nesta subseção, diferentemente da família arquimediana, não possuem formas explícitas para a determinação de suas formas funcionais, apesar de serem provenientes de funções distribuição simétricas bastante conhecidas. Esta 
última propriedade impõe a restrição de que variações positivas são tão prováveis quanto variações negativas, implicando no fato de que o parâmetro da cópula expressa a mesma dependência em situações favoráveis e desfavoráveis, o que pode ser um tanto irreal.

Se $Y \sim N_{d}(\mu, \Sigma)$ é um vetor aleatório, então a sua cópula é chamada Cópula Normal. A partir da operação de padronização das margens, devido à aplicação de transformações estritamente crescentes, pode-se considerar que o vetor $\mathrm{Y}$ possui a mesma cópula que o vetor aleatório $Y \sim N_{d}(0, P)$, em que $P$ é a matriz de correlação de Y. Assim, esta cópula é dada por:

$$
C_{P}^{N}(u)=\mathbb{P}\left(\Phi\left(X_{1}\right) \leq u_{1}, \ldots, \Phi\left(X_{d}\right) \leq u_{d}\right)=\Phi_{P}\left(\Phi^{-1}\left(u_{1}\right), \ldots, \Phi^{-1}\left(u_{d}\right)\right),
$$

em que $\Phi$ denota a função distribuição da Normal padrão e $\Phi_{P}$ é a função distribuição conjunta de X. A notação $C_{P}^{N}(u)$ enfatiza que a cópula é parametrizada por $\frac{1}{2} d(d-1)$ parâmetros da matriz de correlação. Como caso particular, em duas dimensões tem-se $C_{\rho}^{N}\left(u_{1}, u_{2}\right)$, em que $\rho=\rho\left(X_{1}, X_{2}\right)$, e a forma funcional da cópula é dada por:

$$
C_{\rho}^{N}\left(u_{1}, u_{2}\right)=\int_{-\infty}^{\Phi^{-1}\left(u_{1}\right)} \int_{-\infty}^{\Phi^{-1}\left(u_{2}\right)} \frac{1}{2 \pi\left(1-\rho^{2}\right)^{1 / 2}} \exp \left\{\frac{-\left(s_{1}^{2}-2 \rho s_{1} s_{2}+s_{2}^{2}\right)}{2\left(1-\rho^{2}\right)}\right\} d s_{1} d s_{2}
$$

Apesar de não se tratar de uma forma explícita, com algum esforço computacional obtémse valores para a cópula por algum método de simulação de variáveis aléatórias normais. Além disso, pode-se perceber facilmente a partir da Equação 4.17 que o parâmetro $\rho$ carrega a estrutura de dependência e que interpola as dependências perfeitas, positiva e negativa, representando a força desta dependência. Como resultado bastante conhecido da teoria das probabilidades, coeficiente de correlação zero implica independência entre duas variáveis aleatórias normais.

Analogamente, consegue-se extrair uma cópula implícita de qualquer outra distribuição com funções distribuição marginais contínuas. Por exemplo, a Cópula t-Student bidimensional tem a forma:

$$
C_{v, \rho}^{t}\left(u_{1}, u_{2}\right)=t_{v, \rho}\left(t_{v}^{-1}\left(u_{1}\right), t_{v}^{-1}\left(u_{2}\right)\right.
$$

em que $t_{v}$ é a função distribuição de uma distribuição t-Student padrão com $v$ graus de liberdade e $\rho$ é o coeficiente de correlação entre $X_{1}$ e $X_{2}$.

Uma vez mais, como finalidade de ilustração, foi gerada uma amostra aleatória de tamanho 2000 das cópulas descritas pelas Equações 4.17 e 4.18, todas com coeficiente de correlação $\rho=0,5$ e, para as cópulas t-Student, especificados os graus de liberdade $v=3$ e, em seguida, $v=15$. Na segunda linha da figura, são mostradas as respectivas curvas de nível. Os resultados estão apresentados na Figura 4.2 a seguir. 

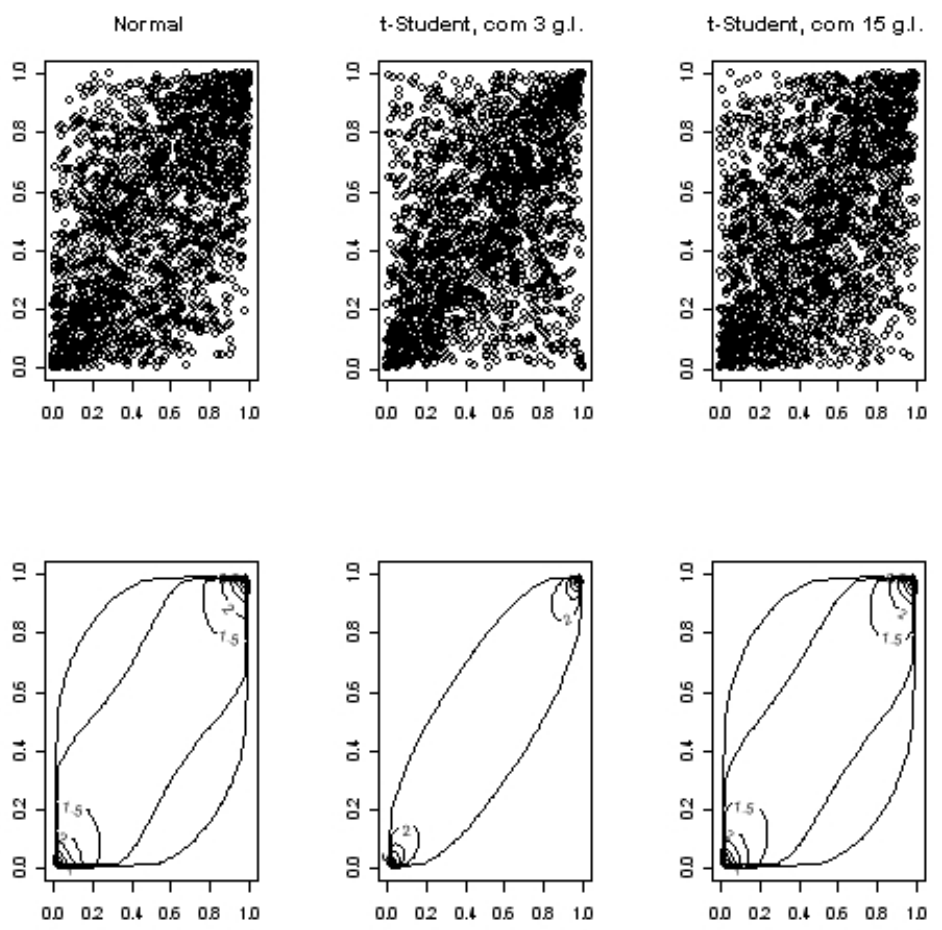

Figura 4.2: Amostras simuladas das cópulas Normal e t-Student, com as respectivas densidades representadas pelas curvas de nivel.

Avaliando a Figura 4.2 pode-se perceber claramente a grande similaridade do formato dos dois tipos de cópula, evidenciando o fato de que ambas possuem propriedade de simetria e captam ambas as caudas. O fator diferenciador destes dois tipos de cópulas reside na densidade das caudas: ambas as cópulas t-Student possuem mais densidade nas caudas do que a cópula Normal. Comparando as duas cópulas t-Student, elas diferenciam-se pela densidade da cauda, de modo que quanto menor os graus de liberdade atribuídos à função cópula, mais pesada é a cauda. Estes efeitos podem ser observados no acúmulo de densidade nos extremos, sendo o menor na cópula Normal e o maior na t-Student com 3 graus de liberdade.

\subsubsection{Inferência Paramétrica}

Uma vez definidas as estruturas e formas funcionais que serão utilizadas para a modelagem por cópulas, é necessário adotar um critério para escolher a cópula que melhor descreve o comportamento conjunto das variáveis.

O método da máxima verossimilhança. O primeiro passo é determinar a densidade conjunta das variáveis

$$
\begin{gathered}
f\left(x_{1}, \ldots, x_{d} \mid \Theta\right)=\frac{\partial^{d} F\left(x_{1}, \ldots, x_{d} \mid \Theta\right)}{\partial x_{1} \ldots \partial x_{d}}= \\
=\frac{\partial^{n} C_{\theta}\left(F_{X_{1}}\left(x_{1} \mid \theta_{1}\right), \ldots, F_{X_{d}}\left(x_{d} \mid \theta_{d}\right)\right)}{\partial x_{1} \ldots \partial x_{d}}=c_{\theta}\left(F_{X_{1}}\left(x_{1} \mid \theta_{1}\right), \ldots, F_{X_{d}}\left(x_{d} \mid \theta_{d}\right)\right) \frac{\partial F_{X_{1}}\left(x_{1} \mid \theta_{1}\right)}{\partial x_{1}} \ldots \frac{\partial F_{X_{d}}\left(x_{d} \mid \theta_{d}\right)}{\partial x_{d}},
\end{gathered}
$$


em que $\Theta=\left(\theta_{1}, \ldots, \theta_{d}, \theta\right)$ é o vetor de parâmetros e $c_{\theta}\left(F_{X_{1}}\left(x_{1} \mid \theta_{1}\right), \ldots, F_{X_{d}}\left(x_{d} \mid \theta_{d}\right)\right)$ é a função densidade da cópula.

Assim, uma decomposição interessante é obtida:

$$
f\left(x_{1}, \ldots, x_{d} ; \Theta\right)=\underbrace{c_{\theta}\left(F_{X_{1}}\left(x_{1} \mid \theta_{1}\right), \ldots, F_{X_{d}}\left(x_{d} \mid \theta_{d}\right)\right)}_{A} \underbrace{\prod_{i=1}^{d} f_{X_{i}}\left(x_{i} \mid \theta_{i}\right)}_{B},
$$

em que $\Theta=\left(\theta_{1}, \ldots, \theta_{d}, \theta\right)$ é o vetor de parâmetros, $A$ denota a estrutura de dependência, ao passo que $B$ representa a estrutura probabilística das variáveis marginais.

Sendo $n$ o tamanho da amostra aleatória do vetor d-dimensional $\underset{\sim}{X}$, a função de verossimilhança é dada por:

$$
\begin{gathered}
L(X \mid \Theta)=\prod_{j=1}^{n}\left[c_{\theta}\left(F_{X_{1}}\left(x_{1, j} \mid \theta_{1}\right), \ldots, F_{X_{d}}\left(x_{d, j} \mid \theta_{d}\right)\right) \prod_{i=1}^{d} f_{X_{i}}\left(x_{i, j} \mid \theta_{i}\right)\right]= \\
=\prod_{j=1}^{n} c_{\theta}\left(F_{X_{1}}\left(x_{1, j} \mid \theta_{1}\right), \ldots, F_{X_{d}}\left(x_{d, j} \mid \theta_{d}\right)\right) \prod_{j=1}^{n} \prod_{i=1}^{d} f_{X_{i}}\left(x_{i, j} \mid \theta_{i}\right) .
\end{gathered}
$$

Tomando o logaritmo natural (transformação monotônica e estritamente crescente), $l(X \mid \Theta)=$ $\ln L(X \mid \Theta)$, tem-se que:

$$
l(X \mid \Theta)=\sum_{j=1}^{n} \ln c_{\theta}\left(F_{X_{1}}\left(x_{1, j} \mid \theta_{1}\right), \ldots, F_{X_{d}}\left(x_{d, j} \mid \theta_{d}\right)\right)+\sum_{j=1}^{n} \sum_{i=1}^{d} \ln f_{X_{i}}\left(x_{i, j} \mid \theta_{i}\right) .
$$

Portanto,

$$
\begin{gathered}
\widehat{\theta}=\arg \max \sum_{j=1}^{n} \frac{\partial \ln c_{\theta}\left(F_{X_{1}}\left(x_{1, j} \mid \theta_{1}\right), \ldots, F_{X_{d}}\left(x_{d, j} \mid \theta_{d}\right)\right)}{\partial \theta} ; \\
\widehat{\theta}_{i}=\arg \max \left[\sum_{j=1}^{n} \frac{\partial \ln c_{\theta}\left(F_{X_{1}}\left(x_{1, j} \mid \theta_{1}\right), \ldots, F_{X_{d}}\left(x_{d, j} \mid \theta_{d}\right)\right)}{\partial \theta_{i}}+\sum_{j=1}^{n} \frac{\ln f_{X_{i}}\left(x_{i, j} \mid \theta_{i}\right)}{\partial \theta_{i}}\right] .
\end{gathered}
$$

Vale apenas ressaltar que, assim como fora dito na seção anterior, não se tem sempre uma forma fechada para os estimadores das Equações 4.20 e 4.21.

\subsection{Resultados}

A partir dos resíduos de cada um dos modelos ARMA(1,1)-GARCH(1,1) apresentados no capítulo anterior, foi possível ajustar ${ }^{7}$ as cópulas apresentadas neste capítulo.

\footnotetext{
${ }^{7}$ Todos os resultados de procedimentos empíricos deste capítulo foram obtidos no software R versão 2.10.1.
} 
Tabela 4.2: Critérios de seleção da família de cópulas para cada par de séries.

\begin{tabular}{cccccc}
\hline \multicolumn{7}{c}{ Log Verossimilhança } & & \\
\hline & Gumbel & Frank & Clayton & t-Student & Normal \\
\hline Brasil x Argentina & 450,78 & 434,43 & 454,07 & $\mathbf{5 5 8 , 4 0}$ & 456,28 \\
Brasil x México & 603,13 & 564,00 & 592,98 & $\mathbf{7 1 5 , 3 4}$ & 620,11 \\
Brasil x EUA & 490,82 & 473,62 & 449,97 & $\mathbf{5 6 3 , 8 8}$ & 509,56 \\
Brasil x Malásia & 26,09 & 13,61 & 25,48 & $\mathbf{5 9 , 0 6}$ & 16,19 \\
Brasil x Rússia & 114,74 & 94,44 & 126,10 & $\mathbf{1 6 8 , 9 1}$ & 110,91 \\
Argentina x México & 346,73 & 334,92 & 364,68 & $\mathbf{4 3 0 , 6 9}$ & 368,31 \\
Argentina x EUA & 264,69 & 261,66 & 271,98 & $\mathbf{3 4 9 , 1 4}$ & 265,90 \\
Argentina x Malásia & 32,84 & 18,29 & 25,34 & $\mathbf{5 4 , 5 5}$ & 23,03 \\
Argentina x Rússia & 109,61 & 89,55 & 116,34 & $\mathbf{1 5 9 , 3 0}$ & 106,67 \\
México x EUA & 606,57 & 566,60 & 563,36 & $\mathbf{6 8 6 , 6 3}$ & 639,72 \\
México x Malásia & 41,81 & 32,18 & 48,13 & $\mathbf{9 6 , 5 0}$ & 30,54 \\
México x Rússia & 123,81 & 96,69 & 130,22 & $\mathbf{1 8 6 , 2 4}$ & 115,07 \\
EUA x Malásia & 20,06 & 11,83 & 17,72 & $\mathbf{4 2 , 3 3}$ & 13,21 \\
EUA x Rússia & 85,26 & 67,23 & 78,86 & $\mathbf{1 2 5 , 6 3}$ & 74,80 \\
Malásia x Rússia & 76,57 & 71,02 & 102,42 & $\mathbf{1 4 1 , 6 0}$ & 76,40 \\
\hline & & AIC & & & \\
\hline & Gumbel & Frank & Clayton & t-Student & Normal \\
\hline Brasil x Argentina & $-0,39$ & $-0,38$ & $-0,39$ & $\mathbf{- 0 , 4 8}$ & $-0,39$ \\
Brasil x México & $-0,52$ & $-0,49$ & $-0,51$ & $\mathbf{- 0 , 6 2}$ & $-0,54$ \\
Brasil x EUA & $-0,42$ & $-0,41$ & $-0,39$ & $\mathbf{- 0 , 4 9}$ & $-0,44$ \\
Brasil x Malásia & $-0,02$ & $-0,01$ & $-0,02$ & $\mathbf{- 0 , 0 5}$ & $-0,01$ \\
Brasil x Rússia & $-0,10$ & $-0,08$ & $-0,11$ & $\mathbf{- 0 , 1 5}$ & $-0,10$ \\
Argentina x México & $-0,30$ & $-0,29$ & $-0,32$ & $\mathbf{- 0 , 3 7}$ & $-0,32$ \\
Argentina x EUA & $-0,23$ & $-0,23$ & $-0,24$ & $\mathbf{- 0 , 3 0}$ & $-0,23$ \\
Argentina x Malásia & $-0,03$ & $-0,02$ & $-0,02$ & $\mathbf{- 0 , 0 5}$ & $-0,02$ \\
Argentina x Rússia & $-0,09$ & $-0,08$ & $-0,10$ & $\mathbf{- 0 , 1 4}$ & $-0,09$ \\
México x EUA & $-0,53$ & $-0,49$ & $-0,49$ & $\mathbf{- 0 , 5 9}$ & $-0,55$ \\
México x Malásia & $-0,04$ & $-0,03$ & $-0,04$ & $\mathbf{- 0 , 0 8}$ & $-0,03$ \\
México x Rússia & $-0,11$ & $-0,08$ & $-0,11$ & $\mathbf{- 0 , 1 6}$ & $-0,10$ \\
EUA x Malásia & $-0,02$ & $-0,01$ & $-0,01$ & $\mathbf{- 0 , 0 4}$ & $-0,01$ \\
EUA x Rússia & $-0,07$ & $-0,06$ & $-0,07$ & $\mathbf{- 0 , 1 1}$ & $-0,06$ \\
Malásia x Rússia & $-0,07$ & $-0,06$ & $-0,09$ & $\mathbf{- 0 , 1 2}$ & $-0,07$ \\
\hline & & & & &
\end{tabular}

Tendo como base a Tabela 4.2, pode-se concluir que, para todos os pares avaliados, a cópula t-Student apresentou desempenho bastante superior quando comparada às demais cópulas, tanto analisando a log-verossimilhança quanto o AIC. Excluindo-se a cópula tStudent, não há unanimidade quanto à melhor cópula a se utilizar: apenas a cópula Frank foi sempre a de pior ajuste, fato que é facilmente explicado, uma vez que a cópula Frank não permite capturar dependência em nenhuma cauda em especial.

Em seguida, foram obtidas as estimativas dos parâmetros das cópulas aqui abordadas, com seus respectivos erros-padrão, como evidenciado na Tabela 4.3 a seguir. 
Tabela 4.3: Estimativas e erros-padrão dos parâmetros das cópulas ajustadas para cada par de séries.

\begin{tabular}{ccccccc}
\hline & Gumbel & Frank & Clayton & t-Student & g.l. & Normal \\
\hline Brasil x Argentina & 1,553 & 3,920 & 0,971 & $\mathbf{0 , 5 5 4}$ & $\mathbf{3 , 3 9 4}$ & 0,545 \\
& $(0,02)$ & $(0,14)$ & $(0,04)$ & $\mathbf{( 0 , 0 2 )}$ & $\mathbf{( 0 , 3 1 )}$ & $(0,01)$ \\
Brasil x México & 1,685 & 4,566 & 1,176 & $\mathbf{0 , 6 1 4}$ & $\mathbf{3 , 4 5 7}$ & 0,617 \\
& $(0,03)$ & $(0,14)$ & $(0,04)$ & $\mathbf{( 0 , 0 1 )}$ & $\mathbf{( 0 , 3 4 )}$ & $(0,01)$ \\
Brasil x EUA & 1,585 & 4,094 & 0,948 & $\mathbf{0 , 5 7 3}$ & $\mathbf{4 , 8 3 8}$ & 0,570 \\
& $(0,02)$ & $(0,14)$ & $(0,04)$ & $\mathbf{( 0 , 0 1 )}$ & $\mathbf{( 0 , 5 9 )}$ & $(0,01)$ \\
Brasil x Malásia & 1,080 & 0,634 & 0,155 & $\mathbf{0 , 1 0 7}$ & $\mathbf{4 , 9 0 3}$ & 0,112 \\
& $(0,01)$ & $(0,12)$ & $(0,02)$ & $\mathbf{( 0 , 0 2 )}$ & $\mathbf{( 0 , 5 9 )}$ & $(0,02)$ \\
Brasil x Rússia & 1,208 & 1,694 & 0,406 & $\mathbf{0 , 2 7 8}$ & $\mathbf{4 , 3 4 7}$ & 0,287 \\
& $(0,02)$ & $(0,12)$ & $(0,03)$ & $\mathbf{( 0 , 0 2 )}$ & $\mathbf{( 0 , 4 7 )}$ & $(0,02)$ \\
Argentina x México & 1,455 & 3,355 & 0,826 & $\mathbf{0 , 4 9 7}$ & $\mathbf{4 , 0 4 6}$ & 0,498 \\
Argentina x EUA & $(0,02)$ & $(0,13)$ & $(0,04)$ & $\mathbf{( 0 , 0 2 )}$ & $\mathbf{( 0 , 4 4 )}$ & $(0,01)$ \\
& 1,381 & 2,945 & 0,677 & $\mathbf{0 , 4 4 4}$ & $\mathbf{3 , 7 5 8}$ & 0,431 \\
Argentina x Malásia & $(0,02)$ & $(0,13)$ & $(0,03)$ & $\mathbf{( 0 , 0 2 )}$ & $\mathbf{( 0 , 3 6 )}$ & $(0,01)$ \\
Argentina x Rússia & 1,093 & 0,730 & 0,157 & $\mathbf{0 , 1 2 7}$ & $\mathbf{5 , 8 3 4}$ & 0,133 \\
& $(0,01)$ & $(0,12)$ & $(0,02)$ & $\mathbf{( 0 , 0 2 )}$ & $\mathbf{( 0 , 8 1 )}$ & $(0,02)$ \\
México x EUA & 1,201 & 1,654 & 0,387 & $\mathbf{0 , 2 7 1}$ & $\mathbf{4 , 4 6 2}$ & 0,282 \\
& $(0,02)$ & $(0,12)$ & $(0,03)$ & $\mathbf{( 0 , 0 2 )}$ & $\mathbf{( 0 , 4 9 )}$ & $(0,02)$ \\
México x Malásia & 1,684 & 4,542 & 1,109 & $\mathbf{0 , 6 2 0}$ & $\mathbf{5 , 1 1 8}$ & 0,624 \\
México x Rússia & $(0,03)$ & $(0,14)$ & $(0,04)$ & $\mathbf{( 0 , 0 1 )}$ & $\mathbf{( 0 , 6 8 )}$ & $(0,01)$ \\
EUA x Malásia & 1,112 & 0,988 & 0,229 & $\mathbf{0 , 1 6 8}$ & $\mathbf{3 , 9 4 2}$ & 0,153 \\
EUA x Rússia & $(0,01)$ & $(0,12)$ & $(0,03)$ & $\mathbf{( 0 , 0 2 )}$ & $\mathbf{( 0 , 3 8 )}$ & $(0,02)$ \\
Malásia x Rússia & 1,219 & 1,729 & 0,415 & $\mathbf{0 , 2 8 1}$ & $\mathbf{3 , 6 8 8}$ & 0,292 \\
& $(0,02)$ & $(0,12)$ & $(0,03)$ & $\mathbf{( 0 , 0 2 )}$ & $\mathbf{( 0 , 3 6 )}$ & $(0,02)$ \\
& 1,071 & 0,590 & 0,128 & $\mathbf{0 , 1 0 0}$ & $\mathbf{5 , 9 4 1}$ & 0,101 \\
& $(0,01)$ & $(0,12)$ & $(0,02)$ & $\mathbf{( 0 , 0 2 )}$ & $\mathbf{( 0 , 8 5 )}$ & $(0,02)$ \\
& 1,176 & 1,428 & 0,304 & $\mathbf{0 , 2 3 4}$ & $\mathbf{4 , 5 8 0}$ & 0,237 \\
& $(0,02)$ & $(0,12)$ & $(0,03)$ & $\mathbf{( 0 , 0 2 )}$ & $\mathbf{( 0 , 5 2 )}$ & $(0,02)$ \\
& $(0,02)$ & $(0,12)$ & $(0,03)$ & $\mathbf{( 0 , 0 2 )}$ & $\mathbf{( 0 , 3 9 )}$ & $(0,02)$ \\
\hline & & & & & &
\end{tabular}

Como é possível observar na Tabela 4.3, as mais fortes dependências foram capturadas nas cópulas t-Student em pares que envolvem Brasil, Argentina, México e EUA, evidenciando forte integração dos mercados latinos-americanos e dos EUA entre si. Geralmente, os valores estão em torno de 0,50, chegando ao máximo no par México e EUA $(0,620)$, seguido bem de perto pelo par México e Brasil $(0,614)$. Adicionalmente, todos estes mercados mostraram-se pouco associados à Malásia, tendo sido o México o mais associado. A Rússia também é fracamente associada a todos os demais países, inclusive à Malásia, apresentando todos os valores entre 0,230 e 0,281 .

Analisando os graus de liberdade estimados para as cópulas t-Student, pode-se notar o mesmo efeito já observado nos modelos marginais: todas as estimativas apontam para distribuição de caudas pesadas, com o maior valor calculado para o par EUA e Malásia inferior a seis. 
Uma vez selecionada a cópula ótima t-Student para todos os pares de séries e obtidas as estimativas dos parâmetros, são calculados os índices de cauda (em 5\% e 10\% superiores e inferiores), além dos coeficientes de correlação de Kendall e Spearman. Os resultados são apresentados na Tabela 4.4 a seguir.

Tabela 4.4: Índices de cauda e correlações estimados a partir da cópula empírica t-Student.

\begin{tabular}{ccccccc}
\hline & \multicolumn{1}{c}{ Cauda Inferior } & \multicolumn{1}{c}{ Cauda Superior } & \multicolumn{2}{c}{ Correlações } \\
\hline & $5 \%$ & $10 \%$ & $90 \%$ & $95 \%$ & $\tau$ de Kendall & $\rho$ de Spearman \\
\hline Brasil x Argentina & 0,443 & 0,460 & 0,355 & 0,236 & 0,373 & 0,536 \\
Brasil x México & 0,493 & 0,505 & 0,385 & 0,257 & 0,421 & 0,596 \\
Brasil x EUA & 0,437 & 0,460 & 0,339 & 0,193 & 0,389 & 0,555 \\
Brasil x Malásia & 0,189 & 0,219 & 0,090 & $-0,071$ & 0,068 & 0,103 \\
Brasil x Rússia & 0,243 & 0,281 & 0,225 & 0,132 & 0,179 & 0,266 \\
Argentina x México & 0,340 & 0,384 & 0,376 & 0,324 & 0,331 & 0,480 \\
Argentina x EUA & 0,405 & 0,413 & 0,229 & 0,040 & 0,293 & 0,428 \\
Argentina x Malásia & 0,168 & 0,207 & 0,126 & 0,004 & 0,081 & 0,121 \\
Argentina x Rússia & 0,244 & 0,281 & 0,208 & 0,100 & 0,175 & 0,259 \\
México x EUA & 0,405 & 0,453 & 0,440 & 0,379 & 0,426 & 0,602 \\
México x Malásia & 0,266 & 0,279 & 0,062 & $-0,169$ & 0,108 & 0,161 \\
México x Rússia & 0,307 & 0,323 & 0,154 & $-0,029$ & 0,181 & 0,269 \\
EUA x Malásia & 0,160 & 0,198 & 0,108 & $-0,022$ & 0,064 & 0,096 \\
EUA x Rússia & 0,232 & 0,267 & 0,178 & 0,055 & 0,150 & 0,224 \\
Malásia x Rússia & 0,298 & 0,310 & 0,100 & $-0,122$ & 0,153 & 0,227 \\
\hline
\end{tabular}

A primeira informação relevante da Tabela 4.4 aponta para a clara assimetria à esquerda entre os índices de cauda superior e inferior para todos os pares analisados, indicando que a dependência é mais forte nos períodos em que há queda em ambos os mercados do que em períodos de pujança. Além disso, embora todos os parâmetros das cópulas tenham se mostrado significantes e considerando um limiar de 0,3 para Kendall e 0,4 para Spearman, as correlações calculadas a partir da cópula empírica apontam novamente para a forte associação entre todos os pares que envolvem Brasil, Argentina, México e EUA. Tanto o coeficiente de Spearman quanto o de Kendall sinalizam de forma parecida, indicando concordância na análise.

\subsection{Considerações Parciais}

Nos Capítulos 3 e 4 foi avaliada a possível existência de uma estrutura multivariada para as séries temporais financeiras abordadas nesta dissertação. Utilizando a abordagem tradicional dos modelos GARCH multivariados, observou-se que havia influência cruzada tanto de valores passados quanto de volatilidade, na maioria das séries.

Em se tratando dos modelos de cópulas, ficou bastante nítida a presença de estrutura de dependência cruzada entre algumas das séries, evidenciando que há agrupamentos de influência, o que mostra a necessidade de se adotar técnicas adequadas para mensurar o condicionamento das variáveis aleatórias, cuja escolha não pode ser, necesariamente, ad-hoc, como feito em Abbara [2009]. Desta maneira, tendo um país recebido a influência de algum 
choque, pode tê-lo retransmitido a outro país por meio de uma contaminação indireta em alguns passos, causando a interdependência ou contágio entre os mercados. Este evento pode não ser capturado caso o condicionamento inicial do país propagador de crise seja escolhido de maneira errada.

Diante deste cenário, o próximo capítulo apresentará uma abordagem alternativa às utilizadas na literatura, em que a estrutura da dinâmica de interrelação é avaliada sob a ótica de uma técnica de Inteligência Artificial, uma área que vem ganhando cada vez mais importância na ciência, à qual dá-se o nome de Rede Bayesiana. 


\section{Capítulo 5}

\section{Modelagem da interdependência por meio de Redes Bayesianas}

\subsection{Introdução}

Os métodos de análise multivariada de dados estão ganhando importância cada vez maior, à medida em que as informações estão mais acessíveis e os aspectos computacionais, mais robustos. Com o crescente volume de informações disponíveis, aumenta também a necessidade de se extrair conhecimentos relevantes de um banco de dados cuja avaliação é extremamente complexa. Como as informações univariadas e, até mesmo, as bivariadas passam a agregar pouco conhecimento relativamente às possibilidades totais, os métodos de Inteligência Artificial propõem uma verdadeira revolução na maneira de analisar e realizar inferências estatísticas.

Não apenas devido ao enorme montante de informação disponível, as pessoas começaram a perceber a importância de redes de todo tipo em suas vidas. A começar pela internet, em que redes sociais espalham-se rapidamente, conectando indivíduos com características e interesses comuns. Tudo isso faz com que a compreensão adequada da estrutura de uma rede social seja imprescindível, uma vez que possui consequências para os padrões de emprego, desigualdade de renda entre diferentes grupos e para a mobilidade social.

Neste capítulo é apresentado um caso particular de redes, as chamadas Redes Bayesianas. O enfoque a ser adotado nesta dissertação, até onde foi pesquisado para a sua elaboração, desconhece abordagem similar na literatura para o entendimento da estrutura de interdependência e contágio, o que constitui o caráter inovador do trabalho.

A respeito da metodologia descrita neste capítulo, procurou-se seguir de modo fiel a teoria descrita por Neapolitan [2004], bem como a metodologia por Boettcher e Dethlefsen [2003] especificada para a construção e estimação de Redes Bayesianas.

\subsubsection{Inteligência Artificial}

No contexto de Inteligência Artificial, uma Rede Bayesiana é um modelo estatístico gráfico, de simples visualização, que congrega a função de distribuição conjunta de um conjunto de variáveis aleatórias, com o intuito de observar cadeias de causalidade entre as variáveis, de modo bastante intuitivo. Essas redes foram desenvolvidas para lidar com as dificuldades 
de se avaliar relações em ordens superiores a 2 ou 3 e aproveitar a habilidade computacional para trabalhar com volumes imensos de informações e condicionamentos que um humano não seria capaz de resolver.

Uma quantidade substancial de pesquisas em redes tem sido produzida em Sociologia, Economia, Física, Matemática, Ciências Biomédicas e Ciência da Computação. Com a evolução do poder computacional, a partir da década de 1980, foi possível o desenvolvimento não só da teoria, mas também da capacidade de entendimento de processos até então obscuros. Isso mostra a versatilidade da técnica em auxiliar o desenvolvimento de uma ciência multidisciplinar e aplicação nos mais difusos ambientes.

A natureza das variáveis de interesse pode englobar tanto variáveis discretas quanto contínuas. No caso de haver mistura de tipos, dá-se a nomenclatura de Redes Bayesianas com variáveis mistas. Devido à suposição de continuidade das séries estudadas nesta dissertação, o arcabouço teórico descrito neste capítulo dará ênfase para as funções contínuas. No entanto, os casos discretos poderão ser utilizados com a finalidade de desenvolver a intuição do modelo.

\subsection{Probabilidade e independência}

O primeiro conceito fundamental a ser explorado é o de independência. Nos Capítulos 3 e 4 foram exploradas as dependências em dois sentidos: lineares e não lineares, sempre resumindo a informação em uma medida (ou nos coeficientes de associação cruzada entre as variáveis, no caso de modelos GARCH, ou em coeficientes de correlação e suas relações com parâmetros de cópulas). No entanto, é preciso estender o sentido de independência para ser avaliada a influência de uma variável sobre outras.

Definição. Suponha um espaço de probabilidades $(\Omega, P)$ e três conjuntos $A, B$ e $C$ contendo variáveis aleatórias definidas em $\Omega$. Os conjuntos $A$ e $B$ são ditos condicionalmente independentes, dado o conjunto $C$, se, para todos os valores das variáveis aleatórias do conjunto $A=a, B=b$, com $\mathbb{P}(C=c) \neq 0$, os eventos $A=a, B=b$ são condicionalmente independentes, dado $C=c$. Assim, $\mathbb{P}(A=a \mid C=c)=0$ ou $\mathbb{P}(B=b \mid C=c)=0$ ou:

$$
\mathbb{P}(A=a \mid B=b, C=c)=\mathbb{P}(A=a \mid C=c) .
$$

Quando acontecer a situação descrita pela Equação 5.1, escrever-se-á $I_{P}(A, B \mid C)$ ou, simplesmente, que as variáveis $A$ e $B$ são independentes dada a variável $C$.

Por uma questão de brevidade, será dito a partir deste momento "independente"em vez de "condicionalmente independente". Além disso, $\mathbb{P}$ deve ser entendido como função densidade de probabilidade no sentido amplo: tanto para variáveis discretas, quanto contínuas ou ambas.

E, finalmente, tem-se a regra da cadeia para as variáveis aleatóriais, a qual garante que, dadas $n$ variáveis aleatórias $X_{1}, X_{2}, \ldots, X_{n}$ definidas no mesmo espaço amostral $\Omega$,

$$
\mathbb{P}\left(x_{1}, \ldots, x_{n}\right)=\mathbb{P}\left(x_{n} \mid x_{n-1}, \ldots, x_{1}\right) \ldots \mathbb{P}\left(x_{2} \mid x_{1}\right) \mathbb{P}\left(x_{1}\right),
$$

seja qual for o valor da função de distribuição conjunta, desde que $\mathbb{P}\left(X_{1}=x_{1}, X_{2}=\right.$ $\left.x_{2}, \ldots, X_{n}=x_{n}\right) \neq 0$ e existam as densidades marginais condicionais. É simples provar 
esta regra da cadeia, bastando aplicar a regra de Bayes para a probabilidade sucessivamente.

\subsection{Teoria básica de Grafos}

Define-se como um grafo direcional um par (V,E), em que $\mathbf{V}$ é um conjunto finito e não vazio, cujos elementos atribuem-se a nomenclatura de nó (ou vértices), e $\mathbf{E}$ é um conjunto de pares cordenados de $\mathbf{V}$, que são chamados de $\operatorname{arestas}$ (ou $\operatorname{arcos}$ ). Se $(\mathrm{X}, \mathrm{Y}) \in \mathrm{E}$, diz-se que há um arco entre X e Y e que X e Y são incidentes ao arco. Se há um um arco ligando $\mathrm{X}$ a Y ou Y a X, pode-se afirmar que X e Y são adjacentes. Supondo a seguinte situação: $\mathrm{V}=X_{1}, X_{2}, \ldots, X_{k}$, em que $k \geq 2$ e $\left(X_{i-1}, X_{i}\right) \in E$, para todo $2 \leq i \leq k$, atribui-se ao conjunto de arcos que conecta os $k$ nós o nome de caminho de $X_{1}$ até $X_{k}$. Os nós $X_{2}$ a $X_{k-1}$ são chamados de nós interiores no caminho $X_{1}, \ldots, X_{k}$. O subcaminho do caminho $X_{1}, \ldots, X_{k}$ de $X_{i}$ até $X_{j}$ é o caminho $X_{i}, X_{i+1}, \ldots, X_{j}$, em que $1 \leq i \leq j \leq k$. Um ciclo direto é um caminho que leva um nó até ele mesmo. Um caminho simples é um caminho que não contém subcaminhos que sejam ciclos diretos. Um grafo direcional $\mathbb{G}$ é chamado de grafo acíclico direcional ( $D A G$, sua sigla em inglês) se ele não contiver ciclos diretos. Dado um DAG, $\mathbb{G}=(V, E)$, e nós $(\mathrm{X}, \mathrm{Y})$ em $\mathrm{V}, \mathrm{Y}$ é dito pai de $\mathrm{X}$ se há um arco de $\mathrm{Y}$ até $\mathrm{X}$ e, consequentemente, $\mathrm{X}$ é descendente de $\mathrm{Y}$.

Dadas todas essas definições importantes, agora é possível enunciar a seguinte definição: Definição Suponha que haja uma função densidade de probabilidade conjunta $P$ das variáveis aleatórias em algum conjunto $V$ e um $D A G \mathbb{G}=(V, E)$. Diz-se que $(\mathbb{G}, P)$ satisfaz a condição de Markov se, para cada variável $X \in V$, X for condicionalmente independente do conjunto de todos os seus não descendentes, dado o conjunto de todos os seus pais. Utilizando como notação pa $(X)$ e $N D(X)$ para os pais e não descendentes do nó X, respectivamente, então:

$$
I_{P}(X, N D(X)) \mid p a(X) .
$$

Em suma, toda e qualquer variável é independente de seus não-descendentes e de seus não-pais, condicionados em seus pais. E esta definição implica o seguinte teorema:

Teorema. Se $(\mathbb{G}, P)$ satisfaz a condição de Markov, então $P$ é igual ao produto de suas distribuições condicionais de todos os nós dados os valores de seus pais, desde que essas distribuições condicionais existam.

Demonstração. Ver Neapolitan [2004], págs. 34-38.

O que o teorema anterior evidencia é que a condição de Markov implica que qualquer Rede Bayesiana representa uma função densidade de probabilidade única que pode ser fatorada como $p(\underset{\sim}{X})=\prod_{i} p\left(X_{i} \mid p a\left(X_{i}\right)\right)$.

\subsection{Redes Bayesianas}

Seja $\mathbb{G}=(V, E)$ um grafo direcional e acíclico $(D A G)$, em que $V$ é um conjunto finito de nós e $E$ é um conjunto finito de arcos direcionais entre os nós. Desta maneira, a Rede Bayesiana está estruturada por $\mathbb{G}$.

Cada um dos nós $v \in V$ deste grafo representa uma variável aleatória $X_{v}$, e será referido 
apenas por $v$, e comporá o conjunto de variáveis constantes no grafo $\mathbb{G}$ com as demais variáveis. Para cada nó pai de $v$, será adotada a nomenclatura de $p a(v)$. Além disso, é atribuída uma função de probabilidade relacional entre $v$ e $p a(v)$ definida, condicionalmente, por $p\left(x_{v} \mid x_{p a(v)}\right)$. Já o conjunto das funções de probabilidades relacionais da rede é $P$. Uma Rede Bayesiana para um dado conjunto de variáveis aleatórias é o par $(D, P)$.

Uma eventual falta de arcos direcionais em $\mathbb{G}$ denota independência condicional entre duas variáveis aleatórias por meio do critério da fatoração da função de probabilidade conjunta usual, decorrente do Teorema de Bayes, a saber:

$$
p(x)=\prod_{v \in V} p\left(x_{v} \mid x_{p a(v)}\right)
$$

em que $V=\Delta \cup \Gamma, \Delta$ e $\Gamma$ são os conjuntos de nós discretos e contínuos, respectivamente.

O conjunto de variáveis $X$ pode ser escrito como $X=\left(X_{v}\right)_{v \in V}=(I, Y)=\left(\left(I_{\delta}\right)_{\delta \in \Delta}, Y_{\gamma}\right)_{\gamma \in \Gamma}$, de tal forma que $I$ e $Y$ são os conjuntos das variáveis discretas e contínuas, respectivamente. Para uma variável discreta $\delta$ denota-se $\mathcal{I}_{\delta}$ a sigma-álgebra.

A fim de garantir que haja métodos de computação local exata, o algoritmo não permite que variáveis discretas possuam pais contínuos. No caso de se ter um conjunto de variáveis mistas, a função densidade de probabilidade conjunta é fatorada da seguinte maneira:

$$
p(x)=p(i, y)=\prod_{\delta \in \Delta} p\left(i_{\delta} \mid i_{p a(\delta)}\right) \prod_{\gamma \in \Gamma} p\left(y_{\gamma} \mid y_{p a(\gamma)}\right)
$$

\subsubsection{Arcos causais}

Dado um conjunto de variáveis aleatórias $V$, se para todo $(X, Y) \in V$ for desenhado um arco entre $\mathrm{X}$ e $\mathrm{Y}$, e se e só se, $\mathrm{X}$ for a causa direta de $\mathrm{Y}$ em relação a $V$, pode-se dizer que o $D A G$ resultante é um DAG causal. Nesta seção, seguindo Neapolitan [2004], será ilustrado o porquê de um DAG causal satisfazer a condição de Markov. Mas, antes, será discutido o conceito de causalidade e um método para determinar influências causais.

Uma definição de dicionário ${ }^{8}$ é "o que determina um acontecimento". Outras definições poderiam ser dadas, como Neapolitan [2004]: "aquilo, como uma pessoa, coisa, evento ou condição, que é responsável por uma ação ou resultado". Vale reparar que, seja qual for a definição, ilustra um método operacional de identificar as relações causais. Ou seja, se a ação de fazer a variável $\mathrm{X}$ assumir algum valor altera os valores assumidos por $\mathrm{Y}$, então presume-se que $\mathrm{X}$ é responsável por algumas alterações dos valores de $\mathrm{Y}$ e pode-se concluir que X é uma causa de Y. No entanto, Neapolitan [2004] alerta para o fato de não se ter plenos conhecimentos acerca das reais condições a que um experimento está sujeito e que a correlação estatística pode esconder as reais cadeias de causalidade.

Isto significa que o fato de se observar fortes correlações entre X e Y pode não revelar qual variável causa ou recebe a influência ou um caso ainda pior: se há alguma outra variável não observada que pode estar causando simultaneamente os fenômenos observados. No entanto, por mais que haja um controle rigoroso no planejamento do experimento, ainda pode haver causas ocultas ou uma difícil determinação do sentido da causalidade. Desta forma, a Rede Bayesiana fornece a evidência de maior probabilidade, uma vez que ela trata de independências no sentido pleno, diretamente das incertezas associadas e não das expectativas

\footnotetext{
${ }^{8}$ Segundo o dicionário Michaelis.
} 
das variáveis aleatórias, como são todos os coeficientes de correlação.

Se duas variáveis aleatórias têm uma causa oculta comum, então poderia haver uma dependência entre elas, mas que a condição de Markov identificaria como uma independência. Por exemplo, considerando a Figura 5.1 a seguir: se forem observadas apenas as variáveis $\mathrm{X}, \mathrm{Y}$ e Z e as relações causais de X e Y sobre Z, a conclusão, pela condição de Markov, seria de que X e Y são independentes. Porém, se ambos possuem uma causa comum H, não observada, eles seriam dependentes. No entanto, pressupondo que a condição de Markov é satisfeita, nenhuma das duas variáveis dentro do conjunto $\mathrm{V}$ poderia ter causa comum oculta ou, se tiverem, deve haver o mesmo valor desconhecido para cada unidade observada. Quando isso ocorrer, diz-se que o conjunto é causadamente suficiente.

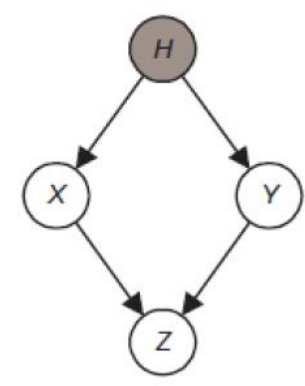

Figura 5.1: Dependência de uma variável não observada.

Notadamente, não se consegue controlar ou mesmo avaliar o que não se observa. Existem técnicas que se propõem a tratar exclusivamente deste problema, como Modelos de Espaços de Estados e Cadeias de Markov Ocultas, mas este trabalho se propõe apenas a estudar o caso observável. E este caso depende muito do conceito a ser estudado na próxima subseção. Tampouco é possível controlar todas as variáveis do universo. Dentro dos limites, são necessárias as adoções de premissas razoáveis e o reconhecimento das limitações do estudo.

Há outras exceções importantes para a causalidade, que se dão por conta do viés de seleção (situação comum em tipos de amostragem intencional, quando se faz opção da seleção das observações por conveniência) e devido a endogeneidade (que, em geral é decorrência de viés de seleção, e pode ser interpretada como uma referência circular, em que uma variável $\mathrm{X}$ causa $\mathrm{Y}$ e vice-versa).

\section{4 .2 d-Separação}

Trata-se de um conceito muito famoso em Redes Bayesianas, uma vez que é a $d$-Separação que garante a independência condicional e direcional de um conjunto de variáveis aleatórias. Definição. Seja um $D A G \mathbb{G}=(V, E)$, com $A \subseteq V$, e $X$ e Y nós distintos em $V \cap A^{c}$. Diz-se que $X$ e $Y$ são direcionalmente-separados (d-separados) por $A$ em $\mathbb{G}$ se toda cadeia entre $X$ e $Y$ é bloqueado por $A$.

Não é complicado perceber que toda cadeia entre X e Y é bloqueada por A se, e somente se, toda cadeia simples entre X e Y é bloqueada por A. Neapolitan [2004] demonstra que a condição de Markov implica que todas as d-separações são independências condicionais, e 
todas as independências condicionais implicadas pela condição de Markov são identificadas pela d-separação. Ou seja, se $(\mathbb{G}, P)$ satisfaz a condição de Markov, toda d-separação em $\mathbb{G}$ é uma independência condicional em P. Mais ainda, toda independência condicional, que é comum a todas as distribuições de probabilidade satisfazendo a condição de Markov com o DAG $\mathbb{G}$, é identificada pela d-separação.

Agora, para fins de simplificação, suponha 3 nós, X, Y e Z e uma Rede Bayesiana $\mathbb{G}$, com X e Z d-separados, definindo, portanto, a seguinte conexão:

$$
X--Y--Z
$$

Há três casos a serem analisados, dependendo do sentido da ligação entre os nós, a saber:

1. $X \rightarrow Y \rightarrow Z$. Nesta situação, tem-se que $\mathrm{X}$ é independente de $\mathrm{Z}$, dado Y. A esta cadeia, dá-se o nome de corrente ou cadeia direta;

2. $X \leftarrow Y \rightarrow Z$. Nesta situação, tem-se que $\mathrm{X}$ é independente de $\mathrm{Z}$, dado $\mathrm{Y}$. A esta cadeia, dá-se o nome de forquilha ou bifurcação, e;

3. $X \rightarrow Y \leftarrow Z$. Nesta situação, tem-se que $\mathrm{X}$ e $\mathrm{Z}$ são dependentes, dado $\mathrm{Y}$. A esta cadeia, dá-se o nome de collider ou bifurcação invertida.

Assim, dois nós quaisquer são incondicionalmente independentes se ambos não possuírem o mesmo nó pai, o que equivale a dizer que entre os dois nós não há um nó dito collider. A seguir, uma importante implicação da d-separação.

Lema. Seja $P$ uma distribuição de probabilidade conjunta das variáveis aleatórias em $V$ e $\mathbb{G}=(V, E)$ um DAG. Então $(\mathbb{G}, P)$ satisfaz a condição de Markov se, e somente se, para todos os três subconjuntos disjuntos $A, B, C \subseteq V$, sempre que $A$ e $B$ forem d-separados por $C$, e $A$ e $B$ são condicionalmente independentes em $P$ dado $C$. Dessa forma, $(\mathbb{G}, P)$ satisfaz a condição de Markov se, e só se,

$$
I_{\mathbb{G}}(A, B \mid C) \Rightarrow I_{P}(A, B \mid C) .
$$

Demonstração. Ver Neapolitan [2004], pág. 74.

O que o lema anterior mostra é que se A e B são d-separados por C em $\mathbb{G}$, a condição de Markov implica em $I_{P}(A, B \mid C)$, o que representa independência também na distribuição conjunta. Devido a este fato, se a Rede Bayesiana satisfizer a condição de Markov, podese afirmar que ela representa um mapa de independência da distribuição conjunta de probabilidades $\mathrm{P}$.

É preciso verificar se poderia haver independências condicionais diferentes das identificadas pela d-separação que fossem implicadas pela condição de Markov. Neapolitan [2004] garante, com a demonstração do Teorema 2.1 (página 76), que todas as independências condicionais são identificadas pela d-separação no DAG $\mathbb{G}$.

\subsubsection{Equivalência de Markov}

As possibilidades de construção de Redes Bayesianas são inúmeras, bastando conectar as variáveis aleatórias duas a duas. Desta maneira, suponha que seja encontrada um DAG 
ótimo. A pergunta que surge, naturalmente, é: ela seria a única Rede Bayesiana que poderia ser ajustada ao conjunto de variáveis aleatórias? A definição anterior de d-separação não garante unicidade de solução: muitos DAGs são equivalentes no sentido de que elas possuem as mesmas d-separações. Como exemplo, a Figura 5.2 ilustra esta situação.
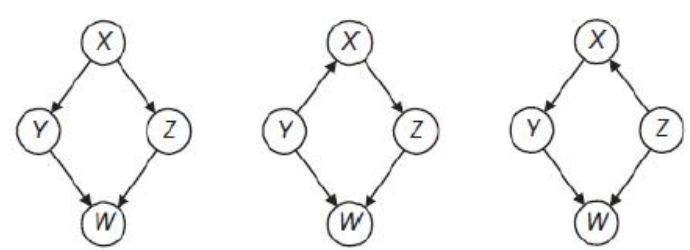

Figura 5.2: Um exemplo ilustrativo de equivalência de Markov.

É possível notar, a partir da Figura 5.2 que, supondo as 4 variáveis X, Y, Z, W com as Redes Bayesianas descritas na figura, o conjunto $\mathrm{X}, \mathrm{Y}$ tem duas d-separações, que podem ser escritas da seguinte maneira $I_{\mathbb{G}}(Y, Z \mid X)$ e $I_{\mathbb{G}}(X, W \mid Y, Z)$. Isso equivale a construir uma estrutura na qual não há direções de causalidade nos arcos, e, portanto, torna-se interessante em determinadas situações, em que os interesses recaem na construção das interligações, cujas ligações dão-se como variáveis aleatórias Bernoulli como, por exemplo, modelagem de epidemias (se um determinado indivíduo teve ou não contato com outro indivíduo infectado com certa doença) e construção de grupos sociais, entre outros. De qualquer modo, Neapolitan [2004] faz uma extensa revisão da chamada equivalência de Markov, com diversos teoremas que garantem equivalências de redes que possuam mesmas ligações, apesar de não terem o mesmo sentido.

No problema desta dissertação, a equivalência de Markov é bastante relevante, dado que o interesse recai em fazer a detecção da estrutura de ligação entre os mercados financeiros, para, em seguida, verificar padrões de contágio, que é o principal assunto desta dissertação. Uma vez identificados os padrões de espalhamento de uma crise, avalia-se o sentido direcional no qual se deu o contágio.

\subsubsection{Verificando dependências em uma Rede Bayesiana}

Até esta subseção foi verificado que a condição de Markov apenas implica independências, mas nada foi mencionado acerca do principal aspecto desejável para atingir o objetivo deste trabalho, que é garantir as dependências. Como consequência, diversas Redes Bayesianas não informativas que podem satisfazer as condições de Markov, podem ser ajustadas a um conjunto de dados.

Define-se um DAG completo $\mathbb{G}=(V, E)$ como um grafo em que há arcos para todos os pares de nós. Em geral, a condição de Markov implica não-independências no caso de um DAG completo $\mathbb{G}=(V, E)$, o que significa que $(\mathbb{G}, P)$ satisfaz a condição de Markov para toda distribuição de probabilidade $\mathrm{P}$ das variáveis em $\mathrm{V}$. Percebe-se, então, que $(\mathbb{G}, P)$ pode satisfazer a condição de Markov sem $\mathbb{G}$ informar nada sobre P.

Dada uma distribuição de probabilidades $\mathrm{P}$ das variáveis em algum conjunto $V$ e $(X, Y) \in$ $V$, diz-se que há uma dependência direta entre $\mathrm{X}$ e $\mathrm{Y}$ em $\mathrm{P}$ se $\mathrm{X}$ e $\mathrm{Y}$ forem não condicionalmente independentes dado qualquer subconjunto de V. O problema com a condição 
de Markov isolada é que ela implica que a ausência de um arco entre X e Y significa que não há dependência direta entre eles, mas não garante que a presença deste arco signifique que haja a dependência direta. A Figura 5.3 ilustra essa situação.

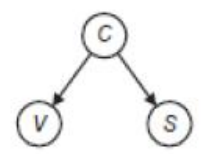

(a)

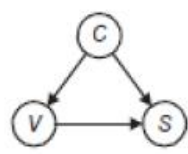

(b)

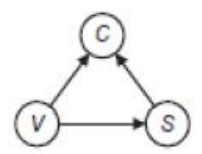

(c)

Figura 5.3: Um exemplo ilustrativo de distribuição de probabilidade que satisfaz a condição de Markov e d-separação.

A Figura 5.3 evidencia que em (a) não há arco entre V e S, e, portanto, eles são dseparados por C. Além disso, em (b), o arco entre V e S não significa que V e S sejam não independentes condicionalmente, dado C. Mas, de fato, eles podem ser.

Como, em geral, é desejável que um arco represente esta dependência direta, surge o conceito de fidedignidade, como a definição a seguir.

Definição. Suponha que se disponha de uma distribuição de probabilidades conjunta $P$ de variáveis aleatórias em certo conjunto $V$ e de um $D A G \mathbb{G}=(V, E)$. Diz-se que $(\mathbb{G}, P)$ satisfaz a condição de fidedignidade se, baseado na condição de Markov, $\mathbb{G}$ implicar todas e somente independências condicionais em P. Assim, as seguintes condições são válidas:

1. $(\mathbb{G}, P)$ satisfaz a condição de Markov, o que significa que $\mathbb{G}$ implica somente independências condicionais em $P$, e;

2. Todas as independências condicionais em P são implicadas por $\mathbb{G}$, baseadas nas condições de Markov.

Quando $(\mathbb{G}, P)$ satisfizer a condição de fidedignidade, diz-se que $\mathrm{P}$ e $\mathbb{G}$ são fidedignas umas a outras, e também é possível dizer que $\mathbb{G}$ é um mapa perfeito de P. Quando isso não for válido, elas são não-fidedignas umas a outras. Por não serem o objeto desta dissertação, maiores detalhes dos teoremas que garantem essa relação probabilística entre as Redes Bayesianas e as funções de probabilidade conjuntas podem ser obtidos em Neapolitan [2004], págs. 96 - 104.

Ainda há um conceito bastante importante a ser observado, que é a minimalidade. Uma Rede Bayesiana pode possuir independências que são escondidas por uma dada distribuição de probabilidades. Em alguns casos, um arco pode ser inútil, no sentido de não revelar uma dependência explícita, e, neste caso, este nó pode ser removido da rede. Em outras situações, um arco não pode ser retirado, uma vez que sua ausência, por todas as razões descritas até aqui, pode revelar uma falsa independência.

Desta maneira, diz-se que uma Rede Bayesiana é mínima se nenhum arco puder ser removido da estrutura. Vale notar que se um problema admitir uma rede fidedigna, então ela por consequência será mínima. No entanto, a volta pode não valer. Formalmente, tem-se 
a seguinte definição de minimalidade:

Definição. Suponha que se disponha de uma distribuição de probabilidades conjunta $P$ de variáveis aleatórias em certo conjunto $V$ e de um $D A G \mathbb{G}=(V, E)$. Diz-se que $(\mathbb{G}, P)$ satisfaz a condição de minimalidade se as duas condições a seguir são válidas:

1. $(\mathbb{G}, P)$ satisfaz a condição de Markov, e;

2. Se forem removidos quaisquer arcos de $\mathbb{G}$ e o DAG resultante não mais satisfizer as condições de Markov com P.

Tendo como exemplo, novamente, a Figura 5.3, pode-se ter uma idéia de como um DAG pode satisfazer a condição de minimalidade, mas sem ser fidedigno. Supondo que o DAG em (a) seja a única rede fidedigna a $P$, pode-se verificar que o caso (c) também satisfaz a condição de minimalidade em P. Se fosse o contrário, isto é, o DAG em (c) fosse a única situação fidedigna a $\mathrm{P}$, a afirmação não seria válida. Portanto, um DAG não pode ser fidedigno sem satisfazer a minimalidade com a distribuição. Neapolitan [2004] demonstra este teorema.

Um outro problema que pode surgir é: em tendo a Rede Bayesiana uma quantidade grande de nós, a probabilidade de um certo nó pode ser influenciada por um nó distante d-separado (por exemplo, "pelo pai do pai do pai"...). Desta maneira, pode ocorrer de um conjunto de nós fazer um certo nó $\mathrm{X}$ tornar-se condicionalmente independente de todos os demais nós da rede. A este conjunto de nós, dá-se o nome de cobertor de Markov, cuja definição formal é:

Definição. Seja $V$ um conjunto de variáveis aleatórias, $P$ sua função de probabilidade conjunta e $X \in V$. Então, um cobertor de Markov $M_{X}$ de $X$ é qualquer conjunto de variáveis tal que $X$ é condicionalmente independente de todas as outras variáveis dado $M_{X}$, que é

$$
I_{P}\left(X, V-\left(M_{X} \cup X\right) \mid M_{X}\right)
$$

Neapolitan [2004] apresenta um teorema cujo enunciado é:

Teorema. Suponha $(\mathbb{G}, P)$ satisfazendo a condição de Markov. Então, para cada variável $X$, o conjunto de todos os pais de $X$, descendentes de $X$ e pais de filhos de $X$ é um cobertor de Markov de X.

Demonstração. Ver Neapolitan [2004], pág. 108.

Ao conjunto $M_{X}$ mínimo dá-se o nome de limite de Markov. A seguir, um exemplo ilustrativo de como seria uma rede sem um cobertor de Markov.

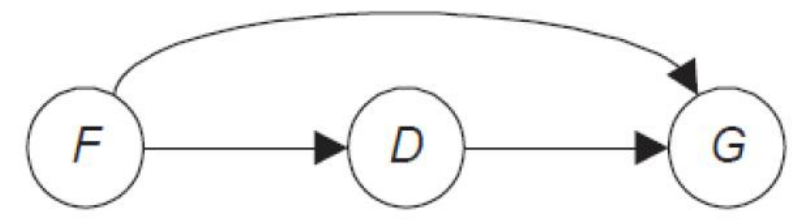

Figura 5.4: Um exemplo ilustrativo de inexistência de um cobertor de Markov. 
Na Figura 5.4, a variável $D$ não é um cobertor de Markov. No entanto, ela se torna ao se retirar a ligação $F \rightarrow G$ e ainda assim esta rede estará satisfazendo a condição de Markov.

\subsubsection{Mais sobre Redes Bayesianas causais}

Se for criada uma rede causal $\mathbb{G}=(V, E)$ e assumir que a distribuição de probabilidades das variáveis em $V$ satisfaz as condições de Markov com $\mathbb{G}$, pode-se dizer que está sendo feita uma premissa de causalidade de Markov. Quando foi falado de Arcos Causais, argumentou-se que poderia ser feito algum tipo de planejamento de experimento que controlasse a causalidade. Nesta subseção será discutida mais três premissas fundamentais para se dar validade à rede empírica que será ajustada aos dados.

A premissa de minimalidade causal

Se for criado um DAG causal $\mathbb{G}=(V, E)$ e assumir que a distribuição de probabilidade das variáveis $V$ satisfaz a condição de minimalidade com $\mathbb{G}$, pode-se dizer que se está assumindo a premissa de minimalidade causal, pois se $\mathrm{P}$ satisfaz a condição de minimalidade com $\mathbb{G}$, então P satisfaz a condição de Markov com $\mathbb{G}$. Portanto, a premissa de minimalidade causal presume a premissa causal de Markov.

Além disso, se for definida a causalidade, e, ainda que subjetivamente, válida a premissa causal de Markov, Neapolitan [2004] justifica ser possível esperar, em geral, que a premissa de minimalidade causal seja válida, e vai além: a única exceção aparente poderia ser a inclusão de um arco $X \Rightarrow Y$ quando $\mathrm{X}$ é apenas uma causa indireta para $\mathrm{Y}$, por meio de outras variáveis em $V$. Recorrendo ao exemplo demonstrado na Figura 5.3, o DAG poderia não ser uma descrição mínima da distribuição de probabilidades por ser possível retirar o arco $F \Rightarrow G$ e a condição de Markov ainda ser satisfeita. No entanto, se for definido que este DAG puder apenas conter relações causais diretas, o exemplo da Figura 5.3 não seria um DAG causal neste sentido. Portanto, dada essa definição de DAG causal, esta situação não é, de fato, uma exceção à premissa de minimalidade causal.

\section{A premissa de fidedignidade causal}

Se for criado um DAG causal $\mathbb{G}=(V, E)$ e pressuposto que a distribuição de probabilidade das variáveis $V$ satisfaz a condição de fidedignidade com $\mathbb{G}$, pode-se dizer que se está assumindo a premissa de fidedignidade causal, pois se $\mathrm{P}$ satisfaz a condição de fidedignidade com $\mathbb{G}$, então P satisfaz a condição de minimalidade com $\mathbb{G}$. Para tanto, a fidedignidade causal presume a minimalidade causal.

Além disso, se for definida a causalidade, e, ainda que subjetivamente, válida a premissa de minimalidade causal, Neapolitan [2004] justifica ser possível esperar, na maioria dos casos, que a premissa de fidedignidade causal seja válida e exemplifica: se a alteração em uma variável $\mathrm{X}$ leva a uma mudança na distribuição de probabilidades $\mathrm{Y}$ e a uma alteração na distribuição de probabilidade de $\mathrm{Z}$, então seria razoável não esperar que $\mathrm{Y}$ e $\mathrm{Z}$ fossem independentes, além de detectar causalidade de X em Y e Z.

Lembrando que quase sempre (se não sempre), é inviável acessar as verdadeiras relações, bem como a verdadeira distribuição conjunta dos dados e observação de variáveis ocultas, a eventual ausência de fidedignidade é, muitas vezes, inerente aos problemas.

\section{A premissa de fidedignidade causal incorporada}

Quando se falou de Arcos Causais neste trabalho, foram discutidos três problemas para a validade da premissa de causalidade. O primeiro é que não se pode haver causas comuns 
ocultas; o segundo e o terceiro estão, de certo modo, relacionados: viés de seleção e endogeneidade. Considerando que a fidedignidade causal presume a causalidade de Markov, há alguns problemas nesta primeira, em que o principal, segundo Neapolitan [2004], parece ser as causas ocultas comuns, por meio do viés de seleção.

Como exemplo, suponha que sejam identificadas as seguintes relações causais, por meio de um experimento:

$$
\begin{aligned}
& X \text { causa } Z \\
& Y \text { causa } W \\
& Z \text { causa } S \\
& W \text { causa } S
\end{aligned}
$$

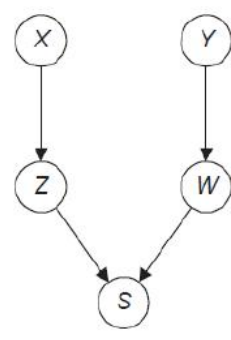

(a)

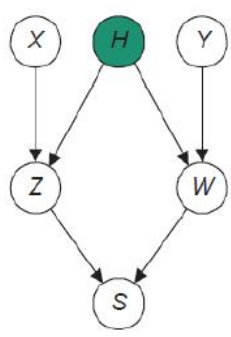

(b)

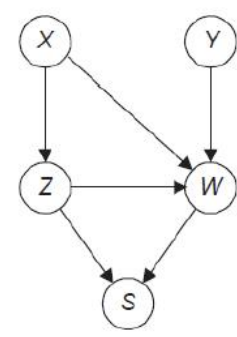

(c)

Figura 5.5: Um exemplo ilustrativo de como uma causa oculta pode afetar a fidedignidade da Rede Bayesiana.

Esta rede foi desenhada na parte (a) da Figura 5.5. Nela se pode reparar em algumas situações. Notadamente, a primeira é a própria situação descrita nas condições do exemplo, em que a condição de Markov implica que $I_{P}(Z, W)$ para esta rede. Na parte (b) foi incluída uma variável oculta comum, causando $Z$ e W, simultaneamente. Nesta situação, não seria esperada independência entre as variáveis $\mathrm{Z}$ e W. Mas se não for identificada esta causa comum, não seria esperado que fosse satisfeita a condição de Markov com a distribuição de probabilidades das variáveis, o que significa que não estaria satisfeita também a condição de fidedignidade com a distribuição.

No entanto, seria esperada a fidedignidade da Rede Bayesiana que contivesse todas as causas comuns ocultas possíveis. Voltando à parte (b) da Figura 5.5, se H fosse a única causa oculta possível, seria razoável que a distribuição de probabilidades das seis variáveis satisfizesse a condição de fidedignidade com a rede desenhada na Figura 5.5, o que significaria que a distribuição de probabilidades de X, Y, Z, W e S está fidedignamente incorporada na Rede Bayesiana. Se for assumida que a distribuição de probabilidades das variáveis observadas está fidedignamente incorporada em uma rede causal contendo essas variáveis e suas causas ocultas comuns, então diz-se que a premissa de fidedignidade causal incorporada é válida.

Vale notar, ainda na Figura 5.5, que foram acrescidos dois arcos adicionais na parte (a) para chegar na rede descrita na parte (c), com a inclusão de $X \Rightarrow W$ e $Z \Rightarrow W$. A 
distribuição de probabilidade de X, Y, Z, W e S satisfaria a condição de Markov com a rede resultante, uma vez que este DAG não implica $I_{P}(Z, W)$ ou quaisquer outras independências não implicadas pela parte (b). No entanto, há um problema com a parte (c): tem-se $I_{P}(X, W)$ e a figura evidencia que não há (pela ligação direta entre $\mathrm{X}$ e W). Isso significa que a rede descrita na parte (c) não é fidedigna à distribuição de probabilidades de X, Y, Z, W e S. Portanto, essa distribuição só pode ser incorporada pela rede da parte (b) da Figura 5.5.

Porém, independentemente disso, o DAG da parte (c) da Figura 5.5 é uma descrição mínima da distribuição apenas de X, Y, Z, W e S, e constitui uma Rede Bayesiana com a distribuição conjunta. Desta maneira, quaisquer inferências por meio de algoritmos para Redes Bayesianas são aplicáveis a um caso similar, apesar de não ser mais um DAG causal.

\subsection{Inferência em Redes Bayesianas}

A Inferência Estatística constitui um método estruturado e científico para a tomada de decisões a partir de valores observáveis, tendo uma medida de incerteza (probabilidades, não observáveis) acerca do fenômeno. A teoria bayesiana atribui à probabilidade um grau de crença, subjetivo, portanto, à veracidade de alguma proposição, o que se distingue fundamentalmente do que se convencionou chamar de teoria clássica.

Esta seção seguirá de perto a metodologia de Boettcher e Dethlefsen [2003].

\subsubsection{Aprendizagem dos parâmetros: a abordagem bayesiana}

Do ponto de vista estatístico, diz-se que o treinamento de uma rede corresponde à estimação de parâmetros do modelo, segundo algum critério e tendo o conhecimento de algum conjunto de dados. Para estimar os parâmetros em uma rede, usa-se a abordagem bayesiana, tendo como objetivo codificar a incerteza sobre parâmetros $\theta$ em uma distribuição a priori $p(\theta)$, e utilizando os dados $\underset{d}{d}$ (por meio da função de verossimilhança), atualiza-se a incerteza com a distribuição a posteriori $p(\theta \mid \underset{\sim}{d})$, usando o Teorema de Bayes:

$$
p(\theta \mid d)=\frac{p(d \underset{d}{d} \mid \theta) h(\theta)}{\int_{\theta \in \Theta} p(\underline{d} \mid \theta) h(\theta) d \theta}, \theta \in \Theta,
$$

em que $\Theta$ representa o espaço paramétrico, $\underset{\sim}{d}$ é a amostra aleatória da distribuição de probabilidades $p(X \mid \theta)$ da variável aleatória $\mathrm{X}$ e $p(d \mid \theta)$ é a função de verossimilhança. Por se tratar de um mecanismo de atualização, a Equação 5.6 será chamada de aprendizagem do parâmetro ou simplesmente aprendizagem.

Será assumido que os parâmetros associados a uma variável são independentes dos parâmetros relativos a outras variáveis e parâmetros são independentes de cada configuração dos pais discretos, isto é:

$$
p(\theta)=\prod_{\delta \in \Delta} \prod_{i_{p a(\delta)} \in I_{p} a(\delta)} p\left(\theta_{\delta \mid i_{p a(\delta)}}\right) \prod_{\gamma \in \Gamma} \prod_{i_{p a(\gamma)} \in I_{p a(\gamma)}} p\left(\theta_{\gamma \mid i_{p a(\gamma)}}\right)
$$

À Equação 5.7 referir-se-á como independência dos parâmetros. Esta equação garante 
ser possível a aprendizagem dos parâmetros de um determinado nó de modo independente dos parâmetros de outros nós, isto é, a atualização da distribuição a priori local $p\left(\theta_{v \mid i_{p a(v)}}\right)$ para cada nó (tanto discreto quanto contínuo) sem influência nas distribuições similares dos demais nós.

No problema específico desta dissertação, a suposição desde o início é a de distribuição contínua para cada uma das variáveis aleatórias, de tal forma que daqui por diante só serão feitas as definições do modo de cálculo e distribuições inerentes a esta classe de nós. A distribuição a priori para os parâmetros será a distribuição Normal Gamma-Inversa (NGI), devido à sua propriedade de conjugação ${ }^{9}$ com a distribuição Normal das observações, o que garante facilidade nos cálculos das distribuições a posteriori. A partir deste instante, a função Gamma-Inversa será generalizada para a versão multivariada, que é denotada por função Wishart-Inversa (WI) e sua definição é apresentada no Apêndice B.

Tais suposições não são absurdas, na medida em que, apesar de a Normal não ter sido aderente aos resíduos dos modelos ARMA-GARCH, eles acabaram por serem bem ajustados por uma distribuição t-Student, que é uma distribuição com muita similaridade a uma Normal, apenas possuindo curtose mais elevada. No Apêndice C estão apresentadas as demonstrações da conjugação da Normal e Gamma-Inversa (como versão univariada da WishartInversa) e, no Apêndice D, a construção da distribuição t-Student como uma mistura de Normal com uma Gamma-Inversa (novamente como versão univariada da Wishart-Inversa) para a sua variância.

Assumindo válida a premissa de conjugação, estabelecem-se as distribuições de probabilidades a priori de cada nó como regressões lineares, utilizando a seguinte parametrização:

$$
\theta_{\gamma \mid i_{p a(\gamma)}}=\left(m_{\gamma \mid i_{p a(\gamma)}}, \beta_{\gamma \mid i_{p a(\gamma)}}, \sigma_{\gamma \mid i_{p a(\gamma)}}^{2}\right),
$$

e, portanto,

$$
\left(Y_{\gamma} \mid i_{p a(\gamma)}, y_{p a(\gamma)}, \theta_{\gamma \mid i_{p a(\gamma)}}\right) \sim N\left(m_{\gamma \mid i_{p a(\gamma)}}+y_{p a(\gamma)} \beta_{\gamma \mid i_{p a(\gamma)}}, \sigma_{\gamma \mid i_{p a(\gamma)}}^{2}\right)
$$

Define-se $z_{p a(\gamma)}=\left(1, y_{p a(\gamma)}\right)$ e seja $\eta_{\gamma \mid i_{p a(\gamma)}}=\left(m_{\gamma \mid i_{p a(\gamma)}}, \beta_{\gamma \mid i_{p a(\gamma)}}\right)$, em que $m_{\gamma \mid i_{p a(\gamma)}}$ é o intercepto e $\beta_{\gamma \mid i_{p a(\gamma)}}$ é o vetor de coeficientes.

Uma vez especificadas as distribuições nó a nó, é preciso determinar a função conjunta de todos os nós da rede. Primeiramente deve-se calcular o vetor de médias p-variado $M_{p}$ e a matriz de variâncias-covariâncias $\Sigma_{p}$ das $p$ variáveis envolvidas no estudo. A matriz de covariâncias é dada por:

$$
\Sigma_{\gamma, p}=\Sigma_{p} \beta_{\gamma \mid p}
$$

em que $\beta_{\gamma \mid p}$ é um vetor coluna dos coeficientes da regressão dados por todos os nós calculados a priori. Todos os coeficientes são zero, exceto os correspondentes aos pais do nó, $\beta_{\gamma \mid i_{p a(\gamma)}}$. Assim, a média e a variância da função conjunta são dadas por:

$$
\begin{aligned}
& \Sigma_{\gamma}=\sigma_{\gamma \mid p a(\gamma)}^{2}+\Sigma_{\gamma, p} \beta_{\gamma \mid p}, \\
& M_{\gamma}=m_{\gamma \mid p a(\gamma)}+\beta_{\gamma \mid p}^{T} M_{p} .
\end{aligned}
$$

\footnotetext{
${ }^{9}$ Uma definição formal para esta propriedade é apresentada no Apêndice A.
} 
Na próxima subseção é apresentado o procedimento de Boettcher e Dethlefsen [2003], automatizado para a especificação das distribuições associadas a qualquer DAG possível, bem como o mecanismo de obtenção de distribuições a posteriori.

\subsubsection{O procedimento Master Prior}

Nesta subseção é mostrado como deduzir e atualizar as distribuições a priori dos parâmetros para as variáveis contínuas envolvidas no problema desta dissertação. Este procedimento é chamado de Master Prior.

A idéia básica é que, de uma dada Rede Bayesiana, pode-se deduzir todas as possíveis distribuições a priori para qualquer DAG. O funcionamento do algoritmo é o seguinte:

1. Especificar uma Rede Bayesiana a priori, isto é, estabelecer um DAG a priori e distribuições a priori para cada um de seus nós;

2. Calcular a distribuição de probabilidades a priori conjunta para todos os nós;

3. A partir desta distribuição conjunta, determinar a distribuição marginal de todos os parâmetros envolvidos, consistindo de um nó e seus pais. A este passo, dá-se o nome de distribuição Master Prior, e;

4. As distribuições a priori dos parâmetros para cada nó são determinadas pelo condicionamento na distribuição Master Prior.

Este procedimento garante independência entre os parâmetros. Além disso, ainda possui a propriedade de que, se um certo nó possuir o mesmo conjunto de pais em duas redes diferentes, então os parâmetros a priori para cada nó serão os mesmos nas duas redes. Portanto, o único problema consistirá em deduzir os parâmetros a priori para um nó dado o mesmo conjunto de pais apenas uma vez. Esta propriedade é chamada de modularidade do parâmetro.

Assumindo a premissa de normalidade para as distribuições de probabilidade de cada nó, Boettcher [2004] em sua tese de doutorado desenvolveu o procedimento de como encontrar os parâmetros a priori para cada nó. Seu algoritmo permite que a estimação possa ser feita tanto com variáveis discretas quanto contínuas. No entanto, como só o procedimento contínuo é do interesse desta dissertação, será desenvolvido apenas o caso contínuo Gaussiano.

Seja A um subconjunto de $\Gamma$ e B o complementar de A em $\Gamma$. Assim, calcula-se a média $m$ e a matriz de convariâncias $\Sigma$ amostrais em cada partição do espaço $\Gamma$. Se

$$
(y \mid m, \Sigma) \sim N(m, \Sigma),
$$

então

$$
\left(y_{A} \mid m, \Sigma\right) \sim N\left(m_{A}, \Sigma_{A A}\right)
$$

e

$$
\left(y_{B} \mid y_{A}, m_{B \mid A}, \beta_{B \mid A}, \Sigma_{B \mid A}\right) \sim N\left(m_{B \mid A}+\beta_{B \mid A} y_{A}, \Sigma_{B \mid A}\right)
$$


em que

$$
\begin{aligned}
\Sigma= & \left(\begin{array}{cc}
\Sigma_{A A} & \Sigma_{A B} \\
\Sigma_{B A} & \Sigma_{B B}
\end{array}\right), \quad \Sigma_{B \mid A}=\Sigma_{B B}-\Sigma_{B A}\left(\Sigma_{A A}^{-1}\right) \Sigma_{A B} \\
& m_{B \mid A}=m_{B}-\beta_{B \mid A} m_{A}, \quad \text { e } \quad \beta_{B \mid A}=\Sigma_{B A} \Sigma_{A A}^{-1} .
\end{aligned}
$$

Além disso, se

$$
m \mid \Sigma \sim N\left(\mu, \frac{1}{\nu} \Sigma\right) \quad \text { e } \quad \Sigma \sim W I(\rho, \Phi)
$$

em que a matriz $\Phi$ é particionada como $\Sigma$, então:

1. $\left(m_{A}, \mid \Sigma_{A A}\right) \sim N\left(\mu_{A}, \frac{1}{\nu} \Sigma_{A A}\right)$,

2. $\left(\Sigma_{A A}\right) \sim W I\left(\rho, \Phi_{A A}\right)$,

3. $\left(\Sigma_{B \mid A}\right) \sim W I\left(\rho+|A|, \Phi_{B \mid A}\right)$,

4. $\left(m_{B \mid A}, \beta_{B \mid A} \mid \Sigma_{B \mid A}\right) \sim N\left(\mu_{B \mid A}, \Sigma_{B \mid A} \otimes \tau_{B \mid A}^{-1}\right)$,

5. $m_{A}, \Sigma_{A A}$ independentes de $m_{B \mid A}, \beta_{B \mid A}$ e $\Sigma_{B \mid A}$,

em que:

$$
\begin{gathered}
\mu_{B \mid A}=\left(\mu_{B}-\Phi_{B A} \Phi_{A A}^{-1} \mu_{A}, \Phi_{B A} \Phi_{A A}^{-1}\right), \\
\tau_{B \mid A}^{-1}=\left(\begin{array}{rr}
\frac{1}{\nu}+\mu_{A}^{T} \Phi_{A A}^{-1} \mu_{A} & -\mu_{A}^{T} \Phi_{A A}^{-1} \\
-\Phi_{A A}^{-1} \mu_{A} & \Phi_{A A}^{-1}
\end{array}\right),
\end{gathered}
$$

e $\otimes$ denota o produto de Kronecker. A dimensão de $\mu_{B \mid A}$ é dado por $(|B|,|B| \times|A|)$.

Esse resultado mostra que é possível deduzir as distribuições de probabilidade para cada nó e suas distribuições a priori a partir das distribuições conjuntas. Além disso, devido à independência dos parâmetros, a função densidade de probabilidade conjunta a priori para qualquer rede Gaussiana pode ser especificada como produto de prioris individuais.

DeGroot [1970] mostra que uma distribuição Gaussiana-Wishart Inversa é conjugada a observações de uma distribuição Gaussiana (apresentada no Apêndice C). Assim, tomada a distribuição de probabilidade e suas prioris já definidas e dado um conjunto de observações $d=y_{1}, \ldots, y_{n}$, as distribuições a posteriori são:

$$
(m \mid \Sigma, d) \sim N\left(\mu^{\prime}, \frac{1}{\nu^{\prime}} \Sigma\right) \quad \text { e } \quad(\Sigma \mid d) \sim W I\left(\rho^{\prime}, \Phi^{\prime}\right)
$$

em que

$$
\begin{gathered}
\nu^{\prime}=\nu+n, \\
\mu^{\prime}=\frac{\nu \mu+n \bar{y}}{\nu+n}, \\
\rho^{\prime}=\rho+n, \\
\Phi^{\prime}=\Phi+S Q+\frac{\nu n}{\nu+n}(\mu-\bar{y})(\mu-\bar{y})^{T},
\end{gathered}
$$


com $n$ representando o tamanho amostral, $\bar{y}=\frac{1}{n} \sum_{i=1}^{n} y_{i}$ e $S Q=\left(y_{i}-\bar{y}\right)\left(y_{i}-\bar{y}\right)^{T}$. Os elementos $\nu$ e $\rho$ são estimados a partir do tamanho de uma amostra imaginária, de treinamento da rede. O racional desta amostra imaginária provém da noção da confiança que o pesquisador tem na estrutura de dependência definida na Rede Bayesiana a priori: quanto maior for a confiança na subjetividade, maior deverá ser o $\nu$.

A partir das Equações dadas em 5.10, nota-se que $\nu^{\prime}$ e $\rho^{\prime}$ são atualizados com função do número de observações na base de dados. Já $\mu^{\prime}$ é uma combinação linear entre a média $\mu$ a priori e a média $\bar{y}$ amostral, ponderadas por seus respectivos pesos. Finalmente, $\Phi$ é atualizada pela soma dos quadrados, que representa os desvios observacionais em torno da média amostral e o quanto a média a priori difere da média amostral.

Para especificar a Master Prior, é preciso atribuir valores iniciais a cada parâmetro $\nu, \mu, \rho, \Phi$ e uma estrutura inicial para a Rede Bayesiana. Em seguida, a função densidade de probabilidade conjunta a priori $p(y \mid m, \Sigma) \sim N(m, \Sigma)$ pode ser deduzida. No entanto, se a média $m$ e a matriz de variâncias-covariâncias $\Sigma$ forem calculadas de uma base de dados imaginária, então eles são as próprias médias e covariâncias amostrais. Se for assumido, ainda, que o pesquisador é totalmente ignorante sobre os parâmetros, as fórmulas das Equações 5.10 poderiam ser utilizadas para "atualizar"os parâmetros artificialmente, da seguinte maneira:

$$
\mu=m \quad \text { e } \quad \Phi=S Q=(\nu-1) \Sigma .
$$

\subsubsection{A seleção da melhor estrutura para a Rede Bayesiana}

Nesta subseção, será mostrado como o procedimento aprende a estrutura para o DAG a partir dos dados e como selecionar a melhor rede ajustada ao conjunto de observações. Esta seção seguirá de perto a abordagem de Boettcher [2004].

Existem diversos critérios e algoritmos para avaliar a melhor estrutura em redes para um certo conjunto de variáveis aleatórias. Algumas dessas abordagens são descritas em Neapolitan [2004].

Como medida de quão bem um DAG $\mathbb{G}$ representa as independências condicionais entre as variáveis aleatórias, utiliza-se a medida

$$
S(\mathbb{G})=p(\mathbb{G}, d)=p(d \mid \mathbb{G}) p(\mathbb{G}),
$$

que será chamada de função score da rede.

Boettcher e Dethlefsen [2003] argumentam que esta medida pode ser fatorada, quando dispomos de um problema misto, em uma parte discreta e outra parte contínua. Novamente, apenas será apresentado o caso contínuo, de interesse desta dissertação.

Para um nó contínuo $\gamma$, o seu score é avaliado como:

$$
\begin{aligned}
S_{\gamma}(\mathbb{G}) & =\prod_{i_{p a(\gamma)} \in I_{p a(\gamma)}} \frac{\Gamma\left(\frac{n+\rho_{\gamma \mid i_{p a}(\gamma)}}{2}\right)}{\Gamma\left(\frac{\rho_{\gamma \mid i_{p a(\gamma)}}}{2}\right) \sqrt{\operatorname{det}\left(\rho_{\gamma \mid i_{p a(\gamma)}} s_{\gamma \mid i_{p a(\gamma)}} \pi\right)}} \times \\
\times & {\left[1+\frac{1}{\rho_{\gamma \mid i_{p a(\gamma)}}} a_{\gamma \mid i_{p a(\gamma)}} s_{\gamma \mid i_{p a(\gamma)}}^{-1} a_{\gamma \mid i_{p a(\gamma)}}^{T}\right]^{-\frac{\rho_{\gamma \mid i_{p a(\gamma)}}}{2}}, }
\end{aligned}
$$


em que:

$$
\begin{gathered}
s_{\gamma \mid i_{p a(\gamma)}}=\frac{\phi_{\gamma \mid i_{p a(\gamma)}}}{\rho_{\gamma \mid i_{p a(\gamma)}}}\left(I+z_{p a(\gamma)}^{b} \tau_{\gamma \mid i_{p a(\gamma)}}^{-1}\left(z_{p a(\gamma)}^{b}\right)^{T}\right), \\
a_{\gamma \mid i_{p a(\gamma)}}=y_{\gamma \mid i_{p a(\gamma)}}^{b}-z_{p a(\gamma) \mid i_{p a(\gamma)}}^{b} \mu_{\gamma \mid i_{p a(\gamma)}} .
\end{gathered}
$$

Vale notar que o score da Rede Bayesiana é fatorado em um produto envolvendo apenas um nó e seus pais. Esta propriedade é chamada de decomposição. Além disso, por razões computacionais, é aplicado o logaritmo neperiano.

Pode ser demonstrado que os scores calculados de dois DAGs equivalentes (que informam a mesma independência condicional) são equivalentes. Essa propriedade é chamada de equivalência das verossimilhanças e é uma propriedade do procedimento Master Prior.

Na busca pelo melhor modelo de rede para ajustar a função conjunta, o pesquisador depara-se com um número fatorialmente crescente de redes possíveis à medida que o número de nós aumenta e, com isso, fica impossível avaliar os scores de todos os DAGs possíveis. Como é preciso escolher a rede com o maior valor para o score, faz-se necessário criar um método de busca. Em Boettcher e Dethlefsen [2003], os autores implementam um método eficiente chamado greedy search with random starts baseado em Heckerman et al. [1995].

Uma forma de comparar o score de duas redes distintas $\mathbb{G}$ e $\mathbb{G}^{*}$ é calculando a chance das posterioris, dada por:

$$
\frac{p(\mathbb{G} \mid \underset{d}{d})}{p\left(\mathbb{G}^{*} \mid \underline{d}\right)}=\frac{p(\mathbb{G}, \underset{c}{d})}{p\left(\mathbb{G}^{*}, d\right)}=\frac{p(\mathbb{G})}{p\left(\mathbb{G}^{*}\right)} \times \frac{p(\underset{d}{d} \mid \mathbb{G})}{p\left(\underline{d} \mid \mathbb{G}^{*}\right)},
$$

em que $\frac{p(\mathbb{G})}{p\left(\mathbb{G}^{*}\right)}$ é a chance das prioris e $\frac{p(d \mid \mathbb{G})}{p\left(d \mid \mathbb{G}^{*}\right)}$ é o fator de Bayes. Como, em geral, a distribuição a priori será a mesma para a estrutura inicial da rede, a chance das prioris será igual a 1 e, pela igualdade da Equação 5.13, pode-se comparar o ganho obtido em adotar uma rede tanto pela chance das posterioris quanto pelo fator de Bayes. De qualquer modo, a fim de facilitar os cálculos computacionais, toma-se o logaritmo do critério adotado e optar-se-á pela rede que fornecer um ganho positivo.

Na busca greedy search são comparadas as Redes Bayesianas que diferem por apenas um arco, seja ele adicionado, removido ou invertido. Nestas situações, o fator de Bayes a ser calculado é simples, uma vez que o score da rede pode ser decomposto. Este método funciona da seguinte maneira:

1. Selecione um DAG inicial $\mathbb{G}_{0}$, do qual a busca começará;

2. Calcule o fator de Bayes entre $\mathbb{G}_{0}$ e todas as possíveis redes que diferirem por apenas um arco, e faça:

(a) Um arco é adicionado a $\mathbb{G}_{0}$;

(b) Um arco em $\mathbb{G}_{0}$ é removido;

(c) Um arco em $\mathbb{G}_{0}$ é invertido;

3. Entre as três redes geradas em (2), selecione aquela que maximizar o fator de Bayes;

4. Se o fator de Bayes não for aumentado, pare a busca. Caso contrário, atualiza-se $\mathbb{G}_{0}$ com a rede escolhida e repita os passos a partir de (2). 
O algoritmo de busca pode também ser usado com recomeços heurísticos, cujo método consiste em perturbar a rede inicial com algum parâmetro pré-definido, após a aplicação do método da busca greedy search, além de poder definir a quantidade de vezes que este procedimento poderá ser executado. Esta perturbação é executada da seguinte maneira:

1. Escolha aleatoriamente uma entre as seguintes ações:
(a) Inserir um arco;
(b) Remover um arco;
(c) Inverter um arco;

2. Após a seleção, execute a ação seguindo:

(a) Se o procedimento escolhido em (1) for Inserir, então escolha aleatoriamente entre todas as possibilidades de inserção de um arco;

(b) Se o procedimento escolhido em (1) for Remover, então escolha aleatoriamente entre todas as possibilidades de remoção de um arco;

(c) Se o procedimento escolhido em (1) for Inverter, então escolha aleatoriamente entre todas as possibilidades de inversão de um arco.

Para acelerar o método de busca, o algoritmo desenvolvido em Boettcher e Dethlefsen [2003] utiliza uma relação de equivalência das Redes Bayesianas. Para a descrição do método, suponha dois DAGs distintos $\mathbb{G}_{1}$ e $\mathbb{G}_{1}^{*}$ que diferem por apenas um arco entre os nós $v$ e $w$, com $w \rightarrow v$ em $\mathbb{G}_{1}$ e $w \rightarrow v$ em $\mathbb{G}_{1}^{*}$. Desta maneira, o fator de Bayes para testar um arco de $v$ para $w$ é equivalente a testar este arco em qualquer outra rede, desde que $v$ tenha os mesmos pais que tinha na rede $\mathbb{G}_{1}$.

Uma vez armazenadas em uma lista as tentativas para cada nó da rede, os autores garantem que esta consulta é computacionalmente menos custosa do que executar o procedimento de aprendizagem todas as vezes. No entanto, eles ressaltam que a lista é refeita quando se altera o tamanho da base imaginária ou o banco de dados.

\subsubsection{Observações sequenciais}

Em diversos experimentos, os elementos amostrais podem ser obtidos de maneira sequencial, isto é, um por vez, de modo ordenado. No caso específico desta dissertação tem-se naturalmente este fenômeno, uma vez que se trata de uma série temporal, isto é, um processo ordenado pelo tempo, e cada observação é diária. Além disso, é assumido que as crises ocorreram em subperíodos disjuntos e conhecidos desde o período inicial contemplado até o último instante acompanhado por este estudo. Diante desta situação, é relevante avaliar a melhor forma de atualizar a incerteza sobre os parâmetros à medida que vão sendo coletadas as unidades amostrais.

Sendo a observação $d_{1}$ a primeira realização do processo $D_{t}$ a função densidade de probabilidade a posteriori é calculada usando a relação de Bayes, como já descrito pela Equação 5.6:

$$
p\left(\theta \mid d_{1}\right) \propto f\left(d_{1} \mid \theta\right) h(\theta) .
$$


Esta função densidade de probabilidade, na realidade, serve como distribuição a priori para o parâmetro $\theta$ antes de se observar o segundo elemento $d_{2}$. Assim, depois que se dispuser do elemento $d_{2}$, tem-se que a função atualizada para $\theta$ é dada por:

$$
p\left(\theta \mid d_{1}, d_{2}\right) \propto f\left(d_{2} \mid \theta\right) p\left(\theta \mid d_{1}\right) .
$$

Mas, substituindo (5.14) em (5.15), recursivamente, tem-se que:

$$
p\left(\theta \mid d_{1}, d_{2}\right) \propto f\left(d_{2} \mid \theta\right) p\left(\theta \mid d_{1}\right) \propto f\left(d_{2} \mid \theta\right) f\left(d_{1} \mid \theta\right) h(\theta) .
$$

Por indução e recursão, é possível continuar este processo até que seja possível observar a n-ésima observação, como segue:

$$
\begin{aligned}
p(\theta \mid \underset{\sim}{d}) & =p\left(\theta \mid d_{1}, d_{2}, \ldots, d_{n}\right) \propto f\left(d_{n} \mid \theta\right) p\left(\theta \mid d_{1}, \ldots, d_{n-1}\right) \propto \\
& \propto f\left(d_{n} \mid \theta\right) f\left(d_{n-1} \mid \theta\right) \ldots f\left(d_{2} \mid \theta\right) f\left(d_{1} \mid \theta\right) h(\theta) .
\end{aligned}
$$

Este procedimento demonstra que a função densidade de probabilidade a posteriori para $\theta$ é a mesma, independentemente de serem utilizados todos os elementos amostrais de uma vez ou subconjuntos de modo sequencial.

\subsection{Resultados}

Tal como executado em capítulos anteriores, a partir dos resíduos de cada um dos modelos ARMA(1,1)-GARCH(1,1) univariados apresentados no Capítulo 3, procedeu-se o ajuste das Redes Bayesianas apresentadas neste capítulo.

Em conformidade com a definição dos períodos de tranquilidade e crises, particionou-se a base de dados em 11 momentos e, de modo sequencial, estimou-se uma Rede Bayesiana para cada um dos momentos, de tal forma que o período 1 sirva como estrutura a priori para os eventos (verossimilhanças) do período 2. Utilizando o procedimento bayesiano, esta combinação resulta em uma estrutura a posteriori, que servirá como priori para o período subsequente (momento 3) e assim por diante, até o período 11. O tamanho da base imaginária foi 5 , de tal forma a minimizar o peso da subjetividade na estrutura inicial da Rede Bayesiana.

Como já apresentada no Capítulo 3, a descrição de cada partição é dada a seguir: 
Tabela 5.1: Partição da base de dados para o desenvolvimento sequencial da Rede Bayesiana.

\begin{tabular}{ccccc}
\hline Períodos & Descrição & Início & Fim & Quantidade de observações \\
\hline 1 & Tranquilidade & $08 / 10 / 1996$ & $02 / 07 / 1997$ & 145 \\
2 & Crise Asiática & $03 / 07 / 1997$ & $26 / 01 / 1998$ & 117 \\
3 & Tranquilidade & $27 / 01 / 1998$ & $26 / 04 / 1998$ & 49 \\
4 & Crise da Rússia & $27 / 04 / 1998$ & $16 / 12 / 1998$ & 133 \\
5 & Tranquilidade & $17 / 12 / 1998$ & $04 / 01 / 1999$ & 6 \\
6 & Crise do Brasil & $05 / 01 / 1999$ & $03 / 03 / 1999$ & 30 \\
7 & Tranquilidade & $04 / 03 / 1999$ & $20 / 11 / 2001$ & 534 \\
8 & Crise da Argentina & $21 / 11 / 2001$ & $30 / 12 / 2002$ & 208 \\
9 & Tranquilidade & $31 / 12 / 2002$ & $16 / 09 / 2008$ & 1134 \\
10 & Crise dos EUA & $17 / 09 / 2008$ & $13 / 03 / 2009$ & 89 \\
11 & Tranquilidade & $14 / 03 / 2009$ & $30 / 12 / 2009$ & 163 \\
\hline & Total & $08 / 10 / 1996$ & $30 / 12 / 2009$ & 2608
\end{tabular}

A seguir serão apresentadas as figuras dos resultados ${ }^{10}$ das estruturas estimadas por meio do procedimento sequencial de obtenção das Redes Bayesianas. A presença de arcos entre os países denota interdependência entre eles e as setas, a direção da dependência. Já o critério para a detecção de contágio financeiro, em conformidade à definição adotada para este trabalho no Capítulo 2, será a observação de existência de quaisquer mudanças na estrutura de dependência condicional de um dado país no momento de uma crise, relativamente ao período anterior, com ausência de crise. Isto é, se com o advento de uma crise observa-se a criação ou alteração de sentido de um arco, têm-se evidência de contágio.

Por fim, as estimativas dos parâmetros podem ser encontradas no Apêndice E.

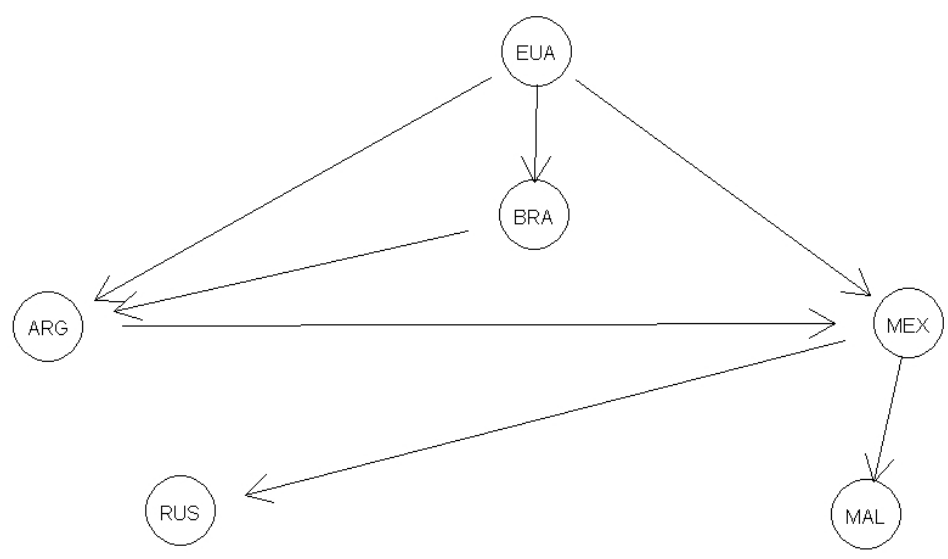

Figura 5.6: Rede Bayesiana no período anterior à crise asiática, até $199 \%$.

\footnotetext{
${ }^{10}$ Todos os resultados de procedimentos empíricos deste capítulo foram obtidos no software $\mathrm{R}$ versão 2.10 .1 .
} 


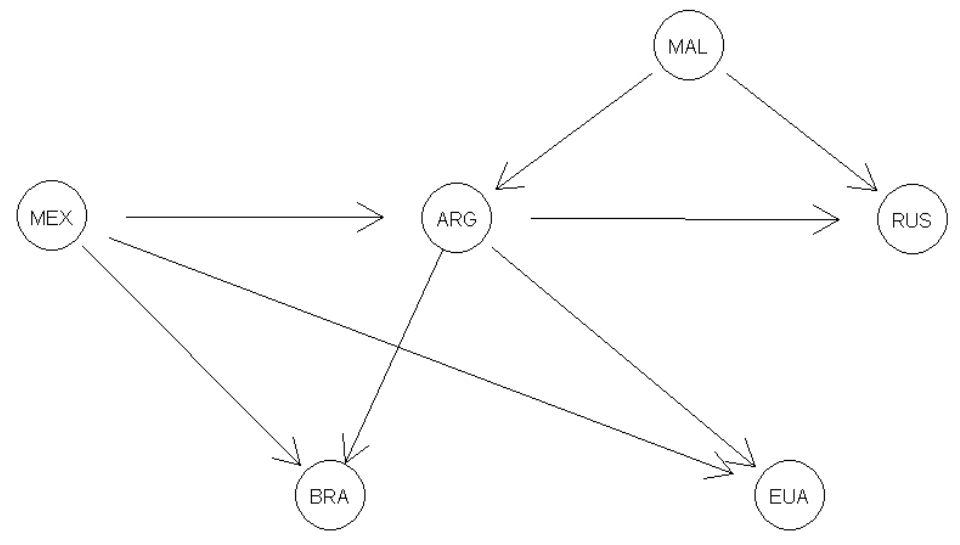

Figura 5.7: Rede Bayesiana durante a crise asiática, em 1997.

Comparando as Figuras 5.6 e 5.7, percebe-se que há oito evidências de contágio. Com o advento da crise asiática, houve a criação de arcos da Malásia para a Rússia e também para a Argentina. A partir da Argentina, criou-se um arco para a Rússia e alterou-se a relação de sentido com os EUA e com o Brasil: com a crise, a Argentina passa a afetar os três países. Assim, a Argentina propaga a crise de forma secundária, tornando-se um cobertor de Markov para a Malásia ser d-separada dos EUA e do Brasil, isto é, a Malásia é condicionalmente independente dos EUA e do Brasil, dada a Argentina. Já a relação da Argentina e da Rússia parece ser endógena, uma vez que a Malásia não funciona como condicionador para a independência entre os dois países. É a típica cadeia do tipo forquilha.

Além disso, o México também passou a exercer um papel de destaque: este país passa a ser um nó pai para o Brasil, por meio da criação de um arco entre ambos, e para a Argentina e EUA, a partir de alteração de sentido do arco já existente. A cadeia entre EUA, México, Brasil e Argentina mostra uma forte relação entre estes países neste período de crise, pois o México é um nó forquilha para a Argentina, os EUA e o Brasil, sendo estes dois últimos nós collider para México e Argentina. 


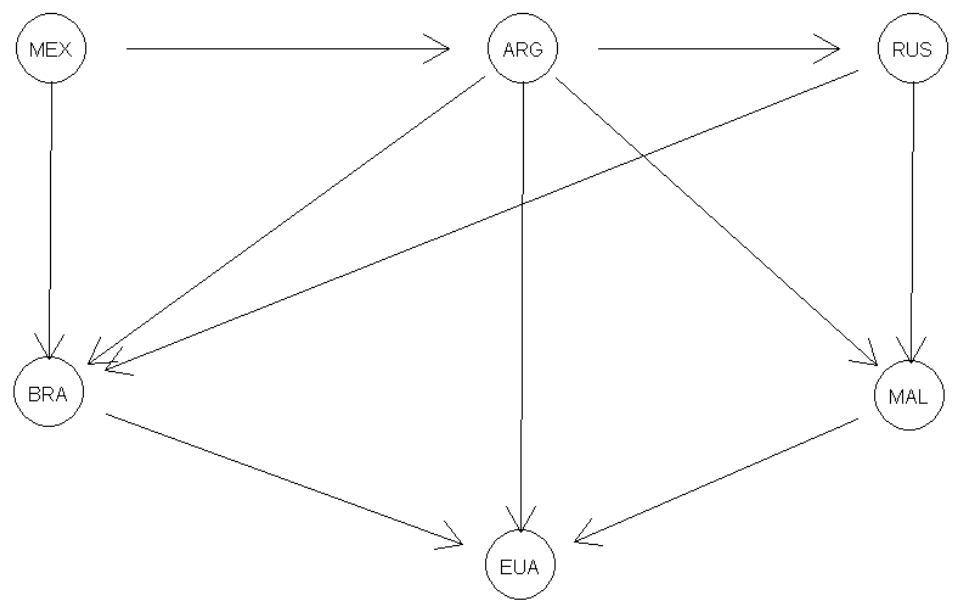

Figura 5.8: Rede Bayesiana no período anterior à crise russa, até 1998.

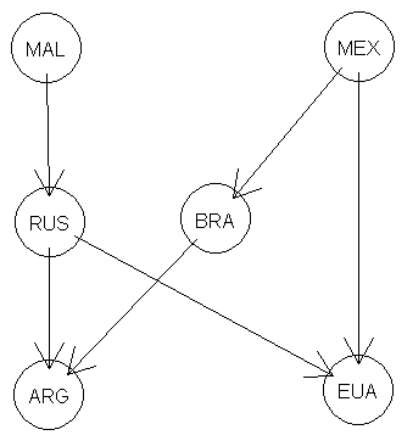

Figura 5.9: Rede Bayesiana durante a crise russa, 1998.

Observando as Figuras 5.8 e 5.9, nota-se que a crise russa apresentou menos evidências de contágio do que a crise asiática, com 2 novas conexões e alteração de 3 ligações préexistentes. A Rússia foi a maior propagadora de contaminação, uma vez que ela tornou-se um nó pai para os EUA, ao criar um arco entre estes países, e para a Argentina, com a alteração de sentido do arco. No entanto, é possível notar que os demais países emergentes também sofreram reflexos, uma vez que foi criado um arco entre México (emissor) e EUA, e alterados os sentidos de dois arcos (Malásia - emissor - para a Rússia e Brasil - emissor - para 
a Argentina). Portanto, a Rússia funciona como um cobertor de Markov entre a Malásia e os EUA e Argentina. Desta forma, a Argentina e os EUA são condicionalmente independentes da Malásia e também entre si dada a Rússia.

Uma cadeia característica das Redes Bayesianas pode ser identificada entre a Rússia, Argentina e Brasil: trata-se de uma cadeia do tipo collider, uma vez que Brasil e Rússia são condicionalmente independentes dada a Argentina. Da mesma maneira, a cadeia entre Rússia, México e EUA, em que a Rússia é condicionalmente independente do México, dados os EUA.

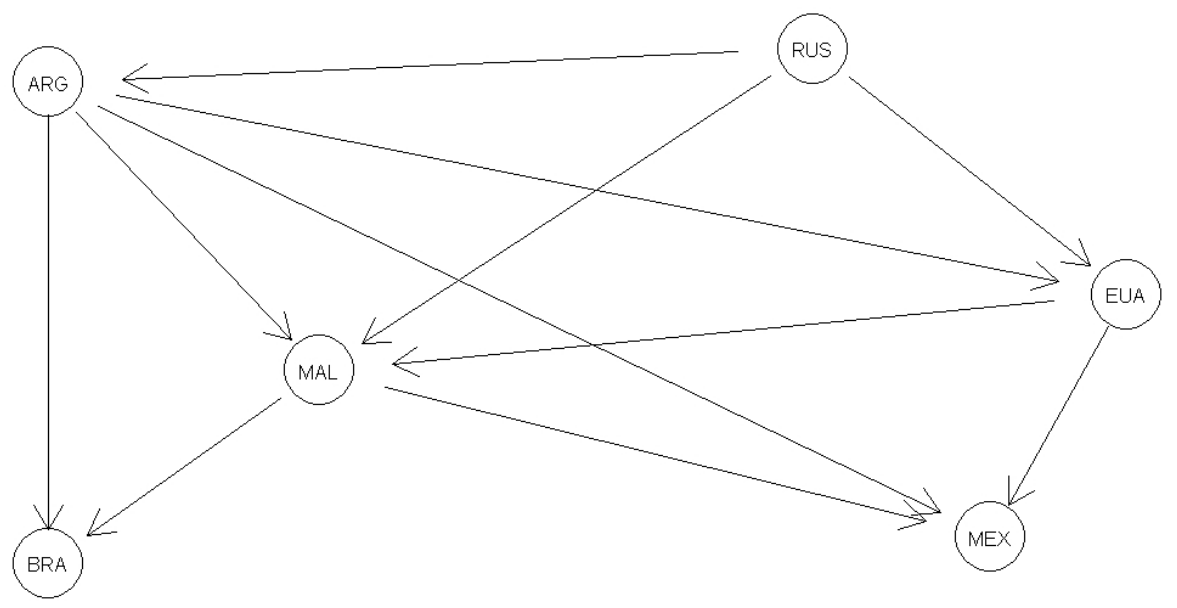

Figura 5.10: Rede Bayesiana no período anterior à crise brasileira, até 1999.

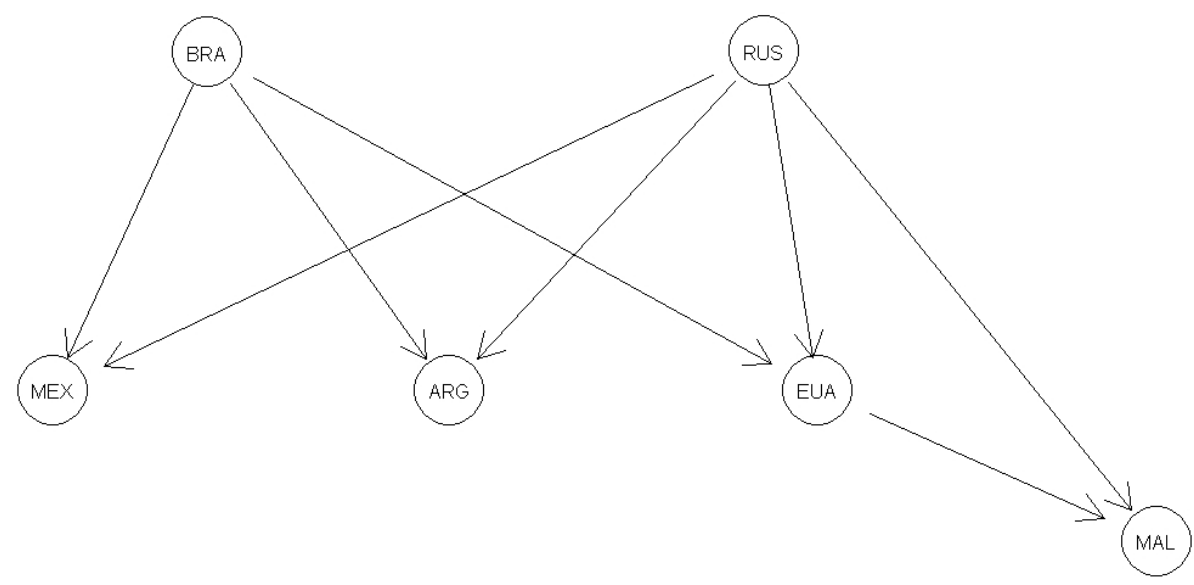

Figura 5.11: Rede Bayesiana durante a crise brasileira, em 1999. 
A partir das Figuras 5.10 e 5.11 é possível inferir que a crise brasileira apresentou um grau ainda menor de contágio do que as crises já descritas, com apenas quatro situações distintas em relação ao período anterior. Tendo o Brasil como epicentro, este país passou a ser nó pai da Argentina (com alteração de sentido do arco), do México e dos EUA, de modo que para estes dois últimos, criaram-se arcos direcionais. Adicionalmente, foi criado um arco da Rússia em direção ao México, de tal forma que o Brasil e a Rússia tornam-se condicionalmente independentes entre si, dado o México, que é um nó collider. Este fato evidencia que a propagação ficou restrita, com exceção da Rússia, a apenas um grupo de países, sem que houvesse propagação secundária.

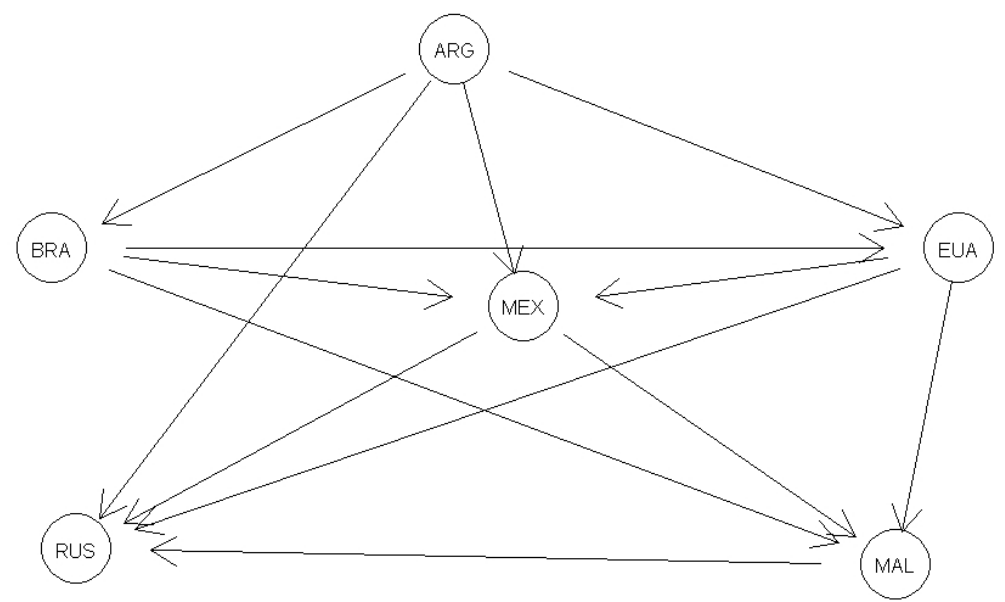

Figura 5.12: Rede Bayesiana no período anterior à crise argentina, até 2001. 


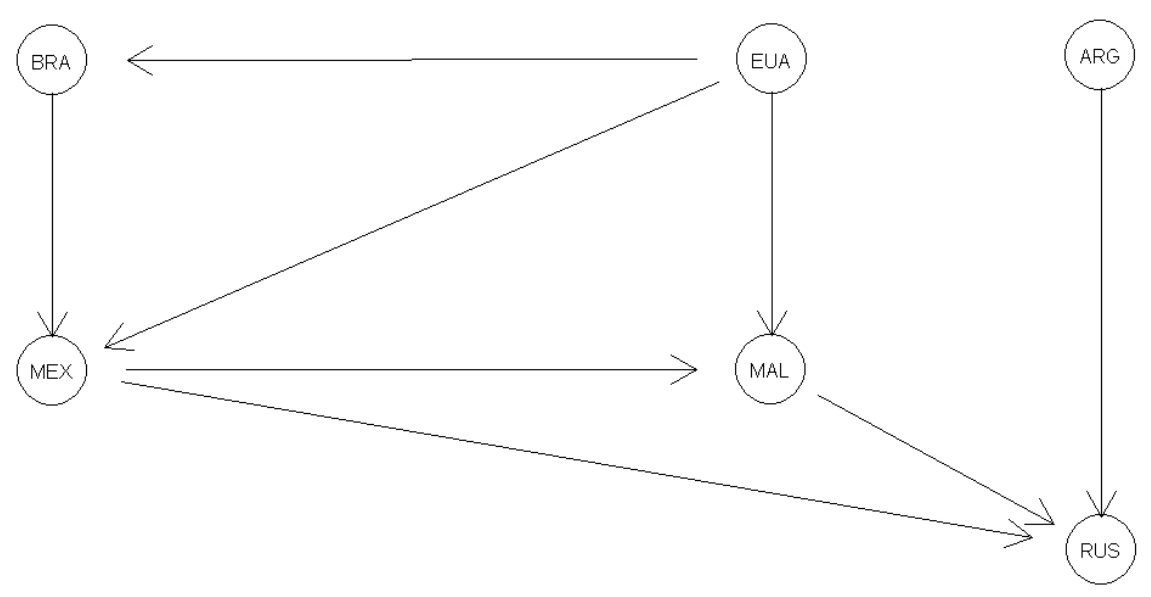

Figura 5.13: Rede Bayesiana durante a crise argentina, em 2001.

Por meio das Figuras 5.12 e 5.13, nota-se que a crise argentina mostrou um isolamento da Argentina, evidenciado pela exclusão de todos os arcos, à exceção de sua ligação com a Rússia, que já existia antes da ocorrência da crise e, portanto, não evidencia um contágio financeiro.

Esta foi a crise com menor proporção, visto que a única evidência de contágio foi a alteração de sentido do arco entre EUA e Brasil, tendo os EUA como nó pai. Como a única evidência de contágio desta crise não está na Argentina, faz-se necessária uma conjectura acerca desta ocorrência. Uma possível explicação para a existência deste contágio é a desconfiança dos investidores nos mercados argentino e de seus parceiros comerciais. Desta maneira, os investidores optaram por realocar seus investimentos para títulos mais seguros, como os do tesouro americano, em detrimento dos papéis especulativos na bolsa brasileira. 


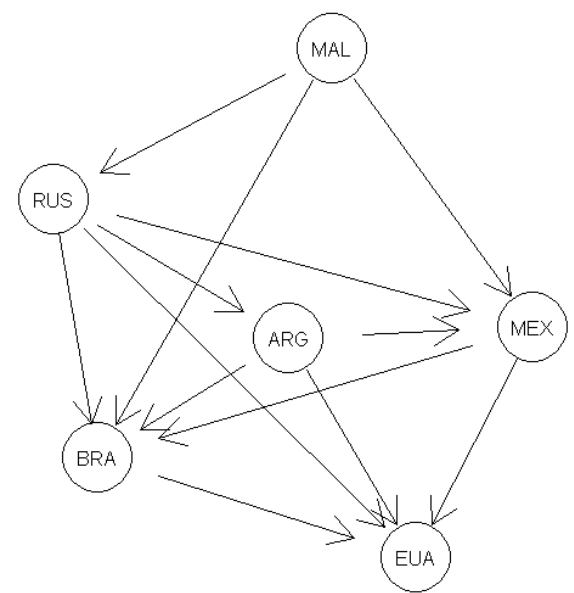

Figura 5.14: Rede Bayesiana no período anterior à crise dos EUA, até 2008.

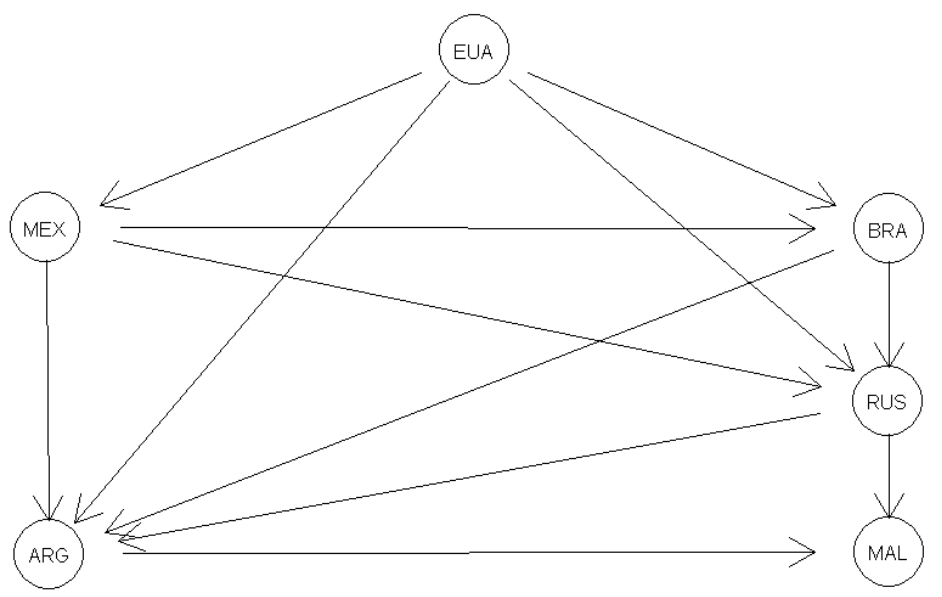

Figura 5.15: Rede Bayesiana durante a crise dos EUA, em 2008.

A crise do subprime, de acordo com as Figuras 5.14 e 5.15, mostrou-se a maior propagadora de contágio financeiro durante o período analisado, corroborando a opinião da imprensa especializada em Economia de que se tratou de uma das piores crises da história ${ }^{11}$.

\footnotetext{
${ }^{11}$ Diversas publicações nacionais e internacionais da imprensa apresentam citações similares, entre outras: reportagem da edição de 10/mar/2009 no sítio da BBC na internet, a edição de 18/set/2008 do diário The Wall Street Journal e, no Brasil, um artigo de 09/jul/2010 da revista Veja.
} 
Como mostra a Figura 5.14, os EUA, considerados o epicentro desta crise, já eram bastante interligados com os outros mercados. Apesar de serem, tradicionalmente, receptores de crises (como já comentado anteriormente, os EUA aparecem como contaminados nas crises asiática, russa e brasileira), durante esta crise os EUA são o principal emissor, tendo como receptores o Brasil, a Argentina, o México e a Rússia, todos com alteração de sentido do arco em relação ao período anterior.

Algumas contaminações secundárias puderam ser observadas, a maioria com alteração de sentido do arco. O México passou a propagar para a Rússia e Argentina; O Brasil também tornou-se responsável por propagar para a Argentina e para a Rússia. Todavia, como é possível perceber pela teoria das Redes Bayesianas, tanto o Brasil quanto o México não se tornaram cobertores de Markov entre EUA e o grupo formado por Argentina e Rússia. Desta maneira, estes três países não são d-separados por Brasil e México, de tal forma que essa propagação foi causada diretamente pelos EUA e esses contágios podem ser considerados endógenos.

Finalmente, contaminações indiretas ocorreram. A Malásia pode ser considerada condicionalmente independente dos EUA, dadas as transmissões a partir da Argentina e da Rússia, sendo esses dois países cobertores de Markov entre Malásia e EUA, que são, portanto, d-separados.

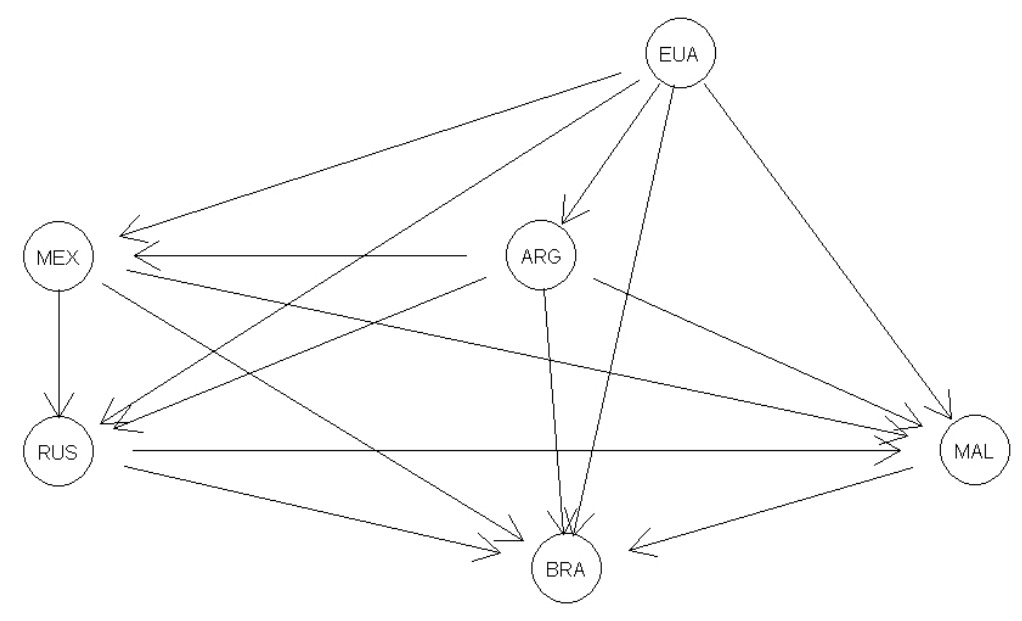

Figura 5.16: Rede Bayesiana para o período final da amostra, até o fim de 2009.

Uma característica que pode ser identificada nas Redes Bayesianas mostradas nas Figuras 5.6 a 5.16 é a forte interligação entre os mercados em períodos posteriores a crises financeiras, sugerindo a existência de preferência por diversificação de portfólio. Outros fatores que podem ter colaborado com esse fenômeno são o aumento do grau de abertura dos mercados financeiros dos países analisados durante o período considerado, e avanços recentes nos meios de comunicação e de pagamento, facilitando a obtenção de informações e a realização de transações entre países. 
A seguir, será feito um resumo dos contágios detectados pela metodologia das Redes Bayesianas.

Tabela 5.2: Períodos de crise em que foram encontrados os contágios financeiros entre cada par de paises.

\begin{tabular}{cccccc}
\hline & ARG & MEX & EUA & MAL & RUS \\
\hline BRA & Ásia; Rússia; Brasil & Ásia; Brasil & Brasil; Argentina; EUA & - & EUA \\
ARG & & Ásia; EUA & Ásia; EUA & Ásia; EUA & Ásia; Rússia \\
MEX & & & Ásia; Rússia; EUA & - & Brasil; EUA \\
EUA & & & & - & Rússia; EUA \\
MAL & & & & & Ásia; Rússia; EUA \\
\hline
\end{tabular}

O corpo da Tabela 5.2 está preenchido com os períodos de crises financeiras, em conformidade com as descrições apresentadas na Tabela 5.1. A partir do resumo apresentado nesta tabela, percebe-se que houve evidências de contágio financeiro para todos os pares de países, com a notória exceção dos pares formado pela Malásia e pelo grupo Brasil, México e $E U A$, exatamente os mesmos pares que se mostraram não-significantes no modelo GARCH multivariado apresentado no Capítulo 3 e fracamente correlacionados nos modelos de cópulas no Capítulo 4.

Ademais, os pares de países que apresentaram contágio financeiro em mais períodos de crises foram os mesmos que apresentaram os mais altos valores dos parâmetros estimados pelas cópulas e também foram os parâmetros mais fortemente significantes no modelo GARCH multivariado. Todos esses elementos reforçam os resultados obtidos pelas Redes Bayesianas, o que sugere boa aderência deste modelo ao conjunto de dados utilizados neste estudo.

Finalmente, o país mais envolvido com contágios financeiros foi a Argentina, com 12 evidências ao todo (4 como emissor e 8 como receptor), seguida pela Rússia, com 10 contaminações (4 como emissor e 6 como receptor), pelo Brasil com 10 (6 como emissor e 4 como receptor) e pelos EUA também com 10 ( 5 como emissor e 5 como receptor). O México esteve envolvido em 9 situações de contágio (6 como emissor e 3 como receptor) e a Malásia em apenas 5 (3 como emissor e 2 como receptor). Esta consolidação demonstra que o grupo formado por Brasil, Argentina, México e EUA foi responsável por 73,2\% dos contágios identificados (dos quais $75 \%$ como emissores) e, portanto, são mercados fortemente interligados. 


\section{Capítulo 6}

\section{Conclusões}

\subsection{Considerações Finais}

Neste trabalho buscou-se modelar a estrutura de interdependência entre mercados financeiros de uma maneira distinta da usualmente abordada pela literatura clássica do tema, utilizando redes bayesianas. Foram utilizados os modelos GARCH multivariados e modelos de cópulas estáticas para verificar a necessidade de modelagem conjunta da estrutura de dependência, tal qual encontra-se na literatura. Os resultados apontaram para a existência de movimentos conjuntos que deveriam ser investigados com cautela, apesar de não ser possível detectar o causador de mudanças estruturais. Tais causadores de mudanças nas estruturas condicionais, no entanto, foram facilmente observados por meio das redes bayesianas.

Nota-se que as redes bayesianas fornecem, de um modo geral, uma boa aderência à realidade, uma vez que encontram grande respaldo nas descrições das crises apresentadas na literatura, bem como em resultados obtidos neste e em outros trabalhos. Desta forma, esta metodologia constitui-se na principal contribuição acadêmica deste trabalho.

Com relação aos aspectos de modelagem encontrados no presente trabalho, após a análise descritiva das séries realizou-se, em cada uma delas, uma filtragem univariada a fim de eliminar eventuais distorções que poderiam atrapalhar as estimativas obtidas pelos modelos de cópulas e redes bayesianas. Em seguida, seguindo sugestão clássica da literatura, selecionouse a melhor estrutura de correlação - DVEC $(1,1)$ - para um modelo GARCH multivariado ajustado aos resíduos dos ARMA-GARCH univariados, que detectou diversos movimentos conjuntos entre os mercados. Percebeu-se que quase todos os parâmetros foram significantes: das 69 estimativas, apenas 5 delas mostram-se pouco importantes, todas associadas à Malásia e ao grupo formado por EUA, México e Brasil, fato corroborado posteriormente pelas cópulas e redes bayesianas.

Em seguida, no modelo de cópulas bivariadas ficou evidente a presença de estrutura de dependência cruzada entre algumas séries, evidenciando que há agrupamentos de influência, fato que mostrou a necessidade de se adotar técnicas adequadas para mensurar o condicionamento das variáveis aleatórias, cuja escolha não pode ser, necesariamente, ad-hoc, como encontrado na literatura. Desta maneira, tendo um país recebido a influência de algum choque, pode retransmiti-lo, por meio de uma contaminação indireta em alguns passos, a outros países, causando a interdependência entre os mercados. Este evento pode não ser capturado caso o condicionamento inicial do país propagador de crise seja escolhido de maneira errada. 
Visando encontrar um condicionamento ótimo para a propagação de crises nos mercados, buscou-se a metodologia das redes bayesianas. Com os períodos de crise bem definidos e método calcado na teoria de inferência bayesiana, executou-se uma análise sequencial, em que as realidades que precediam períodos de crise foram consideradas situações a priori para os eventos (verossimilhanças). Desta combinação resulta a nova realidade (a posteriori), que serve como priori para o período subsequente e assim por diante. Os resultados apontaram para grande interligação entre os mercados e diversas evidências de contágio em períodos de crise financeira, com causadores bem definidos e com grande respaldo na literatura.

Não obstante, os pares de países que apresentaram evidências de contágio financeiro nas redes bayesianas em mais períodos de crises foram os mesmos que apresentaram os mais altos valores dos parâmetros das cópulas estimadas e também os mais fortemente significantes no modelo GARCH multivariado. Assim, os resultados obtidos pelas redes bayesianas tornamse mais relevantes, o que sugere boa aderência deste modelo ao conjunto de dados utilizados neste estudo. Por fim, verificou-se que, após as diversas crises, os mercados estavam muito mais conectados do que no período inicialmente adotado.

Destaca-se a impossibilidade de decretar relações de causa e efeito nas evidências encontradas neste trabalho, uma vez que são inúmeros os motivos (sejam eles objetivos, como taxas de câmbio ou juros, ou subjetivos, como a confiança de investidores) que podem influenciar na volatilidade dos índices de bolsas de valores, e qualquer que seja a causa, esta seria considerada uma variável oculta para a Rede Bayesiana. Desta maneira, é preciso ter cautela ao realizar inferências sobre a causalidade das redes aqui apresentadas, sendo esta a principal limitação deste estudo.

\subsection{Sugestões para Pesquisas Futuras}

Como sugestão para pesquisas futuras está o tratamento dinâmico dos parâmetros, atualmente estáticos, dos modelos da rede bayesiana, tratamento este que poderá proporcionar a inclusão de estruturas autorregressivas a fim de não necessitar de filtragem prévia univariada nas séries, o que pode retirar parte da dependência intrínseca. Como metodologia, pode-se citar o algoritmo desenvolvido por Lèbre [2009], que propõe um tratamento dinâmico de redes bayesianas, com a inclusão de parâmetros autorregressivos de ordem 1. Embora o contexto desenvolvido tenha sido o da Genética, parece ser bastante adequada a mera substituição das expressões temporais dos genes por evolução dos log-retornos dos mercados de diferentes países.

Convém, para o futuro, estudos incorporando variáveis exógenas, de modo a tornar as redes, de fato, causais, por meio da aplicação de modelos de espaços de estados ou cadeias de Markov ocultas, com particular ênfase no estudo de variáveis ocultas. Além disso, o tratamento por meio de cópulas dinâmicas multivariadas ainda necessita de bastante desenvolvimento, embora um grande passo parece ter sido dado em Abbara [2009]. Uma abordagem bayesiana para a atualização dos parâmetros dinâmicos de cópulas não deve ser ignorada e pode representar grande avanço na área.

Finalmente, pode-se pensar na inclusão de mais países na rede, da mesma maneira que é válido estudar outros mercados, como a dinâmica entre setores de uma economia, e análise integrada de riscos de mercado, crédito, liquidez, judicial, entre outros. 


\section{Apêndice A}

\section{Conjugação}

A família de distribuição a priori escolhida deve satisfazer alguns pré-requisitos, conforme Paulino et al. [2003] explicita:

- Versatilidade para acomodar o maior número possível de crenças a priori;

- Acessibilidade interpretativa para facilitar o processo de resumir os seus membros;

- Simplicidade da derivação analítica das distribuições a posteriori e preditivas.

No entanto, estes requisitos não são geralmente satisfeitos conjuntamente: é possível ter versatilidade matemática mas sem interpretações. A simplicidade da operação bayesiana poderá ser garantida se for imposta a seguinte definição: a família de distribuições a priori $\mathcal{H}$ é fechada sob amostragem de $\mathcal{P}=p(x \mid \theta): \theta \in \Theta$, de tal forma que:

$$
h(\theta) \in \mathcal{H} \Rightarrow h(\theta \mid x) \propto h(\theta) p(x \mid \theta) \in \mathcal{H}
$$

Nestas condições, diz-se que $\mathcal{H}$ é uma família conjugada de $\mathcal{F}$.

No entanto, o requisito apresentado pela Equação A.1 é muito genérico, pois acomoda a família de todas as distribuições. Assim, há a necessidade de estreitar um pouco mais a definição. Seja $\mathcal{H}=h(\theta \mid a): a \in \mathcal{A}$, em que $\mathcal{A}$ representa o conjunto de hiperparâmetros das distribuições. Desta maneira, $\mathcal{H}$ é fechada sob amostragem de $\mathcal{F}$ se $L(\theta \mid x) \propto f(x \mid \theta)$, para cada $\mathrm{x}$, é proporcional a um membro de $\mathcal{H}$ e $\mathcal{H}$ é fechada em relação a produtos, isto é, para todo $a_{0}, a_{1} \in \mathcal{A}$, existe $a_{2} \in \mathcal{A}$ tal que:

$$
h\left(\theta \mid a_{0}\right) h\left(\theta \mid a_{1}\right) \propto h\left(\theta \mid a_{2}\right)
$$

Diz-se, assim, que a família $\mathcal{H}$ é conjugada natural de $\mathcal{F}$. 


\section{Apêndice B}

\section{A distribuição Wishart e sua inversa}

Suponha que $\underset{\sim}{X}, \ldots, \underset{\sim}{X}{ }_{k}$ sejam k vetores aleatórios p-dimensionais e independentes dois a dois. Cada $\underset{\sim}{X}$ tem uma distribuição Normal p-variada de média $\underset{\sim}{0}$ e uma matriz de covariâncias $\underset{\sim}{ }$ de dimensão $p \times p$. Seja $\underset{\sim}{V}$ uma matriz aleatória simétrica de deminsão $k \times k$ definida por:

$$
V=\underset{\sim}{X} \underset{\sim}{X}{\underset{\sim}{T}}_{1}^{T}+\underset{\sim}{X} \underset{\sim}{X}+\ldots+\underset{\sim}{X}{ }_{k} \underset{\sim}{X}
$$

Assim, diz-se que $\mathrm{V}$ tem uma distribuição Wishart com $\mathrm{k}$ graus de liberdade e matriz paramétrica $\underset{\sim}{\Sigma}$.

Vale ressaltar que $\underset{\sim}{ }$ é positiva definida se, e somente se, ela for não-singular. Se $k>p-1$ e $\underset{\sim}{\sum}$ for positiva definida, a distribuição de Wishart é dita não-singular. Neste caso, a matriz de precisão T é definida por:

$$
T=\sum_{\sim}^{-1}
$$

Nessas condições, a sua função densidade de probabilidade é dada por:

$$
f(v \mid p, k, \underset{\sim}{\Sigma})=c(p, k)\left|\sum\right|^{\frac{-k}{2}}|v|^{\frac{k-p-1}{2}} \exp \left[-\frac{1}{2} \operatorname{tr}\left(\sum_{\sim}^{-1} v\right)\right],
$$

em que $t r$ é a função traço e

$$
c(p, k)=\left[2^{\frac{p k}{2}} \pi^{\frac{p^{2}-p}{4}} \prod_{i=1}^{p} \Gamma\left(\frac{k+1-i}{2}\right)\right]^{-1} .
$$

Esta função densidade é denotada por $V \sim W(v, k, T)$.

Como casos particulares, se $p=1$, então a $V \sim \operatorname{Gamma}\left(v, k / 2,1 / 2 \sigma^{2}\right)$. Se $p=1$ e $v=1$, então $V \sim \chi_{(p)}^{2}$.

\section{A distribuição Wishart Inversa}

Se $V \sim W(v, k, \underset{\sim}{\Sigma})$, então $B=V^{-1}$ segue uma distribuição Wishart Inversa $B \sim$ $W I\left(b, k, \Sigma^{-1}\right)$, com função densidade de probabilidade dada por:

$$
f\left(b \mid \sum, k\right)=c(p, k)\left|\sum\right|^{\frac{k}{2}}|v|^{-\frac{(k+p+1)}{2}} \exp \left[-\frac{1}{2} \operatorname{tr}\left(\sum v^{-1}\right)\right],
$$


em que $t r$ é a função traço e

$$
c(p, k)=\left[2^{\frac{p k}{2}} \pi^{\frac{p^{2}-p}{4}} \prod_{i=1}^{p} \Gamma\left(\frac{k+1-i}{2}\right)\right]^{-1} .
$$

Supondo que se deseje realizar inferências sobre a matriz de covariâncias $\underset{\sim}{\Sigma}$, cuja distribuição a priori é uma Wishart Inversa $B \sim W I\left(b, k, \Sigma^{-1}\right)$. Se o vetor de observações $\underset{\sim}{X}=\left(x_{1}, \ldots, x_{n}\right)$ são variáveis aleatórias provenientes de uma distribuição Normal p-variada de vetor de médias $\underset{\sim}{0}$ e matriz de covariâncias $\underset{\sim}{\sum}$, então a distribuição condicional $p\left(\underset{\sim}{\sum} \mid \underset{\sim}{X}\right) \sim$ $W I\left(a, k+n, \sum^{-1}+\underset{\sim}{X} \underset{\sim}{X}{ }^{T}\right)$.

Devido ao fato de que as distribuições a priori e a posteriori pertencem à mesma família, diz-se que a distribuição Wishart Inversa é conjugada à Gaussiana multivariada. Por conta desta conjugação, é possível integrar $\underset{\sim}{X}$ no parâmetro $\underset{\sim}{\Sigma}$, como a seguir:

$$
P\left(\underset{\sim}{X} \mid \Sigma^{-1}, k\right)=\int P(\underset{\sim}{X} \mid \Sigma) P\left(\sum^{-1} \mid \Sigma^{-1}, k\right) d \sum=\frac{\mid \sum_{\sim}^{\mid \frac{k}{2}} \Gamma_{p}\left(\frac{k+n}{2}\right)}{\pi^{\frac{n p}{2}}\left|\sum^{-1}+\underset{\sim}{X} X^{T}\right|^{\frac{k+n}{2}} \Gamma_{p}\left(\frac{k}{2}\right)}
$$




\section{Apêndice C}

\section{A distribuição Normal-Gamma Inversa}

Considere o modelo amostral $\mathcal{F}=N\left(\mu, \sigma^{2}\right): \mu \in \mathbb{R}, \sigma^{2}>0$, com ambos os parâmetros desconhecidos, fazendo parte da família exponencial biparamétrica com parâmetros naturais $\alpha_{1}=\frac{\mu}{\sigma^{2}}$ e $\alpha_{2}=-\left(2 \sigma^{2}\right)^{-1}$ (acoplados a $x$ e $\left.x^{2}\right)$ e $c(\theta)=\left(\sigma^{2}\right)^{1 / 2} \exp \left[-\frac{\mu}{\left(2 \sigma^{2}\right)}\right]$.

Pela forma da função de verossimilhança de uma amostra aleatória de tamanho n, tem-se:

$$
L\left(\mu, \sigma^{2} \mid \underset{x}{x}\right) \propto[c(\theta)]^{n} \exp \left[\frac{\mu}{\sigma^{2}} \sum_{i=1}^{n} x_{i}-\frac{1}{2 \sigma^{2}} \sum_{i=1}^{n} x_{i}^{2}\right]
$$

Desta maneira, deduz-se que a família conjugada natural é definida por:

$$
\begin{aligned}
h\left(\mu, \sigma^{2} \mid b_{0}, b_{1}, b_{2}\right) & \propto\left(\frac{1}{\sigma^{2}}\right)^{1 / 2} e^{-b_{0} \frac{\mu^{2}}{2 \sigma^{2}}+b_{1} \frac{\mu}{\sigma^{2}}} \times\left(\frac{1}{\sigma^{2}}\right)^{\frac{b_{0}-1}{2}} e^{\frac{-b_{2}}{2 \sigma^{2}}} \propto \\
& \propto\left(\frac{1}{\sigma^{2}}\right)^{1 / 2} e^{-\frac{b_{0}}{2 \sigma^{2}}\left(\mu-\frac{b_{1}}{b_{0}}\right)^{2}} \times\left(\frac{1}{\sigma^{2}}\right)^{\frac{b_{0}-3}{2}+1} e^{-\frac{b_{2}+\frac{b_{1}^{2}}{b_{0}}}{2 \sigma^{2}}}
\end{aligned}
$$

para $b_{0}>3, b_{1} \in \mathbb{R}, b_{2}>0$. Essa fatorização é tal que a distribuição condicional de $\mu \mid \sigma^{2}$ é a Normal $N\left(a_{1}, \frac{\sigma^{2}}{a_{0}}\right)$ e a distribuição marginal de $\sigma^{2}$ é a Gamma Inversa $G I\left(\frac{a_{0}-3}{2}, a_{2}\right)$, em que $a_{0}=b_{0}, a_{1}=\frac{b_{1}}{b_{0}}$ e $a_{2}=\frac{1}{2}\left(b_{2}+\frac{b_{1}^{2}}{b_{0}}\right)$. Essa distribuição conjunta $h\left(\mu, \sigma^{2} \mid b_{0}, b_{1}, b_{2}\right)$ é denominada Normal-Gamma Inversa. 


\section{Apêndice D}

\section{A distribuição t-Student}

A distribuição t-Student univariada, cuja notação usual é dada por $t_{k}(\lambda, \delta)$ é unimodal e simétrica, indexada por três parâmetros, os quais seguem: $k$, maior que zero, são os graus de liberdade, $\lambda$ é o parâmetro de localização que indica a moda e a mediana e o parâmetro de escala $\delta$, também estritamente positivo, que informa a dispersão. Sua função densidade de probabilidade é dada por:

$$
f_{Z}(z)=\frac{1}{B(k / 2,1 / 2) \sqrt{k} \delta}\left[1+\frac{(z-\lambda)^{2}}{k \delta^{2}}\right]^{-\frac{k+1}{2}},
$$

de tal modo que $\mathrm{B}(.,$.$) é a função beta de Euler. Vale ressaltar que se \mathrm{k}>1$, então $E(Z)=\lambda$ e $\operatorname{Var}(Z)=\frac{k \delta^{2}}{k-2}$, se $\mathrm{k}>2$. Como caso particular desta distribuição, $t_{1}(\lambda, \delta)$ se trata da distribuição Cauchy.

Prova-se que utilizando uma transformação conveniente, a qual seja $T=\frac{(Z-\lambda)}{\delta}$, define a chamada $t$-Student padrão, $t_{k}(0,1)$, com função densidade de probabilidade dada por:

$$
f_{T}(t)=\frac{1}{B(k / 2,1 / 2) \sqrt{k}}\left[1+\frac{(t)^{2}}{k}\right]^{-\frac{k+1}{2}} .
$$

Além disso, é possível demonstrar que a distribuição t-Student é uma mistura de distribuições Normais com uma Gama Inversa para sua variância. Deste modo:

$$
\left.\begin{array}{r}
Z \mid(\lambda, v, W) \sim N(\lambda, W / v) \\
W \sim G I(a, b)
\end{array}\right\} \Rightarrow Z \mid(\lambda, v, a, b) \sim t_{2 a}\left(\lambda, \sqrt{\frac{b}{a v}}\right) .
$$

Reparametrizando $a=\frac{k}{2}$ e $b=\frac{k c}{2}$, tem-se que $Z \mid(\lambda, k, c) \sim t_{k}(\lambda, \delta), \operatorname{com} \delta=\sqrt{\frac{c}{v}}$. Finalmente, a função densidade conjunta de $\mathrm{Z}$ e $\mathrm{W}$ possui um núcleo da forma:

$$
f_{Z, W}(z, w) \propto\left(\frac{1}{w}\right)^{\frac{a+1}{2+1}} \exp \left\{-\left[b+\frac{v}{2}(z-\lambda)^{2}\right] / w\right\}
$$

cuja denominação é distribuição Normal-Gama Inversa e sua notação é dada por $(Z, W) \sim$ $N G I(\lambda, v, a, b)$. 
Apêndice E

Estimativas dos parâmetros das redes bayesianas 
Tabela E.1: Parâmetros estimados da rede bayesiana pré-crise asiática.

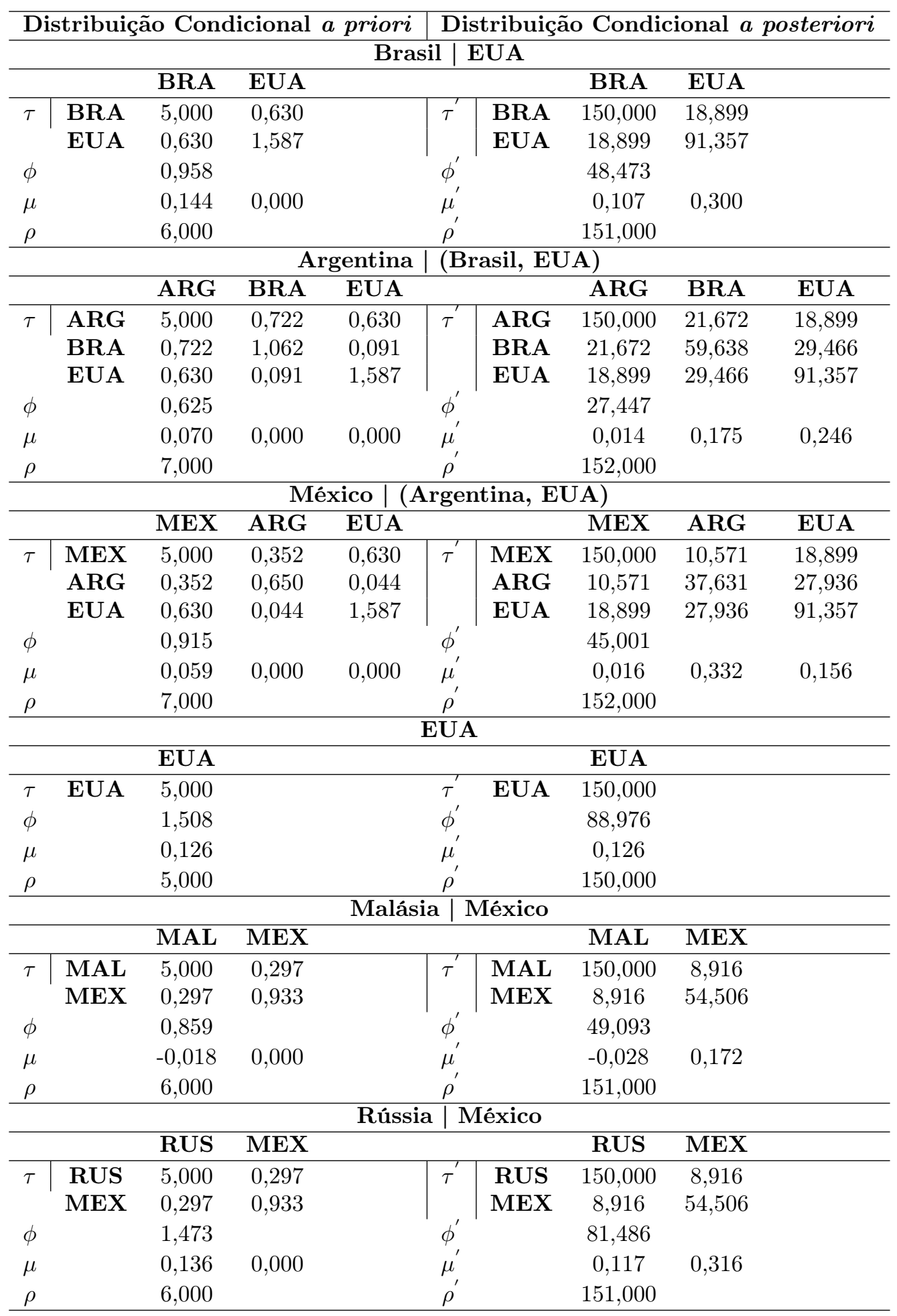


Tabela E.2: Parâmetros estimados da rede bayesiana durante a crise asiática.

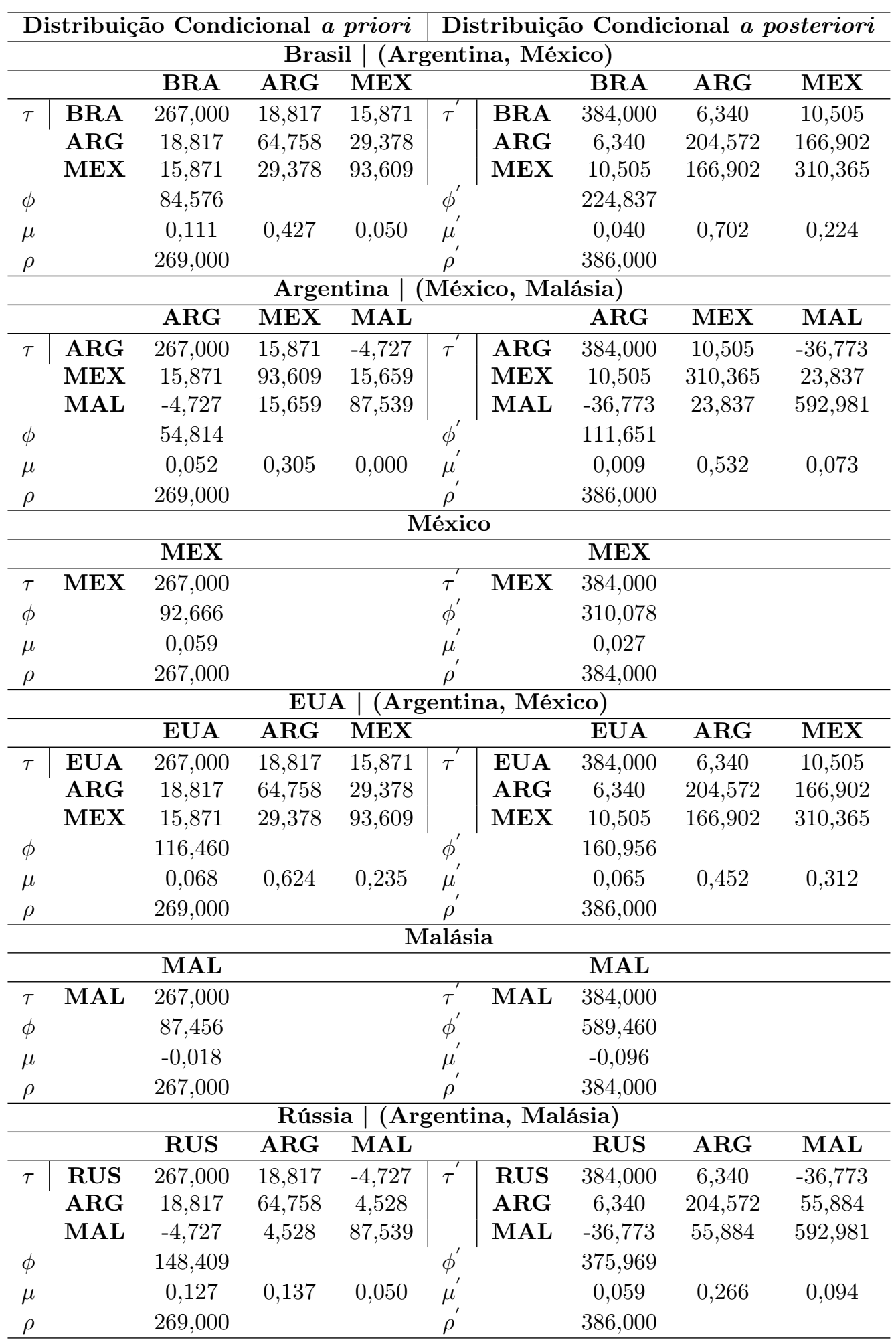


Tabela E.3: Parâmetros estimados da rede bayesiana pré-crise russa.

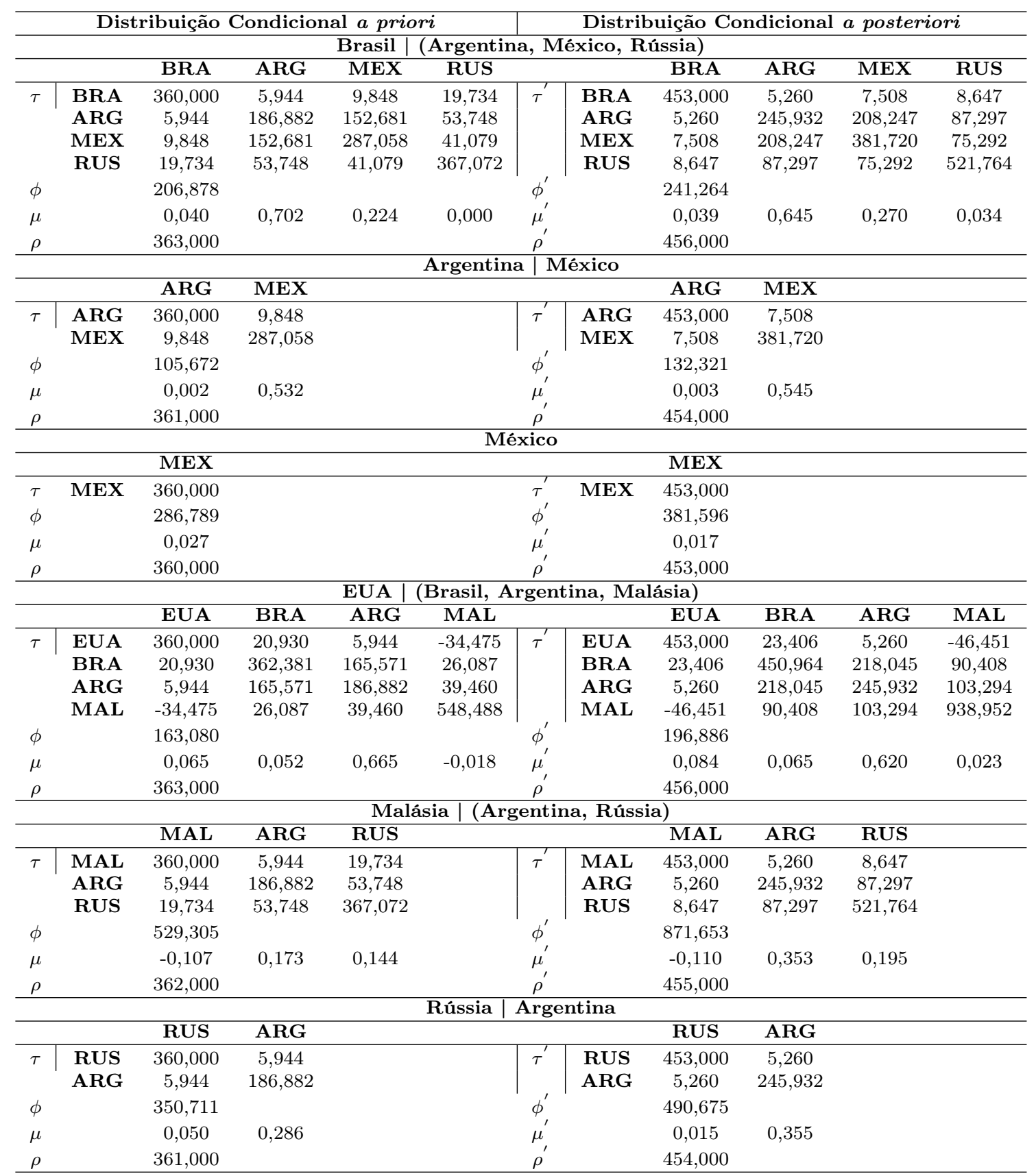


Tabela E.4: Parâmetros estimados da rede bayesiana durante a crise russa.

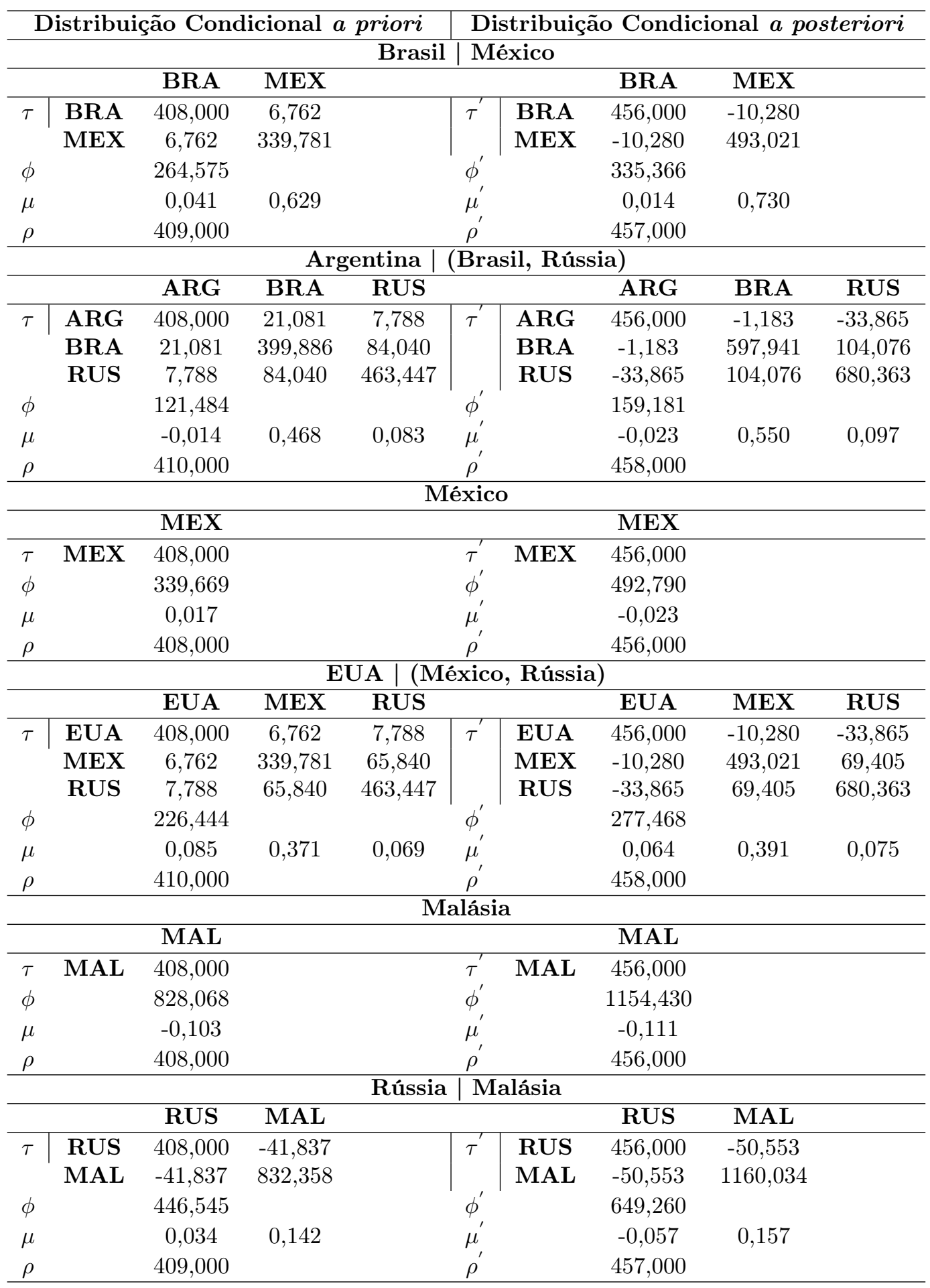




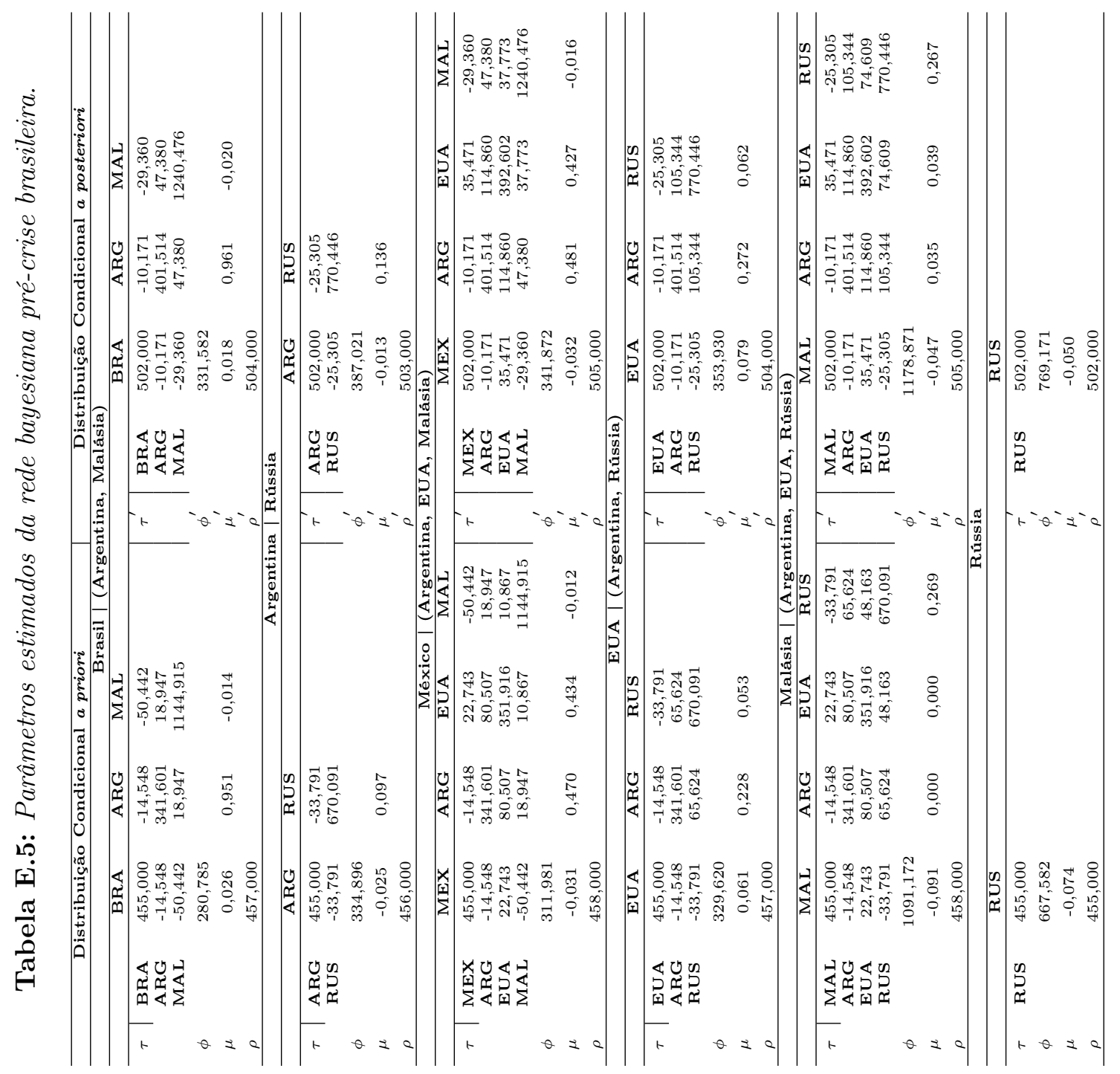


Tabela E.6: Parâmetros estimados da rede bayesiana durante a crise brasileira.

\begin{tabular}{|c|c|c|c|c|c|c|c|c|c|}
\hline \multicolumn{5}{|c|}{ Distribuição Condicional a priori } & \multicolumn{5}{|c|}{ Distribuição Condicional a posteriori } \\
\hline \multicolumn{10}{|c|}{ Brasil } \\
\hline & \multicolumn{4}{|c|}{ BRA } & \multicolumn{5}{|c|}{ BRA } \\
\hline$\tau$ & BRA & 464,000 & & & $\tau^{\prime}$ & BRA & 473,000 & & \\
\hline$\phi$ & & 639,343 & & & $\phi^{\prime}$ & & 914,480 & & \\
\hline$\mu$ & & $-0,001$ & & & $\mu^{\prime}$ & & 0,004 & & \\
\hline$\rho$ & & 464,000 & & & $\rho^{\prime}$ & & 473,000 & & \\
\hline \multicolumn{10}{|c|}{ Argentina | (Brasil, Rússia) } \\
\hline & & ARG & BRA & RUS & & & ARG & BRA & RUS \\
\hline \multirow[t]{3}{*}{$\tau$} & ARG & 464,000 & $-0,235$ & $-23,389$ & $\vec{\tau}$ & ARG & 473,000 & 1,668 & $-25,347$ \\
\hline & BRA & $-0,235$ & 639,343 & 88,330 & & BRA & 1,668 & 914,486 & 85,465 \\
\hline & RUS & $-23,389$ & 88,330 & 704,736 & & RUS & $-25,347$ & 85,465 & 714,325 \\
\hline$\phi$ & & 170,123 & & & $\phi^{\prime}$ & & 188,702 & & \\
\hline$\mu$ & & $-0,017$ & 0,540 & 0,069 & $\mu^{\prime}$ & & $-0,031$ & 0,490 & 0,085 \\
\hline$\rho$ & & 466,000 & & & $\rho^{\prime}$ & & 475,000 & & \\
\hline \multicolumn{10}{|c|}{ México | (Brasil, Rússia) } \\
\hline & & MEX & BRA & RUS & & & MEX & BRA & RUS \\
\hline \multirow[t]{3}{*}{$\tau$} & MEX & 464,000 & $-0,235$ & $-23,389$ & $\vec{\tau}$ & MEX & 473,000 & 1,668 & $-25,347$ \\
\hline & BRA & $-0,235$ & 639,343 & 88,330 & & BRA & 1,668 & 914,486 & 85,465 \\
\hline & RUS & $-23,389$ & 88,330 & 704,736 & & RUS & $-25,347$ & 85,465 & 714,325 \\
\hline$\phi$ & & 430,233 & & & $\phi^{\prime}$ & & 455,053 & & \\
\hline$\mu$ & & $-0,007$ & 0,323 & 0,063 & $\mu^{\prime}$ & & $-0,015$ & 0,295 & 0,078 \\
\hline \multirow[t]{3}{*}{$\rho$} & & 466,000 & & & $\rho^{\prime}$ & & 475,000 & & \\
\hline & \multicolumn{9}{|c|}{ EUA | (Brasil, Rússia) } \\
\hline & & EUA & BRA & RUS & & & EUA & BRA & RUS \\
\hline \multirow[t]{3}{*}{$\tau$} & EUA & 464,000 & $-0,235$ & $-23,389$ & $\vec{\tau}$ & EUA & 473,000 & 1,668 & $-25,347$ \\
\hline & BRA & $-0,235$ & 639,343 & 88,330 & & BRA & 1,668 & 914,486 & 85,465 \\
\hline & RUS & $-23,389$ & 88,330 & 704,736 & & RUS & $-25,347$ & 85,465 & 714,325 \\
\hline$\phi$ & & 335,094 & & & $\phi^{\prime}$ & & 343,554 & & \\
\hline$\mu$ & & 0,075 & 0,146 & 0,081 & $\mu^{\prime}$ & & 0,071 & 0,144 & 0,084 \\
\hline \multirow[t]{3}{*}{$\rho$} & & 466,000 & & & $\rho^{\prime}$ & & 475,000 & & \\
\hline & \multicolumn{9}{|c|}{ Malásia | (EUA, Rússia) } \\
\hline & & MAL & EUA & RUS & & & MAL & EUA & RUS \\
\hline$\tau$ & MAL & 464,000 & 32,786 & $-23,389$ & $\tau^{\prime}$ & MAL & 473,000 & 31,448 & $-25,347$ \\
\hline & EUA & 32,786 & 357,804 & 68,227 & & EUA & 31,448 & 371,852 & 70,841 \\
\hline & RUS & $-23,389$ & 68,227 & 704,736 & & RUS & $-25,347$ & 70,841 & 714,325 \\
\hline$\phi$ & & 1072,339 & & & $\phi^{\prime}$ & & 1080,618 & & \\
\hline$\mu$ & & $-0,048$ & 0,049 & 0,271 & $\mu^{\prime}$ & & $-0,039$ & 0,057 & 0,270 \\
\hline$\rho$ & & 466,000 & & & $\rho^{\prime}$ & & 475,000 & & \\
\hline & & & & & sia & & & & \\
\hline & & RUS & & & & & RUS & & \\
\hline$\tau$ & RUS & 464,000 & & & $\tau^{\prime}$ & RUS & 473,000 & & \\
\hline$\phi$ & & 703,557 & & & $\phi^{\prime}$ & & 712,967 & & \\
\hline$\mu$ & & $-0,050$ & & & $\mu^{\prime}$ & & $-0,054$ & & \\
\hline$\rho$ & & 464,000 & & & $\rho^{\prime}$ & & 473,000 & & \\
\hline
\end{tabular}




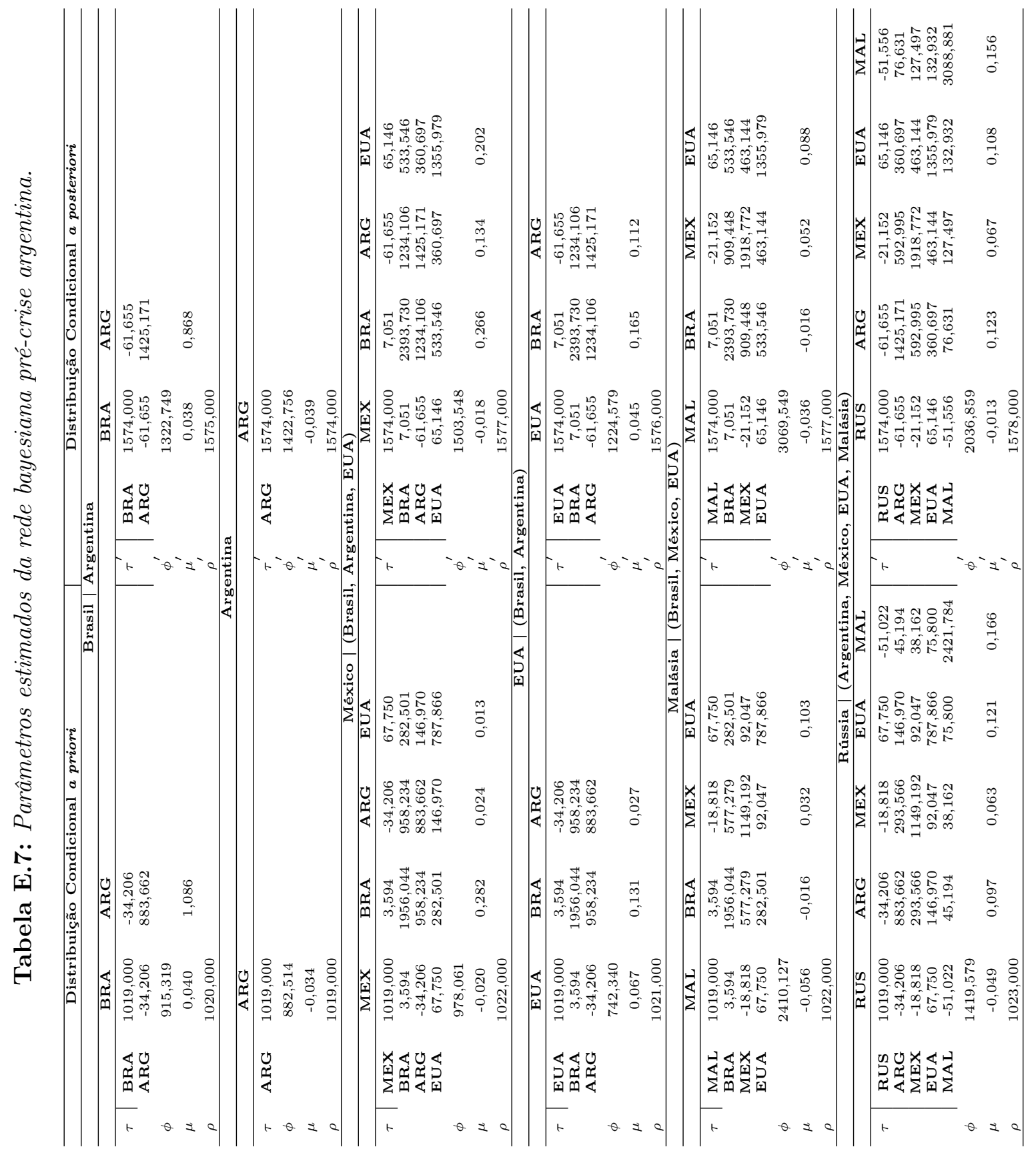


Tabela E.8: Parâmetros estimados da rede bayesiana durante a crise argentina.

\begin{tabular}{|c|c|c|c|c|c|c|c|c|c|c|c|}
\hline \multicolumn{6}{|c|}{ Distribuição Condicional a priori } & \multicolumn{6}{|c|}{ Distribuição Condicional a posteriori } \\
\hline & \multicolumn{5}{|r|}{ Brasil } & \multicolumn{6}{|c|}{ Argentina } \\
\hline & & BRA & ARG & & & & & BRA & ARG & & \\
\hline \multirow[t]{2}{*}{$\tau$} & BRA & 1054,000 & 43,624 & & & $\tau^{\prime}$ & BRA & 1089,000 & 42,033 & & \\
\hline & ARG & 43,624 & 903,233 & & & & ARG & 42,033 & 945,546 & & \\
\hline$\phi$ & & 1455,531 & & & & $\phi^{\prime}$ & & 1483,389 & & & \\
\hline$\mu$ & & $-0,012$ & 0,394 & & & $\mu^{\prime}$ & & $-0,011$ & 0,405 & & \\
\hline$\rho$ & & 1055,000 & & & & $\rho^{\prime}$ & & 1090,000 & & & \\
\hline \multicolumn{12}{|c|}{ Argentina } \\
\hline & & ARG & & & & & & ARG & & & \\
\hline$\tau$ & ARG & 1054,000 & & & & $\tau$ & ARG & 1089,000 & & & \\
\hline$\phi$ & & 948,807 & & & & $\phi^{\prime}$ & & 1272,258 & & & \\
\hline$\mu$ & & $-0,039$ & & & & $\mu^{\prime}$ & & $-0,022$ & & & \\
\hline \multirow[t]{3}{*}{$\rho$} & & 1054,000 & & & & $\rho^{\prime}$ & & 1089,000 & & & \\
\hline & & & & & México | (1 & 3 ras & EUA) & & & & \\
\hline & & MEX & BRA & EUA & & & & MEX & BRA & EUA & \\
\hline \multirow[t]{3}{*}{$\tau$} & MEX & 1054,000 & 4,722 & 43,624 & & $\tau^{\prime}$ & MEX & 1089,000 & 5,066 & 42,033 & \\
\hline & BRA & 4,722 & 1595,771 & 355,719 & & & BRA & 5,066 & 1637,909 & 382,075 & \\
\hline & EUA & 43,624 & 355,719 & 903,233 & & & EUA & 42,033 & 382,075 & 945,546 & \\
\hline$\phi$ & & 1010,106 & & & & $\phi^{\prime}$ & & 1024,285 & & & \\
\hline$\mu$ & & $-0,024$ & 0,333 & 0,212 & & $\mu^{\prime}$ & & $-0,018$ & 0,329 & 0,210 & \\
\hline$\rho$ & & 1056,000 & & & & $\rho^{\prime}$ & & 1091,000 & & & \\
\hline \multicolumn{12}{|c|}{ EUA } \\
\hline & & EUA & & & & & & EUA & & & \\
\hline$\tau$ & EUA & 1054,000 & & & & $\tau^{\prime}$ & EUA & 1089,000 & & & \\
\hline$\phi$ & & 901,427 & & & & $\phi^{\prime}$ & & 943,923 & & & \\
\hline$\mu$ & & 0,041 & & & & $\mu^{\prime}$ & & 0,039 & & & \\
\hline \multirow[t]{3}{*}{$\rho$} & & 1054,000 & & & & $\rho^{\prime}$ & & 1089,000 & & & \\
\hline & & & & Malá & sia | (Bras & $1, \mathrm{~N}$ & xico, $\mathrm{E}$ & JA) & & & \\
\hline & & MAL & MEX & EUA & & & & MAL & MEX & EUA & \\
\hline \multirow[t]{3}{*}{$\tau$} & MAL & 1054,000 & $\begin{array}{l}-14,164 \\
\end{array}$ & 43,624 & & $\tau^{\prime}$ & MAL & 1089,000 & $-9,003$ & 42,033 & \\
\hline & MEX & $-14,164$ & 1277,594 & 308,622 & & & MEX & $-9,003$ & 1295,657 & 323,665 & \\
\hline & EUA & 43,624 & 308,622 & 903,233 & & & EUA & 42,033 & 323,665 & 945,546 & \\
\hline$\phi$ & & 2043,452 & & & & $\phi^{\prime}$ & & 2058,581 & & & \\
\hline$\mu$ & & $-0,036$ & 0,046 & 0,084 & & $\mu^{\prime}$ & & $-0,029$ & 0,051 & 0,083 & \\
\hline$\rho$ & & 1056,000 & & & & $\rho^{\prime}$ & & 1091,000 & & & \\
\hline & & & & Rússia & (Argentir & $a, 1$ & xico, $N$ & alásia) & & & \\
\hline & & RUS & ARG & MEX & MAL & & & RUS & ARG & MEX & MAL \\
\hline \multirow[t]{4}{*}{$\tau$} & RUS & 1054,000 & $-41,286$ & $-14,164$ & $-34,524$ & $\tau^{\prime}$ & RUS & 1089,000 & $-23,860$ & $-9,003$ & $-28,269$ \\
\hline & ARG & $-41,286$ & 950,424 & 395,459 & 30,238 & & ARG & $-23,860$ & 1272,781 & 399,776 & 20,408 \\
\hline & MEX & $-14,164$ & 395,459 & 1277,594 & 84,904 & & MEX & $-9,003$ & 399,776 & 1295,657 & 92,919 \\
\hline & MAL & $-34,524$ & 30,238 & 84,904 & 2056,013 & & MAL & $-28,269$ & 20,408 & 92,919 & 2071,951 \\
\hline$\phi$ & & 1364,212 & & & & $\phi^{\prime}$ & & 1384,422 & & & \\
\hline$\mu$ & & $-0,007$ & 0,142 & 0,087 & 0,159 & $\mu^{\prime}$ & & $-0,004$ & 0,135 & 0,091 & 0,160 \\
\hline$\rho$ & & 1057,000 & & & & $\rho^{\prime}$ & & 1092,000 & & & \\
\hline
\end{tabular}




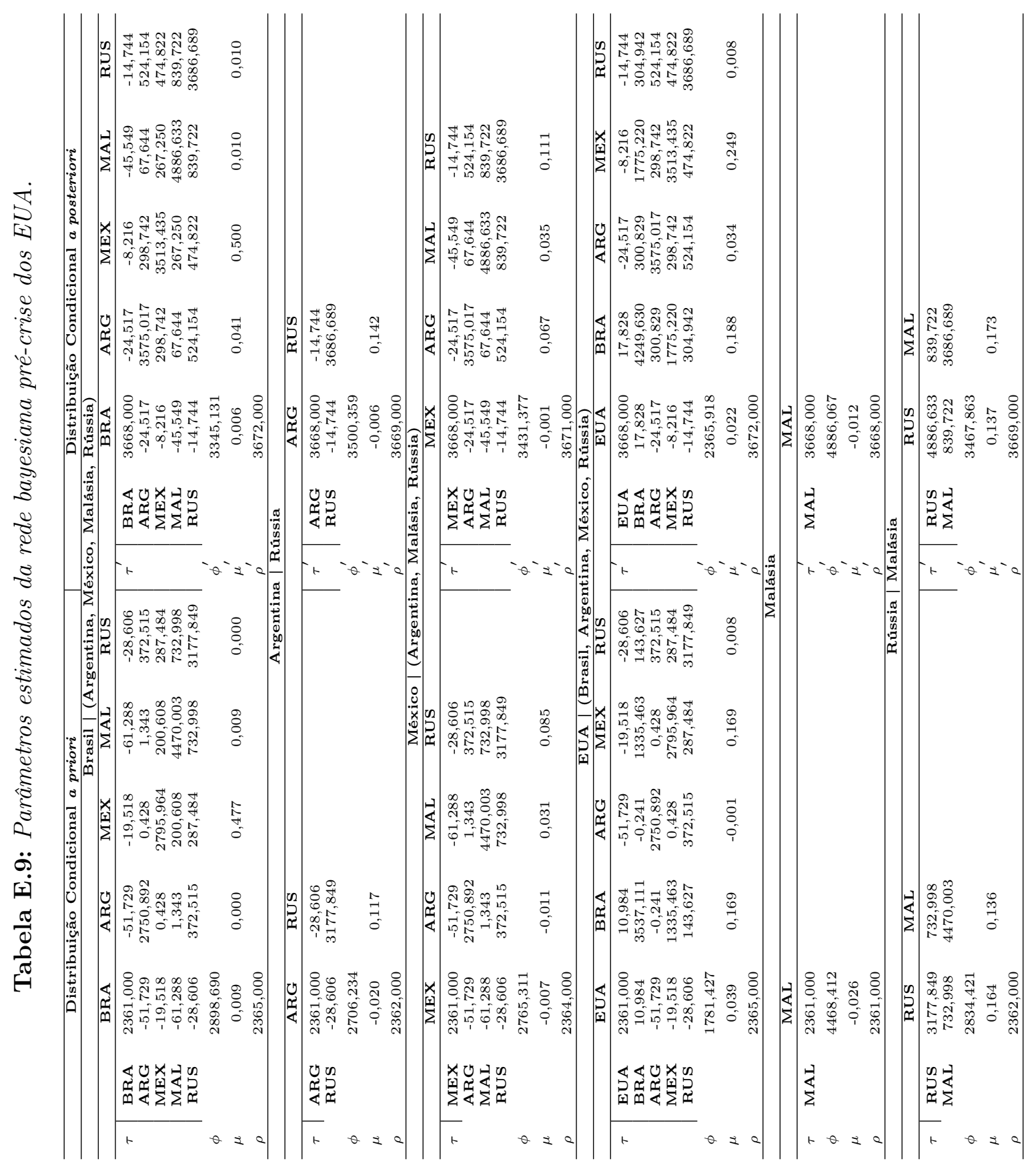




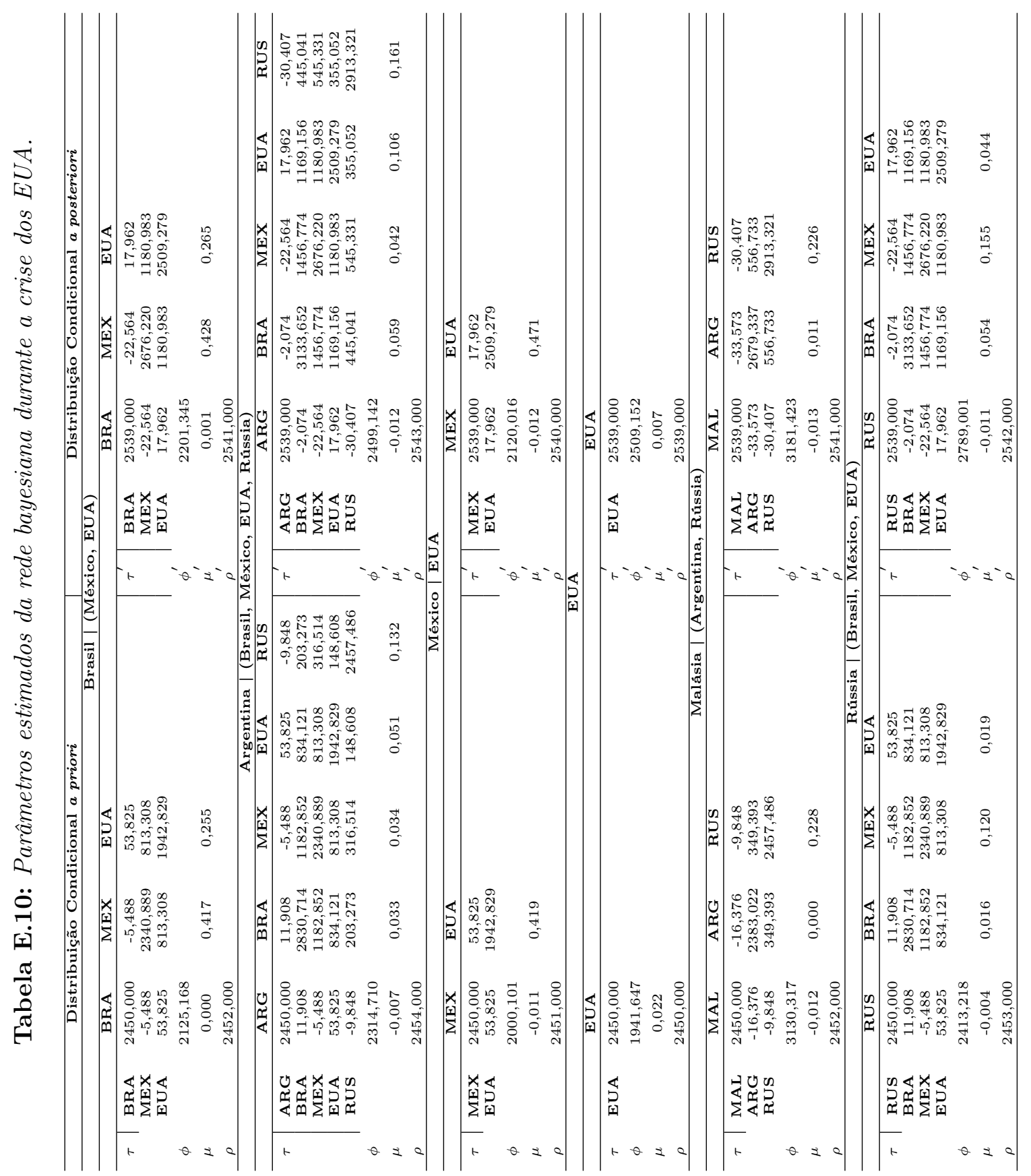




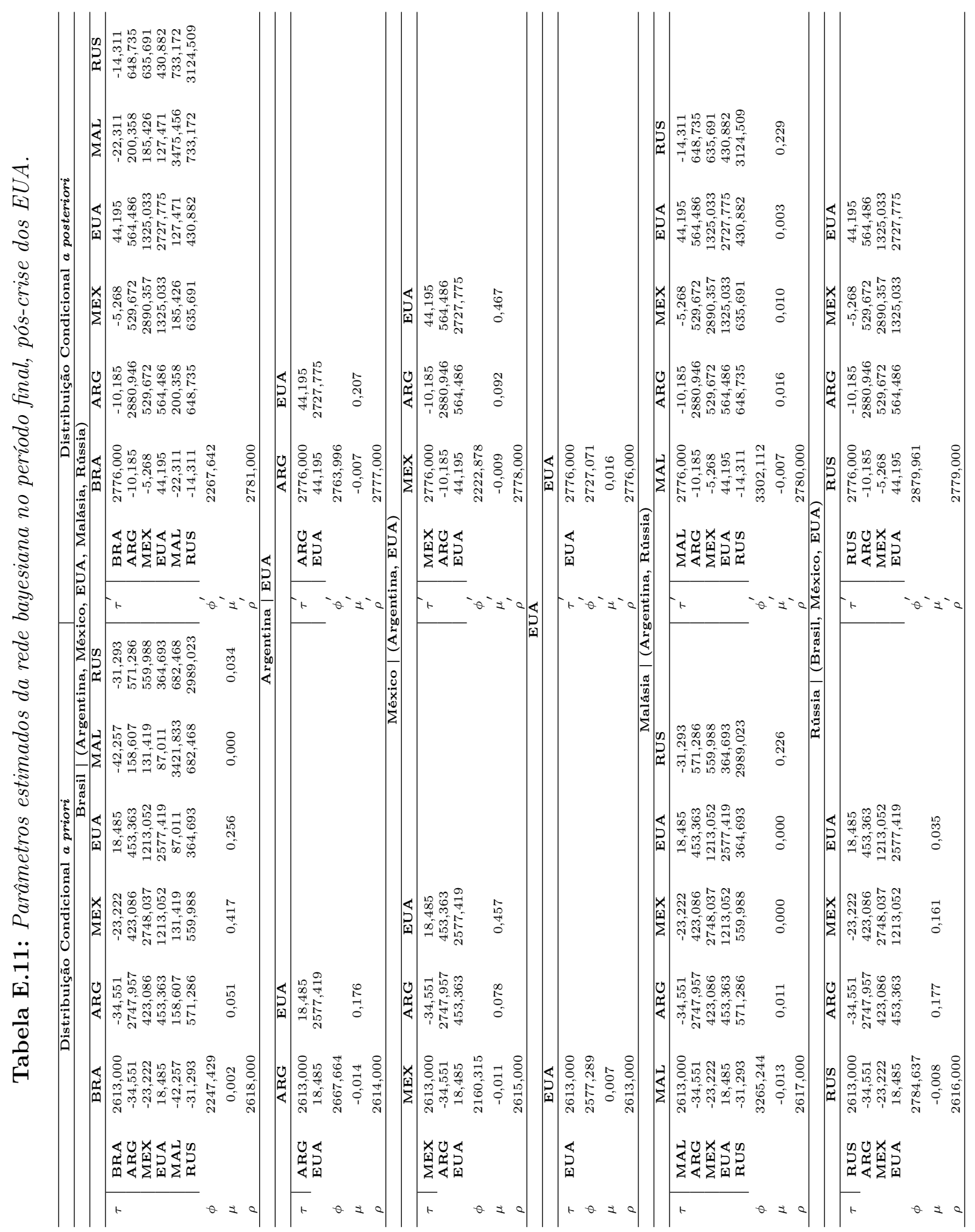




\section{Referências Bibliográficas}

Abbara, O. M. F. (2009), Modelagem de Dependência em Séries Financeiras Multivariadas, Dissertação de Mestrado, Campinas.

Averbug, A. e Giambiagi, F. (2000), "A Crise Brasileira de 1998/1999 - Origens e Consequências," BNDES Texto para discussao, 25-60.

Baig, T. e Goldfajn, I. (2000), "The Russian Default and the Contagion to Brazil," IMF Working Paper, 1-48.

Bessler, D. A. e Yang, J. (2003), "The structure of interdependence in international stock markets," Journal of International Money and Finance, 261-287.

Boettcher, S. G. (2004), Learning Bayesian networks with mixed variables, Tese de Doutorado, Dinamarca.

Boettcher, S. G. e Dethlefsen, C. (2003), "deal: A Package for Learning Bayesian Networks," Journal of Statistical Software, 8, 1-40.

Borça-Júnior, G. R. e Torres-Filho, E. T. (2008), "Analisando a crise do subprime," Revista do BNDES, 15, 129-159.

Canuto, O. (2000), "A crise asiática e seus desdobramentos," Econômica, Niterói, II, 25-60.

Chang, R. e Majnoni, G. (2002), "Financial crises, fundamentals, beliefs, and financial contagion," European Economic Review, 801-808.

Chollete, L., de la Peña, V., e Lu, C. (2005), "Comovement of International Financial Markets," Working paper, Columbia University.

Ciccarelli, M. e Rebucci, A. (2003), "Measuring Contagion with a Bayesian Time-Varying Coefficient Model," IMF Working Paper, 1-32.

Corsetti, G., Pericoli, M., e Sbracia, M. (2005), "Some contagion, some interdependence: more pitfalls in tests of financial contagion," Journal of International Money and Finance, 1177-1199.

DeGroot, M. H. (1970), Optimal Statistical Decisions, New York: McGraw-Hill.

Dornbusch, R., Park, Y. C., e Claessens, S. (2000), "Contagion: Understanding How It Spreads," The World Bank Observer, 15, 177-197.

- (2001), Contagion: Why crises spread and how this can be stopped, In: CLAESSENS, S.; FORBES, K. (Ed.). International Financial Contagion: Washington: Springer. 
Dungey, M., Fry, R., González-Hermosillo, B., e Martin, V. (2002), "International Contagion Effects from Russian Crisis and the LTCM Near-Collapse," IMF Working Paper, 1-47.

Feldstein, M. S. (2007), "Housing, Credit Markets and the Business Cycle," NBER Working Paper, 1-13.

Filetti, J. P., Hotta, L. K., e Zevallos, M. (2008), "Analysis of Contagion in Emerging Markets," Journal of Data Science, 6, 601-626.

Forbes, K. e Rigobon, R. (2002), "No contagion, only interdependence: measuring stock market comovements," The Journal of Finance, LVII, 2223-2261.

Fund, I. M. (2003), "Lessons from the Crisis in Argentina," Disponivel em: www.imf.org/external/np/pdr/lessons/100803.pdf, 1-87.

Furman, J. e Stiglitz, J. (1998), "Economic Crises: Evidence and Insights from East Asia," Brookings Papers on Economic Activity, 1-136.

GPO (2011), "The Financial Crisis Inquiry Report: Final Report of the National Commission on the Causes of the Financial and Economic Crisis in the United States," US Government Printing Office, 1-663.

Granger, C. W. J. (1969), "Investigating causal relationships by econometric models and cross-spectral methods," Econometrica, 424438.

Heckerman, D., Geiger, D., e Chickering, D. (1995), "Learning Bayesian networks: The combination of knowledge and statistical data," Machine Learning.

Hernández, L. e Valdés, R. O. (2001), "What Drives Contagion: Trade, Neighborhood, or Financial Links?" IMF Working Paper, 1-22.

Joe, H. (1997), Multivariate Models and Dependence Concepts, London: Chapman And Hall.

Lèbre, S. (2009), "Inferring Dynamic Genetic Networks with Low Order Independencies," Statistical Applications in Genetics and Molecular Biology, 8.

Lombardi, I. T., Galvão, A. B., Laurini, M. P., e Valls Pereira, P. L. (2004), "A dinâmica do contágio entre Brasil e Argentina," Working paper IBMEC-SP.

Lopes, H. F. e Migon, H. S. (2002), "Comovements and Contagion in Emergent Markets: Stock Indeexes Volatilities. Case Studies On Bayesian Statistics," Case Studies On Bayesian Statistics VI, 285-300.

Marçal, E. F. e Pereira, P. L. V. (2008), "Testing the Hypothesis of Contagion Using Multivariate Volatility Models," Brazilian Review of Econometrics, 28, 191-216.

McNeil, A. J., Frey, R., e Embrechts, P. (2005), Quantitative Risk Management: concepts, techniques and tools, New Jersey: Princeton University Press.

Morettin, P. A. (2008), Econometria Financeira, São Paulo: Edgard Blücher.

Morettin, P. A. e Toloi, C. M. C. (2006), Análise de Séries Temporais, São Paulo: Edgard Blücher. 
Neapolitan, R. E. (2004), Learning Bayesian Networks, New Jersey: Upper Saddle River: Pearson.

Nelsen, R. B. (2006), An Introduction To Copulas, New York: Springer.

Paulino, C. D., Turkman, M. A., e Murteira, B. (2003), Estatística Bayesiana, Lisboa: Fundação Calouste Gulbenkian.

Peng, Y. e Ng, W. L. (2009), "Measuring Financial Contagion with Copulas," Proceedings of 2009 Far East and South Asia Meeting of the Econometric Society.

Rodriguez, J. C. (2007), "Measuring financial contagion: A Copula approach," Journal of. Empirical Finance, 401-423.

Sklar, A. (1959), "Fonctions de répartition à n dimensions et leurs marges," Publications de l'Institut de Statistique de L'Université de Paris, 229-231.

Stove, B., Tjostheim, D., e Hufthammer, K. O. (2010), "Measuring Financial Contagion by Local Gaussian Correlation," NHH Dept. of Finance and Management Science Discussion Paper.

Viale, A. M., Kolari, J. W., Bessler, D., e Pynnönen, S. (2008), "On the structure of Financial Contagion: Econometric Tests and Mercosur Evidence," Anais do LACEA-LAMES, Rio de Janeiro, Brasil.

Zivot, E. e Wang, J. (2005), Modeling Financial Time Series with S-PLUS, New York: Springer-Verlag. 